\title{
III. Alpenland Die stammesföderalistischen Neugliederungskonzepte
}

\section{Die Alpenlandbewegung}

\section{Der Föderalist und Katholik Bernhard Dietrich}

Alle Gerüchte, die sich bis in die fünfziger Jahre um die alpine Union ${ }^{1}$ rankten, haben ihren Ursprung in den Aktivitäten des Mediziners und Regimekritikers Dr. Bernhard Dietrich $^{2}$. In der Nachkriegszeit verselbständigte sich der von Dietrich geprägte Begriff „Alpenland“ rasch, vor allem durch Rezeption in südwestdeutschen und bayerischen Milieus bei gleichzeitig unterlassener Tradierung der Urheberschaft. Ohne Zugang zu den initiierenden konservativ-katholischen Kreisen gehabt zu haben, hatten auch prominente Politiker der späteren Bundesrepublik Deutschland wie Carlo Schmid oder Franz Josef Strauß unmittelbar nach 1945 von den Alpenlandplänen Kenntnis erhalten: Doch nicht nur Schmid und Strauß vermuteten den französischen Geheimdienst hinter den Planungen zu einer „union alpine“"3, selbst Angehörige der französischen Militärregierung hielten das Alpenlandprojekt für Überlegungen der Sûreté Nationale ${ }^{4}$. Doch Mutmaßungen in Richtung Frankreich entbehren jeder Grundlage, bei dem Alpenlandplan handelte es sich vielmehr um ein, in Jahrzehnten geformtes, geistiges Produkt des glühenden Föderalisten Bernhard Dietrich.

Aus katholischem Elternhaus stammend, wurden Dietrichs politische Anschauungen im jugendlichen Alter von den Föderalismustheorien eines Constantin Frantz geprägt.

\footnotetext{
${ }^{1}$ "Alpenland“ oder die französische Übersetzung „union alpine“ wurden als synonyme Begriffe in der Nachkriegsdiskussion verwandt. Erneut an die Oberfläche gelangte der Begriff ,alpine Union " in der Auseinandersetzung um den Südweststaat; man schob den Begriff fälschlicherweise den Verfechtern der alten Länder unter, um damit deren vermeintlich "separatistische" Neigungen anzuprangern; Weinacht, Neugliederungsbestrebungen, S. $338 \mathrm{f}$. Auch im Artikel „....noch ist Baden nicht verloren " im Südwestdeutschen Echo vom 3. 9. 1951 wurde im Sinne der Befürworter des Südweststaates auf die "alpine Union" eingegangen. Der Untertitel "Wunschbild ,Alpine Union“" lautete wie folgt: „Daß der Plan, Südbaden und Südwürttemberg zu vereinigen, nicht verwirklicht wurde, ist nicht das Verdienst der Herren Wohleb und Zürcher. Das Wunschbild der Alpinen Union wurde vielmehr durch eine zugkräftigere politische Vorstellung, den Gedanken des Südweststaates verdrängt."

${ }^{2}$ Dietrich, Bernhard (1897-1961). Ein konziser Lebenslauf stammt von seiner Ehefrau Dr. Hedda Dietrich (1896-1993), die ebenfalls seit 1927 als praktizierende Ärztin in Singen tätig war. Vgl. Dietrich, Lebenslauf. Vgl. außerdem Kappes, Bürgermeister, S. 180-183. Die Biographie Dietrichs ist auf den folgenden Seiten in den Text eingearbeitet.

${ }^{3}$ Strauß, Erinnerungen, S. 100. Carlo Schmid vermutete hinter den Alpenlandplänen "bestimmte französische Kreise aus der Umgebung des Generals Leclerc"; Ders., Erinnerungen, S. 229. Der nach 1945 in der bayerischen Staatskanzlei tätige Diplomat und spätere Botschafter der Bundesrepublik Deutschland in Rom, Hans Herwarth von Bittenfeld, hatte Kenntnis von den alpinen Neugliederungsplänen, er selbst hielt in der unmittelbaren Nachkriegszeit „die Errichtung eines ,Walls gegen den Osten', bestehend aus Österreich und den süddeutschen Staaten, für geboten“; Herwarth, Adenauer, S. 28.

${ }^{4}$ Heinemann, Hochschuloffiziere, S. 139.
} 
Schon vor dem Ersten Weltkrieg, während er sich auf das Abitur vorbereitete, war in ihm die Überzeugung herangereift, daß eine Abkehr von der preußischen Geschichtsauffassung und damit vom kleindeutschen Geschichtsbild und eine Hinwendung zum föderalistisch-abendländischen Standpunkt zwingend vonnöten sei. Mit siebzehn Jahren legte Dietrich bei Kriegsausbruch in Konstanz die Reifeprüfung ab und immatrikulierte sich zum Wintersemester 1914/15 an der Albrecht-Ludwigs-Universität in Freiburg. Von seinem Wunsch, ein Studium der katholischen Theologie zu beginnen, mußte er jedoch nach seiner Einberufung zur Gebirgsartillerie Abschied nehmen. In den Vogesen, in Ungarn, Serbien und Mazedonien wurde Dietrich als Frontsoldat eingesetzt, bevor er sich nach Kriegsende an der Universität Freiburg erneut immatrikulieren konnte, nun allerdings an der Medizinischen Fakultät. In der Breisgaumetropole trat er im Februar 1919 der nichtschlagenden, katholischen Verbindung „Hohenstaufen“ im CV bei 5 . Nach bestandenem Physikum wechselte Bernhard Dietrich an die Universität Erlangen, legte dort im Mai 1922 das Staatsexamen ab und promovierte im November desselben Jahres zum Doktor der Medizin. Neben seinem Studium hatte er sich bereits parteipolitisch engagiert. In der Bayerischen Volkspartei (BVP) trat er in Versammlungen als Redner auf und bekämpfte in den folgenden Jahren kämpferisch die Ideologie des Nationalsozialismus. Sein Auskommen fand der junge Assistenzarzt zuerst in Erlangen, später in Zittau und Mannheim. Zu Beginn des Jahres 1927 ließ sich Dietrich in Singen am Fuße des Hohentwiels als praktischer Arzt nieder. Umgehend engagierte er sich in verschiedenen katholischen Vereinen in der jungen Industriestadt; dem Zentrum, das in seinen Augen den zentralistischen und preußisch-deutschen Reichsgedanken pflegte, trat er allerdings nicht bei ${ }^{6}$.

Für die fünfte Auflage des im katholischen Verlag Herder in Freiburg herausgegebenen Staatslexikons verfaßte Bernhard Dietrich 1932 den Artikel über die deutschen Stämme ${ }^{7}$. Aus der Mitarbeit beim renommierten Staatslexikon läßt sich schließen, daß Dietrich als Protagonist des Stammesföderalismus schon in den Weimarer Jahren in Deutschland bekannt war. Publizistisch versuchte er des weiteren in der Allgemeinen Rundschau in diese Richtung zu wirken. So rief er 1932 mit Gleichgesinnten zur Gründung einer konstituierenden Versammlung der Landsmannschaften auf ${ }^{8}$, mit dem Ziel, „eine alemannisch-schwäbisch-bajuvarische und eine großfränkische Landsmannschaft“ ins Leben zu rufen. "Siegesbewusst erhebt der preussische Unitarismus sein Haupt“, konstatierte Dietrich und beschrieb schon vor der nationalsozialistischen „Machtergreifung“ die Katastrophe, in die der Nationalismus Deutschland treiben würde. Eine Lösung proklamierte der Singener Arzt in der Bildung eines „neuen deutschen Bundes der freien deutschen Stämme“. Ausschließlich auf der Grundlage des als gesellschaftliches Prinzip verstandenen Föderalismus konnte in seinen Augen eine funktionierende Neuordnung der Verhältnisse in Deutschland vollbracht werden; „Frieden

\footnotetext{
${ }^{5}$ Eintragung von 1925: „Dietrich, Bernhard, Dr. med. Ass.-Arzt, E. Kz., i. Mannheim, städtische Krankenanstalten, Prosekutor [Hohenstaufen/Freiburg]“, in: Ehrenmitglieder, 1925, S. 224.

${ }^{6}$ Kappes, Bürgermeister, S. 181.

7 Dietrich, Stamm. Dort heißt es: „Die großen Stämme mit ihren weitgedehnten Landschaften können eine brauchbare Unterlage sein für den Neubau des Reiches"; ebenda, Sp. 42.

${ }^{8}$ „Aufruf: Freunde der Allgemeinen Rundschau! Föderalistische Kampfgenossen!“, Artikel von Bernhard Dietrich in der von Georg Moenius herausgegebenen Allgemeinen Rundschau vom 17. 12. 1932.
} 
und Freiheit in einem natürlich geordneten, christlichen Abendland" war die Vision Dietrichs in bezug auf eine gesamteuropäische Ordnung. Der Kongreß, für den er München, Lindau oder Bregenz als Tagungsorte vorgeschlagen hatte, fand nicht mehr statt, die Ereignisse überrollten die Planungen. Die Jahre des NS-Regimes sollten für Dietrich Emigration, Verfolgung und Verhaftungen mit sich bringen.

Unmittelbar nach der „Machtergreifung“ wurde Bernhard Dietrich vom Singener Stadtrat Schüle informiert, daß die Nationalsozialisten ihn als führenden Gegner verhaften und „liquidieren“ wollten". Ohne lange zu zögern, verließ er seine Ehefrau und acht Kinder und suchte bei Freunden im Elsaß Zuflucht. In Mülhausen wurde er herzlich von Dr. Paul Specklin aufgenommen, der ihn mehrere Monate beherbergte. Über Specklin hatte Dietrich Verbindungen zu nationalen französischen Kreisen, allen voran zu Dr. Haenggy, dem Chefredakteur des Elsässer Boten. Spätestens in der Emigration erfuhr er auch von der Gründung des „Elsässisch-Lothringischen Heimatbundes“ im Jahr 1926 ${ }^{10}$. Zum damaligen Zeitpunkt nach Deutschland zurückzukehren, schien Dietrich nicht ratsam, und deshalb beantragte er die französische Staatsbürgerschaft, um sich mit seiner großen Familie entweder in Frankreich oder in einer französischen Kolonie niederlassen zu können. Doch das Vorhaben konnte ebensowenig verwirklicht werden wie die Bildung von „Kampfgruppen, die entschlossen gewesen wären, den Widerstand gegen Hitler mit der Waffe aufzunehmen"11. Einige Monate später wagte Dietrich den Grenzübertritt nach Deutschland zurück; die Angst um die Familie und der Glaube, die Lage habe sich seither beruhigt, hatten ihn nach Singen zurückkehren lassen. Tatsächlich widerfuhr ihm zunächst nichts, argwöhnisch aber registrierten die regionalen Parteistellen seine Anwesenheit. Trotz aller Gefahren machte Dietrich in den folgenden Jahren keineswegs einen Hehl aus seiner Einstellung gegenüber Hitler und der NSDAP: 1935 kritisierte er heftig die Saarabstimmung ${ }^{12}$ und sah sich deshalb im Gefängnis wieder. Auch den Einmarsch deutscher Truppen ins Rheinland im folgenden Jahr mißbilligte er entschieden, und seine öffentlichen Äußerungen führten zur erneuten Verhaftung. Das Haus Dietrich galt zudem während der zwölfjährigen Herrschaft der Nationalsozialisten als Zufluchtsort für Verfolgte und Regimegegner, die vielfach über die nahe Grenze in die Schweiz gelangen konnten.

Bernhard Dietrich war als „Mainlinienstratege“ und „Französling " im national gesonnenen Teil der Bevölkerung stigmatisiert. Bei Ausbruch des Zweiten Weltkrieges als "wehrunwürdig" eingestuft, ging er weiterhin seinem Beruf nach. Beim Praktizieren ließ er keine Gelegenheit aus, seine Patienten - soweit er ihnen leidlich vertrauen konnte während der Behandlung in politische Diskussionen zu verwickeln, in deren Zentrum der Föderalismus stand ${ }^{13}$. Der Arbeitskräftemangel, der sich im Laufe des Krieges ein-

${ }^{9}$ Kappes, Bürgermeister, S. 181.

${ }^{10}$ Die Bezeichnung "Heimatbund" inspirierte Dietrich mit hoher Wahrscheinlichkeit nach 1945 bei der Namensgebung des „Schwäbisch-Alemannischen Heimatbundes“.

${ }^{11}$ Bernhard Dietrich: „Gedanken und Vorschläge zur politischen Entwicklung Deutschlands in Vergangenheit und Zukunft“ [1945] (masch. 6 S.); PA Victor Hell.

12 Dietrichs Äußerungen sind im Lagebericht Nr. 11 des Geheimen Staatspolizeiamts Karlsruhe für die Monate Oktober bis Dezember 1934 protokolliert. Abgedruckt bei: Schadt, Verfolgung, S. 133.

${ }^{13}$ Interview mit Josef Dusel, einem ehemaligen Patienten Dietrichs und Anhänger des „Schwäbisch-Alemannischen Heimatbundes", vom 8. 7. 1994; StadtA KN Cc 775 a. In der Praxis hing 
stellte, wurde auch in dem von Industrie geprägten Singen durch ausländische Arbeitskräfte gedeckt. Viele Zwangsdeportierte brachten „ihrem“ Dr. Dietrich größtes Vertrauen entgegen und wurden in keiner Weise enttäuscht ${ }^{14}$. Das Verhalten Dietrichs war auch in der Schweiz bekannt und wurde nach dem Einmarsch der Franzosen in der Berner Tageszeitung Der Bund gewürdigt ${ }^{15}$. Das Attentat vom 20. Juli 1944 war Anlaß für die Gestapo, Dietrich ein weiteres Mal zu verhaften. Die Schergen brachten den Singener Arzt in die Gestapoleitstelle Karlsruhe, wo er zusammen mit dem späteren Konstanzer Landgerichtspräsidenten Caspar Deufel inhaftiert wurde. Man warf ihm Sabotage vor und plante, dem führenden Kopf der Katholiken in Singen den Prozeß zu machen. Die Gestapo konfrontierte ihn mit französischen Arbeitern, die ihn schwer kompromittierten. Die Verhöre erbrachten jedoch keinerlei Verbindungen Dietrichs zu den Verschwörern des Zwanzigsten Juli. Vier Wochen der Ungewißheit brachte seine große Familie zu, ehe die Gestapo Dietrich nach Singen zurückkehren ließ ${ }^{16}$.

Als sich Anfang April 1945 das Vorrücken der Ersten Französischen Armee in Richtung Schwarzwald und Bodensee abzuzeichnen begann, sah Bernhard Dietrich die Stunde der Befreiung und die Zeit für aktives politisches Handeln gekommen. Die Kampfgruppe Lebel besetzte in den Morgenstunden des 24. April die Hohentwielstadt und fand das Rathaus verlassen vor. Der zum Stadtkommandanten ernannte Oberst d'Alauzier ${ }^{17}$ verlangte umgehend von Stadtpfarrer Adolf Engesser, ihm eine Persönlichkeit zu benennen, die kommissarisch zum Bürgermeister bestellt werden konnte. Der Geistliche wiederum führte den französischen Offizier sogleich zu Dietrich, der nach kurzem Gespräch zum Bürgermeister ernannt wurde ${ }^{18}$. Eine undankbare und schwierige Aufgabe lag nun vor Bernhard Dietrich: Requisitionsforderungen der Besatzungs-

eingerahmt ein Zitat des Humanisten Thomas More: „Nie habe ich daran gedacht, einer Sache zuzustimmen, die gegen mein Gewissen gewesen wäre." Auch ein weiterer Patient, der spätere Staatssekretär des Auswärtigen Amts bzw. nachmalige Chef des Bundespräsidialamtes Paul Frank, notierte rückblickend: Dietrich hielt ,jedem Patienten, bevor er ihn untersuchte, erst einmal einen ausführlichen Vortrag [...], daß jetzt die historische Stunde gekommen sei, sich von Preußen loszusagen“; Frank, Botschaft, S. 324.

${ }^{14}$ Sein Berufsethos und seine Verwurzelung im Katholizismus leiteten Dietrich in den Kriegsjahren. „Deshalb habe ich“, notierte er im Sommer 1945, „weder die durch Geheimerlass befohlene Abtreibung bei ausländischen Arbeiterinnen durchgeführt, noch je den Sterilisationsgesetzen entsprochen“, in: „Gedanken und Vorschläge..."; ebenda.

15 „Heute darf auch gesagt werden, daß der als Arzt außerordentlich populäre Dr. Dietrich sich während der Kriegsjahre in einer selbstlosen Art und Weise der kranken Fremdarbeiter und Kriegsgefangenen angenommen hat und immer wieder mit dem gesamten Gewicht seiner Autorität als Arzt für die humane Behandlung dieser Menschen eingetreten ist ${ }^{c}$; Der Bund vom 28. 4. 1945.

${ }^{16}$ Interview mit Cordula Oexle, einer Tochter Dietrichs, vom 7. 4. 1993; StadtA KN Cc 775 a.

17 D'Alauzier wurde von General de Lattre Mitte Mai 1945 zum Bezirksdelegierten von Konstanz ernannt; vgl. Kapitel $1 / 2$.

${ }_{18}$ Die zum Teil widersprüchlichen Ereignisse, die sich bei der Besetzung von Singen zugetragen haben sollen, sind nachzulesen bei: Meier, Stadt, S. 299-307. Es ist unwahrscheinlich, daß „die einrückenden Franzosen sofort vor dem Rathaus nach Dr. Dietrich" fragten (Dietrichs Sohn Anselm vertrat diesen Standpunkt; Südkurier vom 3. 5. 1985), dem widerspricht die unzureichende Planung und Vorbereitung der Franzosen (Jüngst wurde diese Version von Kappes, Bürgermeister, S. 180 erneut vertreten). Vielmehr wird Dietrich, der gut Französisch sprach und glühend seinen politischen Standpunkt vertreten konnte, im persönlichen Gespräch d'Alauzier schnell von seiner Person überzeugt haben. 
macht waren zu erfüllen, die Entnazifizierung der Verwaltung zu bewerkstelligen, die Versorgung der Bevölkerung zu gewährleisten und das öffentliche Leben zu reorganisieren. Dem neuen Bürgermeister blieb in den ersten Monaten wenig Zeit, sich mit politischen Fragen zu beschäftigen ${ }^{19}$. In Hauptmann Lesur, dem Kreisdelegierten von Konstanz (Land) mit Sitz in Singen, hatte Dietrich einen Verbündeten gefunden ${ }^{20}$; inwieweit Lesur sich für die Umsetzung föderalistischer Planungen engagierte, bleibt mangels Quellenmaterial im unklaren.

Mit einem Paukenschlag betrat Bernhard Dietrich im Sommer 1945 die politische Bühne. Auf eigene Kosten hatte er eine kleine Broschüre bei der Ravensburger Druckerei Hieronymos Weidel in Auftrag gegeben, die seine öffentlich geäußerten Ideen vor 1933 erneut zur Sprache brachte: Alpenland ${ }^{21}$ nannte er das Traktat, das er als Vorschlag einer staatlichen Neubildung im kommenden Abendland konzipiert hatte. Der Singener Bürgermeister verlieh darin seiner Überzeugung Ausdruck, daß die preußische Politik, deren Kulminationspunkt der Nationalsozialismus gewesen sei, zwangsläufig in einer Katastrophe hätte enden müssen. Als überzeugter Abendländer habe er „in Preußen den Geist wider das Reich" erkannt, Abendland und Heiliges Römisches Reich deutscher Nation waren in seinen Augen Synonyme. Die modernen Nationalstaaten betrachtete Dietrich ,als das Produkt der geistigen Zersetzung in Europa und der allmählichen totalen Säkularisation des Denkens"22. Das verfolgte politische Ziel definierte er in der Schaffung eines neuen abendländischen Bundesstaates auf der Grundlage von Geschichte und Kultur von Menschen ,ähnlichen Charakters“. Der geplante Bundesstaat, das Alpenland, sei ein wirtschaftliches Ganzes, es umfasse Österreich mit Vorarlberg, Liechtenstein, Bayern (ohne Franken), und die schwäbisch-alemannischen Teile von Württemberg und Baden. Im Hinblick auf die Rolle der Schweiz vermied Dietrich klare Aussagen, doch besteht kein Zweifel an seinem Wunsch, auch die deutschsprachige Schweiz als alemannisches Land früher oder später der Konföderation „Alpenland“ beitreten zu lassen. Das Vorbild Schweiz wirkte überdies unmittelbar auf die staatliche Organisation des propagierten Alpenlandes: Gleichzeitig mit der Einteilung in Kantone sollte die Schaffung "einer gemeinsamen Ordnungs- und Verwaltungshoheit“23 erfolgen. Zuerst jedenfalls wünschte Dietrich sich eine enge Anlehnung an die Schweiz, um eine dauerhafte Annäherung auf kulturellem und wirtschaftlichem Gebiet zu erreichen. Auf lange Sicht sollte auch der deutschsprachige Teil der Schweiz im Alpenstaat aufgehen; daher schloß er seinen Aufruf mit der Forderung nach der „Gründung des föderalistischen Staates ,Alpenland', der in sich das Gebiet von Wien bis Genf und das zugehörige Alpenvorland umfasst, wobei unter Alpenvorland das alemannische, schwäbische und altbayrische Gebiet verstanden wird“24. Föderalismus ließ sich für Dietrich damit

${ }^{19}{ }_{n}$ Dr. Dietrich konnte frühestens ab Sommer 1945 politisch tätig werden, da die in Singen zu bewältigenden Aufgaben seine Arbeitskraft rund um die Uhr einnahmen, [er] mußte den Karren aus dem Dreck ziehen“; Interview mit Josef Dusel vom 8. 7. 1994; StadtA KN Cc 775 a.

20 Interview mit Cordula Oexle vom 25. 5. 1995; StadtA KN Cc 775 a.

${ }^{21}$ Dr. med. Bernhard Dietrich, Bürgermeister in Singen-Htw.: Alpenland - Vorschlag einer staatlichen Neubildung im kommenden Abendland, Singen/Ravensburg: Weidel [1945]. Abgedruckt in: Klöckler, Ursprünge (im Druck).

22 Ebenda, S. 4.

${ }^{23}$ Ebenda, S. 5.

${ }^{24}$ Ebenda, S. 6. 
nur auf dem stämmischen Prinzip begründen. Die alpine Konföderation hätte das Kernstück des christlichen Abendlandes zu bilden, folgerichtig ließ er seine Ausführungen mit dem Ausruf „Mit Gott ins neue Alpenland“ enden, dem er im eigenen Exemplar handschriftlich „und Abendland“25 hinzufügte. Die Broschüre verteilte Dietrich großzügig im deutschen Südwesten, und die Resonanz ließ nicht lange auf sich warten. Die Wirkung der Schrift wurde des weiteren erheblich durch ein Manifest verbreitert, das im Anschluß an die Gründungsversammlung des "Aktionskomitees des Alpenländischen demokratischen Bundes“ am 10. Oktober 1945 gedruckt und verbreitet werden sollte.

Doch Dietrich hatte zuvor noch Gelegenheit erhalten, eine „hohe französische Persönlichkeit" sprechen zu hören. Per Rundbrief war er in seiner Funktion als Bürgermeister von Singen vom Konstanzer Landeskommissär Marcel Nordmann am 1. Oktober 1945 aufgefordert worden, sich für den 4. Oktober zu einer Reise bereitzuhalten ${ }^{26}$. In mehreren Automobilen sollte die Fahrt insgesamt 22 Vertreter aus Verwaltung und Wirtschaft des Landeskommissariatsbezirks Konstanz nach Freiburg führen. Aus dem gesamten südbadischen und südwürttembergischen Raum wurden die führenden südwestdeutschen Persönlichkeiten in die Breisgaumetropole gebracht, um für General de Gaulle eine geeignete Kulisse zu bilden. Aus Tübingen war Carlo Schmid unter den Honoratioren und erinnerte sich später: „Mir kam [die Rede von de Gaulle] vor, als wolle man uns in die Postkutschenzeit zurückversetzen. Was die Alliierten nun mit Deutschland vorhatten, wußten wir nicht, sollte unser Land in eine Handvoll Staaten auseinandergeschnitten werden?" ${ }^{27}$ In der Tat enthielten die Ausführungen de Gaulles nur Andeutungen über die zukünftige Gestaltung Deutschlands, der Schwerpunkt der Rede lag auf dem Aspekt der Versöhnung und des Willens zum Wiederaufbau. Die französische Versöhnungsbereitschaft machte insbesondere auf den in Freiburg anwesenden Reutlinger Oberbürgermeister Oskar Kalbfell28 tiefen Eindruck, der sich 1945 von der Notwendigkeit einer „alpinen“ Neugliederung überzeugt zeigte.

Bernhard Dietrich konnte sich sehr wohl bei den Worten de Gaulles in seinen Handlungen bestätigt fühlen, mußte nicht eine alpenländische Konföderation auf der Linie der französischen Politik liegen? Hatte de Gaulle nicht von „Verbindungen“ gesprochen, die vor langer Zeit bestanden hätten und die es nun zu erneuern galt?29 Die Rede de Gaulles hinterließ jedenfalls tiefe Spuren, nicht nur bei den unmittelbaren Zuhörern. Der Chef der Provisorischen Regierung Frankreichs hatte die Hand zur Versöhnung ausgestreckt, und begierig nahmen sie die Deutschen an. In bezug auf die Gliederung Südwestdeutschlands konnte man immerhin den Wunsch de Gaulles erkennen, die beiden Länder Baden und Württemberg als Bindeglieder nach Westen zu etablieren. Aber hatten nicht auch Bayern und Österreich solche Verbindungen gehabt? Für Dietrich bestand kein Zweifel: Seine Alpenlandpläne trafen die politischen Vorstellungen der Franzosen - ein verhängnisvoller Trugschluß!

Vom Widerhall seiner propagierten Staatskonstruktion durfte Bernhard Dietrich in jenen Oktobertagen auch durch den Besuch des Münchener Architekten Johannes

${ }^{25}$ NL Bernhard Dietrich.

26 Nordmann an Dietrich vom 1. 10. 1945; StA FR A 96/1 2347.

${ }^{27}$ Schmid, Erinnerungen, S. 227.

${ }^{28}$ Kalbfell, Aufgaben, passim. Biographisches zu Kalbfell und dessen Alpenlandvorstellungen in Kapitel V/1.

${ }^{29}$ De Gaulle, Lettres, S. 94. 
Haecker, dem Sohn seines kurz vor Kriegsende verstorbenen Freundes, des Philosophen und katholischen Schriftstellers Theodor Haecker ${ }^{30}$, freudig Kenntnis nehmen. Der aus der bayerischen Landeshauptstadt angereiste, später für die amerikanische Militärregierung tätige Johannes Haecker war dem Bann der Alpenlandpläne verfallen. Nach München zurückgekehrt, versuchte er den Verleger und Lizenzträger der Süddeutschen Zeitung, Franz Josef Schöningh, den Oberregierungsrat in der Bayerischen Staatskanzlei, Ludwig von Gumppenberg, und Professor Karg vom Radio München für die Pläne zu gewinnen ${ }^{31}$. Deren ablehnende Haltung ließ den Enthusiasmus bei Haecker allerdings bald wieder verschwinden.

\section{Das „Aktionskomitee des Alpenländischen demokratischen Bundes“}

Für den 10. Oktober 1945 hatte Dietrich die Gründung eines „Aktionskomitees“ in Bregenz vereinbart. Der Singener Bürgermeister trat die Reise nach Vorarlberg in Begleitung seines Vertrauten, des Juristen Dr. Leopold Paur ${ }^{32}$, den die Kriegsereignisse ins benachbarte Engen geführt hatten, mit dem Privatwagen an; als Arzt war Dietrich im Besitz eines Automobils und des nötigen Treibstoffes. Der Grenzübertritt bereitete einige Schwierigkeiten, seit 9. Oktober war nämlich die Zollgrenze zwischen Deutschland und Österreich wieder errichtet worden. Daß „der freizügige Personen- und Warenverkehr von Österreich nach Deutschland und umgekehrt [...] nicht mehr gestattet" sei, hatte der Bregenzer Bezirkshauptmann Seeberger in einer schriftlichen Anweisung an alle Bürgermeister der Grenzgemeinden im Oktober $1945^{33}$ unterstrichen. Die Zusammenkunft war von langer Hand geplant und vorbereitet. Der Bezirksdelegierte von Bregenz, Major Benité, hatte mit seinem Informationsoffizier, Hauptmann Hollard, und dem neuen Bürgermeister von Bregenz, Dr. Julius Wachter ${ }^{34}$, mehrmals dessen Singener

30 Theodor Haecker (1879-1945), 1894-98 Kaufmann bei der Esslinger Wollfirma Merkel \& Kienlin; Mitarbeiter der Meggendorfer Blätter seines Schulkameraden Ferdinand Schreiber; 1905 Abitur (nachgeholt) und Immatrikulation in München; 1914 Mitarbeiter der Zeitschrift Der Brenner von Julius von Ficker und des Hochlands von Carl Muth; 1918 Heirat (drei Kinder: Johannes, Irene und Reinhard); 1921 Konversion zum Katholizismus; 1930-35 schriftstellerischer Höhepunkt, u. a. „Vergil, Vater des Abendlands“ (1931); 1933 kurzzeitige Verhaftung; 1935 Redeverbot; 1938 Publikationsverbot; ab 1941 Hauptschriftleiter (ohne Erwähnung im Impressum) des Verlags Ferdinand Schreiber; Verbindung zum Kreis der "Weißen Rose“; Druck seiner Werke im Colmarer Alsatia-Verlag; 1944 in München ausgebombt; 9. 4. 1945 fehlendes Insulin führt in Ustersbach bei Augsburg zu Haeckers Tod. Würdigung bei: Blessing, Haecker, in: NDB 7; ausführliche Interpretation seiner Gedanken mit biographischen Anmerkungen bei: Blessing, Haekker, 1959.

${ }^{31}$ "French Activity in Bavaria" [1947]; OMGUS 2/135 - 2/8.

${ }^{32}$ Leopold Paur (1889-1979). Zur Biographie vgl. Kapitel V/1.

${ }^{33}$ Bezirkshauptmann Seeberger an alle Bürgermeister der Grenzgemeinden zum besetzten Deutschland vom 13. 10. 1945; StadtA BR 1945/126.

${ }^{34}$ Julius. Wachter (1899-1986), geboren in Wolfurt; Sohn des Bregenzer Altbürgermeisters Matthias Wachter; 1905-08 Besuch der Volksschule in Wolfurt; 1910 Besuch des humanistischen Staatsgymnasiums in Bregenz; 1917 Eintritt in das K. und K. Regiment der Tiroler Kaiserjäger, Offiziersausbildung, Einsatz in den Alpen, italienische Kriegsgefangenschaft; 1919 Immatrikulation an der Universität Innsbruck und Abschluß der Studien 1923 mit Promotion zum Dr. iur.; freier Mitarbeiter bei der Vorarlberger Landeszeitung; 1924 Rechtspraktikant und seit August 1924 Geschäftsführer (ab 1940 Prokurist) der Bregenzer Firma Pircher; 1940 Unabkömmlichstellung; 4. 6. 1945 nach Stefan Kohler (nicht mit seinem gleichnamigen Schwiegervater zu verwechseln!) 
Amtskollegen aufgesucht, um das von Dietrich angestoßene Alpenlandprojekt zu besprechen. Eine lange Freundschaft verband Wachter und Dietrich, beide kannten sich aus gemeinsamer Zeit im CV ${ }^{35}$. Das letzte einer Serie von Treffen ${ }^{36}$ fand am 3. Oktober 1945 statt, die Vorbereitungen zur Konstituierung eines „Aktionskomitees“ waren damit abgeschlossen, nun konnte zur Tat geschritten werden. Die Gefühlslage Wachters ist in einem Tagebucheintrag vom 3. Oktober 1945 präzise wiedergegeben: „Es ist doch etwas großes bei dieser Idee, die da heißt ,Alpen-Donaustaat' und in weiter Ferne - Vereinigte Staaten von Europa - Abendland. Ich glaube, daß die Idee, einmal unter das Volk geworfen, zündet. In Deutschland, besonders Süddeutschland, wird man die Idee als Erlösung betrachten aus all der Not der Gegenwart."37 Am Abend des 10. Oktobers 1945 waren im Bregenzer Rathaus außer Dietrich und Paur bedeutende Vorarlberger Honoratioren und Amtsträger anwesend: der Bregenzer Bezirkshauptmann Dr. Emil Seeberger, der ehemalige österreichische Unterrichtsminister Dr. Emil Schneider, der Bregenzer Bürgermeister Dr. Julius Wachter und sein Amtsvorgänger Dr. Stefan Kohler, Professor Hubert Halma, der Bregenzer Hutmachermeister Otto Matt und ein Offizier der Militärregierung. Sprachprobleme traten nicht auf, da Professor Halma, Übersetzer in der Bregenzer Stadtverwaltung, auch an jenem Abend als Dolmetscher fungierte.

Das Komitee verfaßte einen mit Schreibmaschine geschriebenen Bericht, der schließlich - wie schon Dietrichs Broschüre Alpenland - bei der Druckerei Hieronymos Weidel in Ravensburg ohne Genehmigung der in Baden-Baden zuständigen Direction de l'Information und der Direction de l'Education Publique gedruckt wurde. Kurz umriß darin das „Aktionskomitee“ seine politischen Forderungen: Es müsse ein Bund, also eine Konföderation gebildet werden, die sich aus den "alten österreichischen Landen“ („Österreich, Altbayern, Schwaben und Alemannisches Stammesgebiet“) zusammensetzen sollte. Als Bundeshauptstadt kam für die Teilnehmer Salzburg in Frage; der Name der Konföderation sollte „Alpenländischer Bund“ - oder französisch: „union alpine“ sein. Der Bodenseeraum, eine europäische „Zentrallandschaft", würde auch innerhalb des "Alpenländischen Bundes“ eine besondere Rolle spielen. Mit Frankreich und der Schweiz wünschten sich die Honoratioren durch eine Zollunion verbunden. Um dieses geopolitische Programm in die Tat umsetzen zu können, hoffte man auf eine „wohlwollende Prüfung und Anerkennung" der Bestrebungen durch die französische Besatzungs-

zweiter Nachkriegsbürgermeister von Bregenz (bis 5. 6. 1947); Initiator und Begründer der „Bregenzer Festspiele“; Inhaber wichtiger wirtschaftlicher Ämter in Vorarlberg (Präsident der Pfänderbahn AG [1945-1954], Präsident des österreichischen Rheinschiffahrtsverbandes, Aufsichtsrat in verschiedenen verstaatlichten Firmen).

${ }^{35}$ Das Engagement im CV stellt das Bindeglied auch innerhalb des "Aktionskomitees" dar. Seit 30.10.1919 war Wachter Mitglied in der "Leopoldina" an der Universität Innsbruck, der auch Emil Schneider (siehe unten) seit 12.10.1903 angehörte; Dietrich inkorporierte sich in der „Hohenstaufen" in Freiburg i. Br. am 24.2.1919, Emil Schneider wurde außerdem am 16.10.1910 in die "Saxo-Bavaria“ an der Universität Prag aufgenommen. Aus den frühen zwanziger Jahren datierten auch die ersten Kontakte Dietrichs zu Wachter. Dietrich verfügte außerdem über gute Verbindungen zur "Austria" nach Salzburg. Sicherlich war auch der jährlich stattfindende Aulendorfer Dreikönigskommers ein wichtiger Treffpunkt der späteren Alpenlandpropagandisten. Vgl. Ehrenmitglieder, 1925, S. 224, S. 342, S. 552.

${ }^{36}$ An eines der geheimen Treffen in Bregenz kann sich die Tochter Wachters erinnern; Interview mit Brigitte Albrecht vom 28. 4. 1995; StadtA KN Cc 775 a.

${ }^{37}$ Eintrag im Tagebuch von Julius Wachter vom 3. 10. 1945, NL Julius Wachter; Photokopien aller zitierten Tagebucheinträge im Besitz des Verfassers. 
macht und hegte den Wunsch, so schnell als möglich in der Öffentlichkeit wirken zu können.

Der Gründungsbericht wurde dem Bezirksdelegierten Benité vorgelegt, „der sich“, so Julius Wachter, "mit uns lange über alle Fragen unterhielt “38. Das polemische Presseecho auf den „Gründungsakt“ ließ nicht lange auf sich warten. Gerade die Schweiz blickte mit Argusaugen auf die politischen Vorgänge an ihrer nördlichen und östlichen Grenze. Der Schweizer Konsul in Bregenz, Carl Bitz, führte einige Gespräche mit Julius Wachter ${ }^{39}$, wahrscheinlich auch über diese brisante politische Frage ${ }^{40}$. Bereits am nächsten Tag berichtete Radio Frankfurt von der Gründung einer „separatistischen Bewegung“ in Bregenz ${ }^{41}$. Es dürfte dann wohl der Gründungsbericht vom 10. Oktober gewesen sein, der gänzlich die Aufmerksamkeit der Presse auf die Bregenzer Ereignisse lenkte. Das Sankt Galler Tagblatt bezog in dem Artikel "Separatisten am Bodensee“ vom 9. November 1945 Stellung: „Nach allen Informationen aus dem politischen Leben im süddeutschen Grenzland muss vielmehr festgestellt werden, dass sich am Bodensee immer deutlicher die Bildung einer separatistischen Bewegung abzuzeichnen beginnt. [...] Man wird damit rechnen müssen, daß die französischen Besatzungsbehörden diesem aufkeimenden Separatismus am Bodensee kaum Schwierigkeiten in den Weg legen, sondern alle diese Regungen mit Wohlwollen fördern dürften. " ${ }^{42}$ In Übersetzung sandte der französische Botschafter in Bern, Henri Hoppenot ${ }^{43}$, Tage später diesen Zeitungsartikel an das Außenministerium, um Paris bezüglich der „separatistischen“ Tendenzen auf dem laufenden zu halten ${ }^{44}$. Von Bern aus verfügte Hoppenot, dessen kritische Haltung gegenüber der französischen Besatzungspolitik in Paris bekannt war, nicht nur durch die schweizerische Presse, sondern auch durch Vertrauensmänner45 über einen intimen Einblick in die „separatistischen“ Kreise.

${ }^{38}$ Eintrag im Tagebuch von Julius Wachter vom 10.10. 1945; NL Julius Wachter.

${ }^{39}$ Unter anderem am 6. 10. 1945 nach Mitternacht im Hotel "Weißes Kreuz"; Eintrag im Tagebuch von Julius Wachter vom 6. 10. 1945; NL Julius Wachter.

${ }^{40}$ Carl Bitz übersandte in unregelmäßigen Abständen Berichte an seine vorgesetzte Dienststelle, das Eidgenössische Politische Departement (Außenministerium) in Bern. Adressiert sind die Berichte an den zuständigen Legationsrat Probst. In den Akten des Bundesarchivs in Bern befinden sich unter der Signatur E 2300 BREGENZ 1 die Berichte der Jahre 1945-1947. Darunter existiert jedoch kein Dokument, das sich mit den oben geschilderten Vorgängen befaßt.

${ }^{41}$ Der Beitrag von Radio Frankfurt wurde wie folgt im Bulletin Hebdomadaire Nr. 13 vom 17. 11. 1945 des SGAAA in Paris zusammengefaßt: „On apprend de Brégenz la naissance d'un mouvement séparatiste sous le nom de [sic!], Union démocratique Alpine‘. Il a pour but de créer une fédération autonome groupant l'Autriche et le pays de Bade. Il aurait pour capitale Salzbourg"; MAE Y-Int. 1944-1949652.

${ }^{42}$ Sankt Galler Tagblatt vom 9. 11. 1945.

${ }^{43}$ Henri Hoppenot (1891-?), Studium und Diplôme de l'Ecole des Sciences politiques; 1914-17 im MAE im Service de Communication angestellt; danach auf verschiedenen Posten in Teheran, Beirut und Peking eingesetzt; 1938-40 in Paris in der Abteilung Europa verwandt; 1945-51 Botschafter in der Schweiz; 1952-55 französischer Vertreter im UN-Sicherheitsrat; 1955-56 Hoher Kommissar in Vietnam.

${ }_{44}$ Hoppenot an die Abteilung Europa im MAE vom 13. 11. 1945; AdO GMFB Berlin G II d p. 91.

${ }^{45}$ Der politische Teil des Nachlasses von Henri Hoppenot befindet sich im Archiv des französischen Außenministeriums. Über seine Tätigkeit in Bern liegt ein Faszikel vor, das allerdings keine Hinweise auf die deutschen Vertrauensmänner, die ihm Informationen über Südwestdeutschland zuspielten, enthält. MAE PA-AP 270-Hoppenot 12 [Bern 03/1945-10/1951]. 
Auch in anderen Tageszeitungen fanden die Bregenzer Ereignisse ihren Widerhall. Die Deutsche Volkszeitung berichtete darüber im Frühjahr 1946: „Die hier offen ausgesprochenen deutschfeindlichen separatistischen Absichten und Pläne sind wohl kaum noch zu überbieten. "46 Selbst die englischsprachige Continental Daily Mail informierte über das „ehrgeizige Ziel, einen aus Süddeutschland und Österreich bestehenden alpinen Staat zu schaffen "47. Ein vollständiger Abdruck des Gründungsberichtes erschien in der Zeitschrift Die Leuchtkugel ${ }^{48}$, einer in Innsbruck im Verlag Josef Ronczay herausgegebenen „unabhängigen, politisch-satirischen Streitschrift ${ }^{\text {“49 }}$, die einen polemischen Angriff auf die mit österreichischen Geldern bezahlten Vorarlberger Politiker führte. Nach über einem Jahr erkannte die Berliner Tageszeitung Der Morgen in den Bregenzer Vorgängen vom Oktober 1945 die Geburtsstunde aller Diskussionen um eine Donaukonföderation $^{50}$, die in Bayern noch einmal virulent wurden.

\section{Die Vorarlberger Kreisest}

Aktiv trat nach der Gründungsversammlung des „Aktionskomitees“ der Bregenzer Bürgermeister Julius Wachter für die Idee einer alpinen Union ein; er war der Motor der Alpenlandbewegung in Vorarlberg. Seinen Wunsch, einen mitteleuropäischen Staat zu gründen, um damit vom „preussischen Ghetto" 52 deutlich getrennt zu sein, propagierte er allerorten. Hierzu schrieb und vervielfältigte Wachter Flugblätter, die er im Februar 1946 in Vorarlberg und „den Regionen, die geeignet wären, Teile der alpinen Union zu bilden "53, verbreitete. Auch gegenüber Vertretern der französischen Besatzungsmacht unterbreitete der Bregenzer Bürgermeister im Winter 1945/46 schriftlich Vorschläge zur staatlichen Neugestaltung Mitteleuropas ${ }^{54}$. Sein Ansprechpartner war der Bregenzer Bezirksdelegierte Benité, der ihn stets ermunterte, Gedanken in diese Richtung zu formulieren. Emphatisch schlug Julius Wachter im Dezember 1945 in einer Denkschrift für die

\footnotetext{
${ }^{46}$ Deutsche Volkszeitung vom 10.4. 1946.

47 "Germans want an Alpine State“, in: Continental Daily Mail vom 14. 9. 1946.

${ }^{48}$ Die Leuchtkugel Doppelnummer 7/8 vom Oktober 1946.

${ }^{49}$ So lautet der Untertitel der Zeitschrift Die Leuchtkugel. Vgl. dazu weiter Fischer/Dietzel, Zeitschriften, Bd. 2, S. 444.

50 "Die totgeborene Donaukonföderation", in: Der Morgen vom 1. 2. 1947.

${ }^{51} \mathrm{Vgl}$. dazu weiter: Klöckler, Neugliederungskonzepte.

52 Der Bregenzer Bürgermeister äußerte diese Vorstellung gegenüber dem französischen Sonderberichterstatter der Zeitung Ce Soir, Louis Parrot. Jener ließ daraufhin einen Artikel mit dem Titel "Jules Avec Dieu, vers le nouvel Occident' proclame Julius Wachter" erscheinen; vgl.: Ce Soir vom 19.2. 1946 und AdO SGAAA Centre d'Etudes c. 2664 p. 9. Parrot bezeichnete die Gründungsmitglieder der "Alpenlandbewegung" als vermeintliche "anciens nazis notoires". Der Artikel ist als polemische Attacke Parrots zu werten, die insbesondere auf die "germanische Provinz“ Elsaß abzielte.

${ }_{53}$ Die Flugblätter sind nicht erhalten geblieben, an deren Existenz besteht jedoch kein Zweifel; vgl. den Bericht der Abteilung Documentation extérieur et Contre-Espionage der Présidence du Gouvernement Provisoire vom 10. 7. 1946; MAE Z-Europe Gén. 1944-1960 39.

${ }^{54}$ "Idées en vue d'une réorganisation des états de l'Europe centrale' par le Dr. Jules Wachter, actuellement maire de Bregenz" [Dezember 1945], StadtA BR 1945/95. Inwieweit es sich bei diesem Dokument um eines der Flugblätter handelt, ist nicht klar, der Umfang von fünf maschinengeschriebenen Blättern und der Zusatz "Traduit par M. le Dr. Halma Hubert" sprechen gegen die Vermutung.
} 
neue Konföderation den Namen „Donau-Alpenland“ 55 vor, eine Bezeichnung, die er, nur geringfügig abgewandelt, schon in seiner Tagebuchnotiz vom 3. Oktober 1945 verwandt hatte. Die wirtschaftliche Situation entpuppte sich als stärkste Triebfeder für Wachters Handeln. Seiner Ansicht nach wäre Österreich 1938 niemals so einfach in die Hände der Nationalsozialisten gefallen, wenn sich die Wirtschaftslage in den Jahren zuvor merklich gebessert hätte. „Um das Schlimmste zu verhindern, muß man aus dem politischen und wirtschaftlichen Chaos herauskommen“, empfahl Julius Wachter; Grundlage dafür sei die Schaffung des Alpenlandes, eines „ethnischen und wirtschaftlichen, von der Natur gegebenen Raumes“. Historische Gründe dienten dem Bregenzer Bürgermeister zum Beweis der föderalistischen Konstruktion, deren Bundesgebiet er aus Österreich mit Südtirol, Bayern, Württemberg und Baden zusammengesetzt sah. Der Zusammenschluß sollte staatenbündisch gebildet werden, um den einzelnen Mitgliedern eine möglichst große Autonomie zu belassen. „Im Innern müßte die Organisation der öffentlichen Verwaltung liberal und föderalistisch sein, gleich wie in den Kantonen der Schweiz." ${ }^{66}$ Die wirtschaftliche Basis der alpenländischen Konföderation mit einer Bevölkerung von 19 Millionen Menschen auf rund $200000 \mathrm{~km}^{2}$ Staatsgebiet könnten Land- und Forstwirtschaft, Industrie und Tourismus sein. Mit einer Bevölkerungsdichte von 103 Bewohner pro km² sah Wachter das Alpenland als "vollkommen befriedigend“ besiedelt an. Mittels tabellarischer Auflistung der Nutzflächen (Wald, Ackerland, Sonderkulturen) kam er zu dem Schluß, daß ein günstiges Verhältnis zwischen Anbaufläche und „dem Reichtum der Wälder" bestehe. Auch die industrielle Struktur des Alpenlandes trage, so Wachter, Gewähr für eine gesunde Entwicklung, als zusätzliche Maßnahme schlug er die Schiffbarmachung des Rheins bis zum Bodensee vor. Letzterer sollte in "das Binnenmeer Mitteleuropas“ verwandelt werden. Des weiteren spreche auch die konfessionelle Struktur von 14 Millionen Katholiken gegenüber 5 Millionen Protestanten eine klare Sprache. Julius Wachter beendete seine Ausführungen mit einer programmatischen Ausführung: „Diese Konföderation würde die Garantie dafür gewähren, nie wieder unter preußische Dominanz zu gelangen und würde ein starkes Gegengewicht gegen den preußischen Einfluß in Deutschland bilden. Kurz: Dieser Staat würde dem Friedenswunsch der Völker, die ihn bewohnen, genügen und würde die Devise in die Tat umsetzen [...]: Nie wieder Krieg !"57

Neben Julius Wachter und Bernhard Dietrich war Dr. Emil Schneider ${ }^{58}$, der in der Ersten Republik zwischen 1922 und 1926 mit dem Amt des österreichischen Unterrichtsministers betraut war, die dritte maßgebliche Figur. Der Vorarlberger bewegte sich aber ungleich vorsichtiger auf dem heißen politischen Parkett, er scheute sich davor, publizi-

55 In der französischen Übersetzung trat neben die Bezeichnung „Donau-Alpenland“ der Begriff „Union danube-alpine“; ebenda.

56 Ebenda.

57 Ebenda.

${ }^{58}$ Emil Schneider (1883-1961), 1913 Professor an der Realschule Dornbirn; 1919 Mitglied der Konstituierenden Nationalversammlung in Wien; 1920 Nationalrat; 1922-26 Bundesminister für Unterricht; 1926-38 Schuldienst (Landesschulinspektor in Wien/Direktor der Bundesrealschule in Dornbirn); 1938 Zurruhesetzung durch die Nationalsozialisten; 1943 Reaktivierung infolge Lehrermangels; 1945 Leitung des Neuaufbaus des Bundesrealgymnasiums für Mädchen in Bregenz; 1949 zweiter und endgültiger Ruhestand; 1950 als Listenführer der ÖVP in den Stadtrat in Bregenz gewählt, dort Referent für Schulangelegenheiten bis 1955. Vgl. auch StadtA BR IX/80; IX/ 55; IX/26. 
stisch in die Neugliederungsdiskussion einzugreifen ${ }^{59}$. Der von Schneider unterschriebene Gründungsbericht des „Aktionskomitees des Alpenländischen demokratischen Bundes“ zeugt hingegen von dessen föderalistischer Grundeinstellung. Allgemein galt Schneider als notorischer Anhänger des Erzherzogs Otto von Habsburg60; der Enkel Kaiser Franz Josephs war sich allerdings dieser Unterstützung nicht bewuß $t^{61}$. In der Ideenwelt Schneiders hat die alpenländische Konföderation sicherlich ein monarchische Gestalt angenommen. Der Name des ehemaligen österreichischen Unterrichtsministers strahlte auf die Alpenlandbewegung in Vorarlberg zurück und verlieh ihr ein seriöses Gesicht. Seiner katholisch-konservativen Grundhaltung entsprechend, hatten die Alpenlandpläne den Gefallen Emil Schneiders gefunden; die Idee eines katholischen Staatenbundes weckte in dem langjährigen Mitglied der Studentenverbindung „Leopoldina“ und überzeugten Konservativen ein unglaubliches Hochgefühl. Politisch engagiert war der im Katholizismus verhaftete Emil Schneider seit 1919 in der Christlich-Sozialen Partei (CSP). Nachdem im Spätsommer 1945 die politischen Parteien in Österreich genehmigt waren, schloß sich Emil Schneider der konservativen Österreichischen Volkspartei (ÖVP) an, in der auch Julius Wachter seine politische Heimat gefunden hatte. Damit ist das Milieu, aus dem sich die Anhänger der Alpenlandbewegung rekrutierten, offenkundig: katholisch und konservativ sind die bezeichnenden Prädikate, die ÖVP die entsprechende politische Partei.

In der Vorarlberger und Tiroler Bevölkerung stießen die Alpenlandpläne 1945/46 durchaus auf Wohlwollen. In einer französischen Meinungsumfrage bezeichneten sich jeweils 29 Prozent der Befragten in beiden Bundesländern als Anhänger [partisan] einer derartigen Föderation ${ }^{62}$. Auch der bis zum heutigen Tage spürbare Unabhängigkeitswille der Bevölkerung westlich des Arlbergs fand in der unmittelbaren Nachkriegszeit seinen Ausdruck: So tauchten um die Jahreswende 1946/47 unzählige Flugblätter mit dem Titel „Los von Wien " in Vorarlberg auf ${ }^{63}$. Die Forderungen nach einem „freien und unabhängigen Vorarlberg“ und, in Anlehnung an die Bestrebungen nach 1918, nach einer „Zollunion mit der Schweiz“ wurden darin proklamiert. Die Urheberschaft übernahm die „Bewegung,Freies Vorarlberg““.

59 Zum Diskussionsbeitrag urteilte rückblickend der Sohn, Lothar Schneider: „Mein Vater hat sich darüber aber kaum geäussert und es ist auch im Nachlass nichts gefunden worden“; Schreiben Schneiders an den Verfasser vom 6. 7. 1993.

60 Auch südlich der Alpen waren die Monarchisten bekannt, was in einem Artikel des Gazzettino vom 8. 12. 1945 seinen Niederschlag fand. Dort heißt es unter anderem: „In Österreich ist der vorgenannte Dr. Schneider gut bekannt wegen seiner Unterstützung, die er dem Erzherzog Otto von Habsburg zukommen läßt." Dieser Artikel wurde zitiert in einem Schreiben des französischen Konsuls in Venedig, Hubert Elie, an Georges Balay, Ministre Plénipotentiare, vom 8. 12. 1945; MAE Z-Europe Gén. 1944-1960 39.

${ }^{61}$ Otto von Habsburg war bekannt, "daß gewisse solche Bestrebungen in Vorarlberg bestanden“; Brief Otto von Habsburgs an den Verfasser vom 12. 1. 1994.

62 Dreiseitiger Fragebogen zu politischen Problemen in Österreich [1946]. Die Datenerhebungsmethoden sind nicht überliefert; MAE Z-Europe Gén. 1944-1960 39.

${ }^{63}$ Mehrere Exemplare des Flugblattes schickte der Schweizer Konsul in Bregenz, Carl Bitz, an das Eidgenössische Politische Departement in Bern; Bitz an EPD vom 5. 2. 1947; BA Bern E 2001 (E) 1969/121 Bd. 236. Das Flugblatt dürfte identisch mit den bei Grabherr, Geschichte, S. 275 erwähnten, in Lustenau aufgetauchten, maschinengeschriebenen Exemplaren sein. 


\section{Die französischen Reaktionen auf die Alpenlandpläne}

Der Protektor der Alpenlandpläne auf seiten der französischen Besatzungsmacht war Major Benité, der Bezirksdelegierte von Bregenz. Er organisierte die Besuche Wachters in Singen und gab sein Einverständnis zur Abhaltung der Gründungsversammlung des "Aktionskomitees des Alpenländischen demokratischen Bundes“. Das eigenständige politische Handeln des Bregenzer Bezirksdelegierten traf indes bei seinen vorgesetzten Dienststellen nicht auf Zustimmung. Ihm wurde das Schicksal zuteil, das auch den Promotor der „Vereinigung Abendland“, den Freiburger Informationsoffizier Jordy, getroffen hatte: Ende 1946 war die Versetzung auf einen entlegenen Posten die Wiener Reaktion auf die als Provokation empfundene Politik Benités.

Das französische Außenministerium wurde erst Mitte November 1945 über die Vorgänge in Bregenz informiert. Die Brisanz der Angelegenheit erforderte es, ohne Umschweife eine spezielle Akte anzulegen ${ }^{64}$, die Vorgänge waren von höchstem politischen Interesse für Frankreich. Neben dem bereits zitierten Schreiben des französischen Botschafters in Bern traf wenig später ein kommentarloses Schreiben von Saint Hardouin, dem Conseiller Politique im Kabinett Koenig, im Quai d'Orsay ein ${ }^{65}$. Diesem war eine französische Übersetzung des Gründungsberichts beigefügt. Trotz der mangelhaften Informationen war in Paris längst über die Zukunft Österreichs und damit indirekt auch über die Alpenlandpläne entschieden worden. Bereits im Januar 1945 hatte der Generalstab für die Nationale Verteidigung (EMDN) deutlich gemacht, daß die Wiedererrichtung eines vom Reich unabhängigen Österreichs beschlossene alliierte Politik sei ${ }^{66}$. Von diesem Axiom rückte in den folgenden Monaten auch de Gaulle nicht ab. Eindeutig formulierte der Chef der Provisorischen Regierung im Juli 1945 in der Geheimdirektive $\mathrm{N}^{\circ}$ 2, welche die Richtlinien der französischen Österreichpolitik umriß ${ }^{67}$, den geltenden Standpunkt erneut: „Die wichtigste Prämisse unserer Politik besteht darin, ein unabhängiges, von Deutschland vollkommen losgelöstes Österreich zu schaffen, das wirtschaftlich lebensfähig ist. " Die Grenzen sollten in etwa mit denen des Vertrags von Saint Germain identisch sein, allerdings trat de Gaulle für eine Angliederung Südtirols ${ }^{68}$ an Österreich ein. Ganz entschieden sprach er sich gegen jede Form einer alpinen Union aus: „Es liegt nicht in unserem Interesse, Bayern mit Österreich zu vereinigen, unter dem Vorwand, einen Block süddeutscher, katholischer Staaten zu gründen, die sich dem preußischen Einfluß widersetzen. "69 Viel zu groß erschien nicht nur de Gaulle die Gefahr, daß Österreich unter den Einfluß Bayerns käme und in nicht allzu ferner Zukunft eine Neu-

${ }^{64}$ MAE Z-Europe Gén. 1944-1960 39. „Union alpine“. Dieses Dossier ist zugänglich, wohingegen ein weiteres Faszikel mit dem Titel „Alpenland 1945/49“ im AdO Colmar noch bis ins Jahr 2009 nicht vorgelegt wird; AdO Bade Sec. Pol. c. 2170/1 p. 1 (résérvé).

${ }^{65}$ Saint Hardouin an Bidault vom 16. 11. 1945; MAE Z-Europe Gén. 1944-1960 39.

66 "Note - Occupation de l'Autriche“, EMDN vom 31. 1. 1945; SHAT 4 Q 11.

${ }^{67}$ Die Dokumente $\mathrm{N}^{\circ} 1$ und $\mathrm{N}^{\circ} 3$ behandelten die Deutschlandpolitik und sind bei Ménudier, Allemagne, S. 169-182 publiziert. "Document $N^{\circ} 2$ - Directives pour notre action en Autriche“, GPRF vom 19. 7. 1945; MAE Y-Int. 1944-1949 Dejean 679. Veröffentlicht in: Klöckler, Quellen, S. 9-12.

68 "Österreich muß seinen Besitz über Südtirol, das bis zu einer Linie südlich von Meran, Bozen und Cortina d'Ampezzo verläuft und sich in etwa mit der Sprachgrenze deckt, wiedererlangen“; ebenda, S. 10.

${ }^{69}$ Ebenda, S. 10. 
auflage eines „Großdeutschlands" zu befürchten wäre, das es schließlich zu verhindern galt. Außerdem wies de Gaulle entschieden den Plan zurück, Österreich in einer Art Föderation mit der Tschechoslowakei und Ungarn verbinden zu wollen. Die Unabhängigkeit Österreichs zu wahren, galt ihm als unabdingbare Voraussetzung für die weitere französische Politik in Mitteleuropa.

In den Augen Frankreichs sollte das neue Österreich auch bis zu einem gewissen Punkt föderalistisch gegliedert sein. Für Vorarlberg und Tirol schlug de Gaulle eine "ausreichend große Autonomie “ innerhalb des österreichischen Staates vor. Einer Ausgliederung der französisch besetzten Länder redete de Gaulle keinesfalls das Wort, vielmehr verlangte er von der dortigen Militärregierung, daß „keine separatistischen Tendenzen ermutigt werden dürfen "70. Das bäuerliche, vom Katholizismus geprägte französische Besatzungsgebiet in Österreich wies seiner Meinung nach noch nennenswerte monarchistische Tendenzen auf, derer sich aber die französischen Behörden keinesfalls bedienen dürften. Daher müsse man sich auf das konservativ-katholische Milieu stützen und gleichzeitig den Monarchisten entschieden entgegentreten. De Gaulle zeigte sich überzeugt davon, daß Frankreich auf diejenigen in Österreich zurückgreifen mußte, deren Aversion gegen "Anschluß" und Nationalsozialismus bekannt war.

Die offizielle Politik Frankreichs ließ demnach keine Zweifel an der Zukunft Österreichs. Eine Unterstützung derjenigen Kräfte, die versuchten, Österreich in eine Konföderation katholischer Staaten hineinzuziehen, war ausgeschlossen und wurde sowohl von de Gaulle als auch von den maßgeblichen Stellen im Quai d'Orsay entschieden abgelehnt. Auch General Marie-Emile Béthouart ${ }^{71}$, der französische Oberkommandierende in Wien, teilte in Kenntnis der Direktive $\mathrm{N}^{\circ} 2$ die Pariser Einschätzungen bezüglich der Zukunft Österreichs. Eine süddeutsche Konföderation unter Einschluß Österreichs lag für Béthouart jenseits des politisch Machbaren und Wünschbaren, und deshalb ließ er umgehend weitere Aktionen der Alpenlandbewegung verbieten. Gegenüber seinem Baden-Badener Pendant Pierre Koenig äußerte sich der französische Oberbefehlshaber in Wien im Februar 1946 sehr skeptisch und sah in der Bewegung „Alpenland" einen letzten einer Vielzahl von Versuchen, die seit einem Jahrhundert unternommen worden seien, das deutsche Problem zu lösen, indem man den „katholischen Staaten des Südens erlaubt, dem politischen und wirtschaftlichen Einfluß der durch Preußen dominierten Staaten des Nordens zu entweichen"72. Das Verbot, den Sitz des „Aktionskomitees des Alpenländisch demokratischen Bundes“ in Bregenz einzurichten, war die konsequente Reaktion Béthouarts. Außerdem untersagte er jede Genehmigung für die Gründung eines Bundes oder einer Vereinigung, die im alpenländischen Sinn Propaganda betreiben wollte. Die strikte Haltung und das Vorgehen gegen die Alpenlandbe-

\footnotetext{
70 Ebenda, S. 11.

${ }^{71}$ Marie-Emile Béthouart (1889-?), Offiziersjahrgang von Charles de Gaulle und Alphonse Juin; 1914-18 Infanterieoffizier; Besatzungsoffizier in Zweibrücken/Pfalz; 1940 General im Norwegen-Feldzug; nach dem Waffenstillstand von der Vichy-Regierung in Marokko eingesetzt; wegen mangelndem Widerstand gegen die vorrückenden Alliierten Anklage vor einem Kriegsgericht; Chef der freifranzösischen Militärmission in Washington; 1944 Chef des Generalstabs; Oberbefehlshaber des Ersten Armeekorps; 1945-50 französischer Oberkommandierender und Hochkommissar in Österreich. Memoiren: Ders., Bataille und Ders., années; vgl. außerdem Eisterer, Besatzungspolitik, S. $22 \mathrm{ff}$.

72 Béthouart an Koenig vom 14. 2. 1946; MAE Z-Europe Gen. 1944-1960 39.
} 
wegung hatte Béthouart längst mit seinem in Innsbruck residierenden Generalverwalter Pierre Voizard ${ }^{73}$ koordiniert. Auch Voizard entpuppte sich nicht als Freund der Alpenlandpläne. Mit Generalverwalter Emile Laffon in Baden-Baden sprach er auf dessen Anfrage hin die Vorgehensweise ab, wobei er keinen Zweifel daran ließ, daß er eine negative Haltung zu diesem Projekt einnahm. „Ich habe es nicht für angebracht erachtet, die Niederlassung des Sitzes der Bewegung in Bregenz zu genehmigen, und ich habe befohlen, jede Anfrage diesbezüglich abzulehnen"74, teilte er am 20. Januar 1946 dem Baden-Badener Generalverwalter mit. Die Teilnehmer der Gründungsversammlung waren Pierre Voizard bekannt, er verfügte über präzise Angaben der untergeordneten Dienststellen. Für den Innsbrucker Generalverwalter lag der Schluß nahe, daß es sich um einen Versuch „einiger idealistischer oder sentimentaler Intellektueller"75 handele, das deutsche Problem zu lösen. Zweifellos lag Voizard bei der Abfassung des Briefes an Laffon im Januar 1946 die schriftliche Ausarbeitung Wachters vor, zu auffällig ist nämlich die identische Anordnung des verwendeten Datenmaterials. Einen Staat auf religiöser Grundlage aufzubauen, schien dem laizistischen Generalverwalter vollkommen undenkbar. Daß eine Konföderation süddeutscher, katholischer Staaten schließlich ein Hindernis hinsichtlich eines neuen „Großdeutschland“ bilden sollte, konnte Voizard nicht nachvollziehen. Die wirtschaftliche Anziehungskraft der süddeutschen Staaten insbesondere auf Vorarlberg bestritt der Generalverwalter hingegen nicht, aber er vermutete, daß Vorarlberg „in keiner Weise eine politische Union" 76 mit Süddeutschland wünsche.

Den Standpunkt Voizards teilte auch der Vertreter des französischen Außenministeriums in Österreich, Louis de Monicault ${ }^{77}$. Er lobte das Verhalten Voizards in einem Schreiben an den Leiter des CGAAA, René Mayer, und schloß seinen Brief nach Paris mit der Bemerkung: „Es gibt wenige Ideen, die wir als gefährlicher einschätzen müssen." 78 Wochen später lieferte de Monicault eine eigene Analyse der Alpenlandbewegung ${ }^{79}$; er ordnete die Bestrebungen in den Rahmen des 20. Jahrhunderts ein und gab zu bedenken, daß auch die Zeit bis zur Friedenskonferenz nach dem Ersten Weltkrieg einige Projekte zur staatlichen Neugestaltung hervorgebracht habe. Die durch Volksabstimmung beschlossene Angliederung Vorarlbergs an die Schweiz ${ }^{80}$ hob de Monicault besonders hervor und bemerkte, daß die Alpenlandbewegung ein Resultat der Zeitum-

${ }^{73}$ Emile Voizard (1896-?), Freiwilliger im Ersten Weltkrieg; Karriere im öffentlichen Dienst; 193641 Präfekt der Départements Aude bzw. Seine-et-Marne; Generalsekretär des französischen Protektorats Marokko; Unterleutnant des französischen Expeditionskorps im Italien-Feldzug; Verwendung im französischen Generalstab; 1945 Generalverwalter im besetzten Österreich. Biographisches bei: Eisterer, Besatzungspolitik, S. $24 \mathrm{ff}$. und Bertholle, Voizard.

74 Voizard an Laffon vom 20. 1. 1946; MAE Z-Europe Gén. 1944-1960 39.

75 Ebenda.

${ }^{76}$ Ebenda.

77 Louis de Monicault führte den Rang eines Ministre Plénipotentiaire, Représentant Politique de la République Française en Autriche und verrichtete seine Dienstgeschäfte in Wien.

78 Monicault an Mayer vom 13. 2. 1946; MAE Z-Europe Gén. 1944-1960 39.

79 "Mouvement Alpenland“, Monicault an Mayer vom 22. 3. 1946; MAE Z-Europe Gén. 1944 196039.

801919 gelang es dem Vorarlberger Landeshauptmann Ender, eine Volksabstimmung durchzusetzen, deren Resultat eine deutliche Mehrheit (71\%) für den Anschluß Vorarlbergs an die Schweiz war. Doch die zögerliche Haltung der Eidgenossen vereitelte die damaligen Pläne. Zu der Problematik ist eine umfangreiche Literatur entstanden: Witzig, Frage; Pichler, Lumpen; Arbeitskreis für Regionalgeschichte (Hrsg.), Eidgenossen. Vgl. außerdem die Einführung. 
stände sei. Daher fiel de Monicaults Urteil dezidiert aus: „Ein solches Projekt erfährt von unserer Seite eine klare Absage. "81 Die Pläne würden von der Vorarlberger und Tiroler Bevölkerung überdies mit Blick auf die bayerische Okkupation von 1809 abgelehnt. Tatsächlich stellten sich politische Vertreter wie der Vorarlberger Landeshauptmann Dr. Ulrich Ilg82 eindeutig ablehnend den Alpenlandplänen gegenüber. Daß der Tiroler Landeshauptmann und spätere österreichische Außenminister Karl Gruber ${ }^{83}$ - wie in Paris vermutet wurde ${ }^{84}$ - die Alpenlandpläne unterstützt hat, ist eher unwahrscheinlich, selbstredend enthalten weder seine schriftlichen Aufzeichnungen noch seine Memoiren Bemerkungen zum Untersuchungsgegenstand ${ }^{85}$.

Für das Cabinet Militaire des französischen Oberkommandos in Wien lieferte Oberstleutnant Quincerot im Februar 1946 eine ausführliche Analyse ${ }^{86}$. Mangelnde Präzision der Ziele und fehlende Basis in der Bevölkerung stellten das Hauptproblem der Alpenlandbewegung dar; „im übrigen“, bemerkte Quincerot, „läuft sie den Entscheidungen der alliierten Regierungen entgegen, die die Wiedererrichtung eines unab-

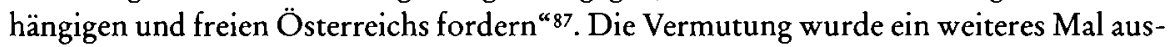
gesprochen, daß sich hinter der Alpenlandbewegung der Beginn eines erneuten „Anschlusses" verbergen könnte.

Auch die französischen Dienststellen in Baden-Baden, Freiburg und Konstanz beschäftigten sich mit der Gründungsversammlung in Bregenz. Der Freiburger Oberdelegierte General Schwartz hatte von der Beteiligung des Singener Bürgermeisters Dietrich an dem Gründungsakt Kenntnis bekommen. An der Existenz einer erteilten Genehmigung zweifelnd, forderte Schwartz von dem sich in Abreise befindlichen Konstanzer Bezirksdelegierten d'Alauzier genaue Nachforschungen ${ }^{88}$. Mit dem Hinweis, daß eine „schnelle und sehr nachdrückliche Untersuchung“ stattzufinden habe, leitete d'Alauzier

${ }^{81}$ Monicault an Mayer vom 22. 3. 1946; MAE Z-Europe Gén. 1944-1960 39.

In der Forschung wurde bisher die quellenmäßig nicht untermauerte These vertreten, daß die Alpenlandbewegung die „volle Unterstützung der französischen Besatzungsmacht" gefunden habe; Pfetsch, Verfassungspolitik, S. 94.

82 Ilg betrachtete die Alpenlandpläne als eine Utopie und trat ihnen entschieden entgegen.

Ulrich Ilg (1905-1985), Staatssekretär für Land- und Forstwirtschaft unter Bundeskanzler Dollfuß, 1934 Vize-Präsident der Vorarlberger Bauernkammer, 1936 Landesbauernführer, 1945-64 Landeshauptmann von Vorarlberg und Landesobmann der ÖVP. Vgl. auch Kessler, Ilg sowie autobiographisch: Ilg, Lebenserinnerungen.

${ }^{83}$ Karl Gruber ("1909), Studium der Rechtswissenschaften; Tätigkeit im Bundeskanzleramt in Wien; 1938 entlassen; 1945 Landeshauptmann von Tirol; 1945-53 Abgeordneter der ÖVP und österreichischer Außenminister; 1954-57 Botschafter in den USA; 1961 Sonderberater der Internationalen Atomenergie-Organisation in Wien; 1961-66 Botschafter in Madrid; 1966-69 Staatssekretär im Bundeskanzleramt; 1970-72 Botschafter in Washington.

${ }^{84}$ "Le mouvement ,Alpenland“" vom 25. 2. 1946; AdO SGAAA c. 2664 9. séparatisme.

${ }^{85} \mathrm{Vgl}$. Gruber, Leben. Der intimste Kenner der Politik Grubers, der Innsbrucker Historiker Michael Gehler, hält eine positive Rezeption der Alpenlandpläne für unwahrscheinlich. Auch in den Papieren Karl Grubers, die am Institut für Zeitgeschichte der Universität Innsbruck lagern und nicht öffentlich zugänglich sind, konnte Gehler im Zusammenhang mit seinem Habilitationsprojekt keinen diesbezüglichen Hinweis finden; Schreiben Gehlers an den Verfasser vom 24. 6. 1994. Weiterführend: Gehler, Gruber.

${ }^{86}$ "Le mouvement ,Alpenland““, Quincerot, Chef de la Section Renseignement vom 13. 2. 1946; MAE Z-Europe Gén. 1944-1960 39.

${ }^{87}$ Ebenda.

${ }^{88}$ Schwartz an d'Alauzier vom 7.11. 1945; AdO Bade C 2101. 
das Schreiben Mitte November 1945 dem neuen Kreisdelegierten von Konstanz, Hauptmann Droin, $\mathrm{zu}^{89}$. Über die Verbindungsoffiziere der Sûreté, die in Singen stationiert waren, bekam er die gewünschten Informationen. Tatsächlich hatte Droin schon am 12. Oktober 1945 d'Alauzier über die Gründungsversammlung in Kenntnis gesetzt. Außerdem fertigte Droin nun einen Bericht über die Hintergründe an ${ }^{90}$, wobei der Konstanzer Kreisdelegierte betonte, daß die Militärregierung in Bregenz das Einverständnis gegeben und einen Offizier zur Gründungsversammlung ins dortige Rathaus entsandt habe. Die Teilnehmer würden nun ungeduldig darauf warten, endlich mit einer Kampagne beginnen zu können. „Viele Südbadener sehen mit großer Genugtuung der Schaffung eines neuen Staates, der die Länder nahe der Alpen vereinen würde, entgegen "91, glaubte Hauptmann Droin zu wissen.

Diese Einschätzung gelangte nicht mehr auf den Schreibtisch des konservativen d'Alauzier ${ }^{92}$, sondern in die Hände des neuen kommunistischen Konstanzer Bezirksdelegierten Marcel Degliame, der aus der französischen Résistance hervorgegangen war. Am Tag seiner Amtseinführung, dem 23. November 1945, bearbeitete er die Anfrage von General Schwartz, indem er sich auf den Bericht Hauptmann Droins stützte und diesen fast komplett wiedergab. Sicherlich war der Brief für Schwartz schon vorbereitet gewesen, ansonsten hätte sich Degliame nicht genötigt gesehen, folgende Zeilen handschriftlich hinzuzufügen: „Ich persönlich glaube, daß man sehr vorsichtig gegenüber dieser Bewegung handeln muß. Ich halte es nicht für geschickt, zum jetzigen Zeitpunkt ihre Bildung und ihre Entwicklung im Bezirk Konstanz zu genehmigen." 93 Frühzeitig gab er sich damit als ausgewiesener Gegner der föderalistisch-autonomistischen Strömungen zu erkennen, ein Fakt, das sich bei der Gründung des „Schwäbisch-Alemannischen Heimatbundes" noch auswirken sollte. Mit diesen Informationen ausgestattet, sprach sich Schwartz entschieden gegen eine Genehmigung der Alpenlandbewegung aus ${ }^{94}$. Nachdrücklich wies der Freiburger Oberdelegierte auf den Wunsch nach Zusammenfassung des alemannischen Stammesgebietes hin und warnte Laffon, daß hiervon auch das Elsaß tangiert sei. Der Generalverwalter selbst erteilte der Alpenlandbewegung eine Abfuhr, der Warnungen des Freiburger Oberdelegierten hätte es nicht bedurft.

\section{Die „Alemannische Freiheitsbewegung“}

Die erste schriftliche Eingabe einer „Alemannischen Freiheitsbewegung " erhielt die USMilitärregierung im Juni 1945 aus dem französisch besetzten Zwiefalten. Unter der zusammenfassenden Bezeichnung "Süddeutsche Befreiungsbewegung" hatte der gebürtige

\footnotetext{
${ }^{89}$ Die beiden Kreismilitärregierungen Konstanz (Landkreis mit Major Lesur in Singen und Stadtkreis mit Hauptmann Hoeppfner in Konstanz) wurden am 6. 9. 1945 zusammengelegt und von Hauptmann Droin als Kreisdelegiertem für Konstanz - Stadt und Land - im folgenden geleitet; Klöckler, Besatzungspolitik, S. 28.

${ }_{90}$ Droin an d'Alauzier vom 19.11. 1945; AdO Bade C 2101.

91 Ebenda.

92 D'Alauzier informierte die Stadtverwaltung Konstanz mit Schreiben vom 23. 11. 1945 von seiner Abberufung; StadtA KN S II 9544.

${ }_{93}$ Degliame an Schwartz vom 23. 11. 1945, dazu handschriftlicher Vermerk; AdO Bade C 2101.

${ }^{94}$ Schwartz an Laffon vom 3. 12. 1945; zitiert nach Wolfrum, Besatzungspolitik, S. 138.
} 
Schweizer Bruno Asprion ${ }^{95}$, der in Sankt Blasien im Schwarzwald während des Krieges ein Nickelbergwerk geleitet hatte, den Amerikanern seine Gruppierung einschließlich der Ziele dargelegt ${ }^{96}$. Es ist nicht unwahrscheinlich, daß es sich bei Asprion auch um den Verfasser zweier Kettenbriefe, die im Sommer 1940 in Südwestdeutschland im Umlauf waren, handelte ${ }^{97}$. Die „Süddeutsche Freiheitsbewegung", so führte Bruno Asprion aus, gliedere sich in zwei Gruppierungen mit Sitz in Ulm und München. Sie ziele auf die Errichtung zweier von Preußen unabhängiger Staaten der Alemannen und der Bayern ab, die Bezeichnungen gab Asprion mit „Fränkisch-Alemannische Freiheitsbewegung “ und „Bayerische Freiheitsbewegung“ an. Beide Bewegungen stünden unter einer gemeinsamen Leitung und setzten sich für die „Ausrottung“ des Nationalsozialismus und des preußischen Militarismus in Süddeutschland ein. Die Ursprünge der Bewegung reichten bis ins Jahr 1918 zurück, ein Vorschlag der Zusammenfassung von Süddeutschland und der Eidgenossenschaft stamme aus dem Jahr 1923; Asprion bezeichnete als geistige Väter dieser Pläne unter anderen den später ermordeten Zentrumspolitiker Matthias Erzberger, das demokratische Mitglied des Reichstages Philipp Wieland und den ersten sozialdemokratischen Staatspräsidenten Württembergs, Wilhelm Blos. Diese Angaben sind allerdings bei Asprion weder belegt noch heute überprüfbar.

Die beiden unabhängigen Staaten, welche die Gruppe um Asprion errichtet sehen wollte, sollten ein föderativ aufgebautes „Franco-Alemannien“ und ein Freistaat Bayern sein. Die föderativen Bestandteile des fränkisch-alemannischen Staates wären Württemberg mit Bayerisch-Schwaben, Baden mit Rheinhessen, Franken südlich des Mains und die deutschsprachige Schweiz mit Vorarlberg gewesen. Der Beitritt des Elsasses durch Option sollte offengehalten werden. Für den Freistaat Bayern verblieben daher Oberund Niederbayern, die Oberpfalz und - nach erfolgreichem Plebiszit - Tirol98. „FrancoAlemannien“ hätte nach Asprions Planungen in die Schweiz „inkorporiert“ werden müssen. Ganz Südwestdeutschland wäre mit weitgehend selbstverwalteten Kantonen

${ }^{95}$ Bruno Asprion war gebürtiger Schweizer, aber naturalisierter Deutscher, und leitete während des Zweiten Weltkrieges ein Nickelbergwerk in Wittenschwand bei St. Blasien im Schwarzwald; er galt als wohlhabender Industrieller; 1945 gelang es ihm, von Zwiefalten aus in die ABZ nach Ulm zu übersiedeln; in Bayern verbreitete er seine föderalistischen Pläne, unterstützt von einem gewissen Dr. Kern.

96 OMGUS RG $2603 / 407$ - 3/9 passim „Subject: separatisme [sic!] in South Germany, South German action for liberty" [Juni 1945]. Die Vorschläge Asprions sind in dieser Akte nur in der englischen Übersetzung, die von dem amerikanischen Offizier Robert A. Berendt gefertigt wurde, erhalten. Erstmals fanden die Pläne Erwähnung bei: Nüske, Württemberg, S. $180 \mathrm{f}$.

${ }^{97}$ Die Ideen der "Alemannischen Freiheitsbewegung" Asprions vom Sommer 1945 und die Ausführungen einer "Alemannischen autonomistischen Bewegung P. G. S." von 1940 haben auffällige Ähnlichkeiten: „Die alemannische autonome Bewegung hat sich zum Ziel gesetzt, das alemannische Volk zwischen Lech und den Vogesen zusammenzufassen zu einem selbständigen neutralen Staat: Alemannien“ (Kettenbrief vom 11.8. 1940, in Stuttgart aufgetaucht). „Alemanne, grübele nicht und denke auch einmal über die Idee der alemannischen autonomistischen Bewegung nach. Grüble und denke einmal ganz gründlich darüber nach [...] Alemanne, unser Volkstum ist in Gefahr! [...] Unsere Art und Sprache muß erhalten bleiben, und das kann nur geschehen in einem freien Staat: Alemannien" (Kettenbrief vom 23. 9. 1940, in ganz Baden aufgetaucht). Abgedruckt in: Boberach, Meldungen, S. $1548 \mathrm{f}$. und S. $1677 \mathrm{f}$.

98 An dieser Stelle ist von Tirol im allgemeinen die Rede, eine Eingliederung Südtirols dürfte allerdings ebenfalls anvisiert worden sein; OMGUS RG 260 3/407 - 3/9 „Proposals for an administrative organization of a state foederation [sic!]". 
überzogen worden, die in Bezirke untergliedert gewesen wären und über die gemeinsame Hauptstadt Ulm verfügt hätten. Der Föderativstaat „Franco-Alemannien“ sollte mit einem in geheimen Wahlen gewählten Parlament, dessen Mitglieder sich als „Föderativkonsuln“ bezeichnen sollten, ausgestattet werden. Dem „Präsidenten der Föderation“ hätte die Nominierung und Bestätigung der Regierung oblegen. Für Bayern fielen die Vorschläge dürftiger aus, eine enge wirtschaftliche Zusammenarbeit war allerdings ausdrücklich gewünscht.

Präzise stellte Asprion ein 25 Punkte umfassendes Sofortprogramm zur Errichtung eines Staates "Franco-Alemannien" auf99. Der naturalisierte Deutsche errichtete ein Gedankenkonstrukt, das auf zwei Säulen basierte: Schaffung eines nach Schweizer Vorbild orientierten, selbständigen fränkisch-alemannischen Staates und Abwendung von einem zentralistischen, von Preußen beherrschten Deutschland. Konkret forderte Asprion die Vereinigung der fränkisch-alemannischen süddeutschen Gebiete mit der deutschsprachigen Schweiz $(1,2,4,5)$, die Ausgliederung der nicht deutschsprachigen schweizerischen Gebiete nach Frankreich (6) und Italien (7), die Übernahme der schweizerischen Gesetze (13) und die enge wirtschaftliche Zusammenarbeit - einschließlich der Zahlung von Reparationen (10) - mit Frankreich $(8,9)$. Die Entnazifizierung Süddeutschlands $(12,17,24,25)$, Einführung einer „alemannischen und bayerischen Staatsbürgerschaft ${ }^{\text {“ }}$ (18) und die Ausweisung der „Preußen“ $(19,21)$ bei gleichzeitiger Einziehung derer Vermögen zu Reparationszwecken (20) bildeten die Grundlage für eine ethnische Strukturierung des Staates „Franco-Alemannien“. Das Schweizer Demokratiemodell stand bei Asprion nicht Pate, vielmehr sollte Südwestdeutschland durchgängig „verschweizert" werden.

Hinter der Bewegung verbargen sich im "alemannischen“ Raum einige Industrielle und zwei Schweizer Staatsbürger, die Asprion den Vertretern der US-Militärregierung namhaft machte. Unter den Genannten befanden sich der kurzzeitige Donaueschinger Landrat und Schwenninger Uhrenproduzent Dr. h. c. Fritz Mauthe ${ }^{100}$ und der Singener Stadtbaurat Jakob Spengler ${ }^{101}$. Auch die „Bayerische Befreiungsbewegung“ unter Führung des Münchener Rechtsanwaltes Dr. Albert Heizer verfügte über ein halbes Dutzend Mitglieder. Das Generalsekretariat der „Süddeutschen Freiheitsbewegung“ befand sich bei Heizer in München, Asprion selbst bezeichnete sich in dem in englischer Sprache abgefaßten Text als "chief of action".

Die beiden geplanten Staaten, die zusammen den gesamten süddeutschen und alpinen Raum einnehmen sollten, hätten von Asprion auch Alpenland genannt werden können,

99 OMGUS RG $2603 / 407$ - 3/9 „Foundation of a foederative [sic!] state ,Franco-Alemannia““.

100 Fritz Mauthe (1875-1951), Sohn des Schwenninger Uhrenherstellers Jakob Mauthe; um 1890 Lehre als Uhrenmechaniker; 1904 Leitung der in eine $\mathrm{GmbH}$ umgewandelten Uhrenfabrik; 1906 Gemeinderat in Schwenningen; 1908-33 und 1945-51 Leiter der Handelskammer Rottweil; 1921 Ehrendoktor der Universität Tübingen; 1924-33 MdL Württemberg (DDP); Aufsichtsratsvorsitzender der Württembergischen Landeszentralbank; 1945 Landrat von Donaueschingen; Berater von industriellen und landwirtschaftlichen Verbänden; 1950 Ernennung zum Ehrenbürger von Schwenningen.

${ }^{101}$ Jakob Spengler (1894-?), Mitarbeit in der Wasser- und Straßenbaudirektion Karlsruhe; 1919 Stadtgeometer in Singen; 1924 Leiter des Stadtbauamtes und des Vermessungsamtes; Wünschelrutengänger; 1927 Stadtbaurat; 1933 Entbindung vom Amt des Stadbaurats und „Degradierung“ zum Leiter des Vermessungsamtes; 1940 auf eigene Bitte hin pensioniert; 1944-46 kommissarischer Leiter des Stadtbauamtes. 
eine Bezeichnung, die schließlich zur gleichen Zeit durch den Singener Bürgermeister Bernhard Dietrich Verwendung gefunden hatte. Den Franzosen präsentierte Asprion seine Gruppierung einige Wochen später als „Alemannische Freiheitsbewegung“ (AFB). Die französischen Dienststellen rückten die Pläne Asprions sofort in die Nähe des Alpenlandprojekts von Dietrich und beobachteten beide Gruppierungen genau ${ }^{102}$. In Innsbruck nahmen sich die französischen Offiziere um Generalverwalter Voizard im Laufe des Jahres 1946 der Pläne an, die Motive des nunmehr in der amerikanischen Besatzungszone lebenden Asprion und seines engsten Vertrauten, Dr. Kern, blieben aber im dunkeln. Die französische Besatzungsmacht nahm an, Asprion und Kern wollten auf der Welle der Sympathie, die den Alpenlandplänen entgegengebracht wurden, mitschwimmen. Kern hatte nämlich mit Julius Wachter Anfang 1946 in Bregenz Kontakt aufgenommen und ihm die Ziele der AFB erläutert. Der Bregenzer Bürgermeister hingegen gab zu verstehen, daß ihm die „Alemannische Freiheitsbewegung“ nicht bekannt sei. Auf seiner Weiterfahrt nach Innsbruck wurde Kern von der österreichischen Polizei festgenommen, die auf Veranlassung des Tiroler Landeshauptmannes Karl Gruber zuschlug. Gruber selbst hatte den amerikanischen Standpunkt verinnerlicht, daß die Propaganda Asprions auf alle Fälle zu unterbinden sei. Auch gegenüber der Alpenlandbewegung hatte Gruber gemeinsam mit seinem Vorarlberger Amtskollegen Ulrich Ilg eine reservierte Haltung eingenommen. Geringfügig revidierte Pläne ließ Asprion zu Beginn des Jahres 1946 der französischen Besatzungsmacht zukommen ${ }^{103}$. In Anpassung an die Verhältnisse forderte er nun nicht mehr sofort die Schaffung eines alemannischen Staates, sondern über den Umweg einer alemannischen Regierung für den Südteil der FBZ, also der Errichtung des Südstaates. Als Fernziel schlug er aber weiterhin die Loslösung und Vereinigung aller alemannischen Gebiete einschließlich der deutschsprachigen Schweiz vor. Dazu propagierte Asprion erneut den „Kampf für die Arlberg-Lechtalgrenze“ und damit für die Angliederung von Vorarlberg und Bayerisch-Schwaben an den zukünftigen alemannischen Staat. Auch die als Endziel geforderte Einbeziehung der deutschsprachigen Teile der Schweiz durch ein Referendum stand für Asprion außer Zweifel: Erleichtert und erreicht werden sollte dies durch die Einführung des „helvetischen Rechts“, einer auf den Franken gestützten, neuen Währung, die Verpachtung der Eisenbahn und der Post an die Schweiz, die Zusammenarbeit mit den schweizerischen Elektrizitätserzeugern und außerdem durch die Zulassung Schweizer Handelsunternehmen im alemannischen Staat.

Die mangelnde Stringenz der Pläne trug wesentlich zur offenen Ablehnung durch die französische Besatzungsmacht bei. Die Gedanken Asprions waren zu „bizarr“, in den französischen Augen „utopisch“ "104; schon die Einbeziehung der Schweiz in den Föderativstaat "Alemannien“ wäre an dem tiefwurzelnden Eigenständigkeitswillen der eidgenössischen Bevölkerung gescheitert. Frankreich hatte durch General de Gaulle die Maxime des Wiederaufbaus der staatlichen Existenz Österreichs ausgegeben, auch an die-

${ }^{102}$ Das Ergebnis der französischen Beobachtungen stellt der vom Commandement en Chef Français en Autriche erstellte, umfangreiche Bericht „Alpenland“ dar. „Alpenland“ (masch. 55 S.) [Sommer 1946]; AdO SGAAA c. 2665 p. 1.

103 "Programme d'action du Mouvement de la libération alémanique (A. F. B.) (Alemannische Freiheitsbewegung)“, französische Übersetzung im Anhang des „Alpenland“-Berichtes des CCF Autriche [S. 53-55]; AdO SGAAA c. 2665 p. 1.

${ }^{104}$ Ebenda. 
sem Punkt mußten die Ideen Asprions bei der französischen Besatzungsmacht auf unüberwindbaren Widerstand stoßen. „Frankreich steht einer Integration Österreichs in einen vielleicht lebensfähigen, aber verschiedenartigen [bétéroclite] Komplex feindlich gegenüber“, urteilte denn auch die Innsbrucker Militärregierung ${ }^{105}$. Und außerdem blieb Asprion nach Ansicht der zuständigen Besatzungsoffiziere eine zwielichtige Gestalt, deren frankophile Haltung man stark bezweifelte; mangelnde Informationen über die Hintergründe und die Person Asprions taten ein übriges, dem Projekt keine weitere Aufmerksamkeit zu schenken. Im übrigen waren Asprion in der amerikanischen Zone die Hände gebunden. In München war seit Juli 1945 die „Bayerische Freiheitsbewegung" von der amerikanischen Militärregierung unter Hinweis auf die Befehle von General Eisenhower verboten und aufgelöst worden ${ }^{106}$, dasselbe Schicksal dürfte auch Asprion und seiner "Alemannischen Freiheitsbewegung“ widerfahren sein.

\section{Die Alpenlandpläne in der Schweiz}

Die Propaganda Dietrichs und seiner Vorarlberger Freunde blieb in der nahen Schweiz nicht ohne Resonanz. Der französische Geheimdienst machte in den katholischen Kreisen der Eidgenossenschaft, vor allem in der Caritas und in der "Schweizerspende“, Personen ausfindig, die von einer leicht abgewandelten Version des Alpenlandes träumten $^{107}$. Allen voran würden der ehemalige Bundesrat Jean-Marie Musy ${ }^{108}$ und der schweizerische Schriftsteller Gonzague de Reynold ${ }^{109}$ - so mutmaßte die Sûreté in Paris - den föderalistischen Zusammenschluß von Österreich, Südtirol, Bayern „und einem wichtigen Teil Süddeutschlands, aber auch der katholischen Kantone der Schweiz und einem Teil Norditaliens" ${ }^{110}$ zu einer alpenländischen Konföderation propagieren. Eine breitangelegte Agitation entfalteten die schweizerischen Anhänger des Alpenlandes aber nicht, die Pläne dürften vielmehr ephemeren Charakter gehabt haben. An die helvetische Öffentlichkeit ist von diesen Vorstellungen nichts gedrungen, weder der Schweizer Presse noch den Behörden waren die Gedankenspiele bekannt ${ }^{111}$.

105 Ebenda, S. 46.

106 "Note sur les partis politiques en Allemagne" (masch. 10 S.) vom 31. 7. 1945; MAE Z-EuropeAllemagne 1944-1960 48.

107 Direction Générale de la Sûreté Nationale: „La politique allemande du Vatican“ (masch. 2 S.) vom 10. 4. 1946; MAE Z-Europe Gén. 1944-1960 39.

108 Jean-Marie Musy (1876-1952), Studium der Rechtswissenschaften in Freiburg/Schweiz; 1901 Lizentiat; 1904 Promotion; 1913-19 Bankrat der Schweizerischen Nationalbank; 1919 Wahl in den Bundesrat als Mitglied der katholisch-konservativen CVP; 1920-34 Leitung des Finanzund Zolldepartements im Bundesrat; Anhänger einer europäischen Neuordnung; offene Ablehnung des Kommunismus; 1944 M.s Kontakte zu Himmler und Schellenberg führen zur Freilassung von 1200 Juden aus dem KZ Theresienstadt (zu dieser Affäre Mendelsohn, Holocaust, Einleitung); eine Würdigung der politischen Leistungen bei Python, Musy, S. 355-360.

109 Louis de Gonzague Reynold de Cressier (1880-?), Studium in Freiburg/Schweiz, Freiburg i. Br. und Paris; 1915-31 Professor für französische Literatur in Bern; 1925 Präsident der Union catholique d'études internationales; seit 1932 Professor für Geschichte in Freiburg/Schweiz; diplomatische Missionen nach Südamerika.

110 "La politique allemande du Vatican“ vom 10. 4. 1946; MAE Z-Europe Gén. 1944-1960 39.

111 Der Verfasser fand in den Inventaren des Bundesarchivs in Bern und des Staatsarchivs Schaff- 
Hinter den katholischen Kreisen der Schweiz stand nach den Erkenntnissen des französischen Geheimdienstes Pater Robert Leiber SJ, der als Drahtzieher der Deutschlandpolitik des Vatikans galt. Papst Pius XII. hatte den Jesuitenpater während seiner Berliner Jahre als Apostolischer Nuntius kennen- und schätzengelernt und ihn zu seinem Privatsekretär gemacht. Ob Leiber tatsächlich diese Version der Alpenlandpläne initiiert hat, wird noch auf lange Jahre hin ungeklärt bleiben ${ }^{112}$, fest steht allerdings, daß er sich nach 1945 befriedigt über den Untergang des protestantischen Bismarckreiches geäußert hat und über die katholische Mehrheit in Westdeutschland erfreut war ${ }^{113}$. Es ist aber unwahrscheinlich, daß der Vatikan aktiv für einen alpenländischen, katholischen Zusammenschluß geworben hat, ansonsten müßten sich auch in den Unterlagen des Erzbistums Freiburg und der Diözese Rottenburg hiervon Spuren finden lassen ${ }^{114}$.

\section{Der „Schwäbisch-Alemannische Heimatbund“}

Die Initiative zur Gründung des „Schwäbisch-Alemannischen Heimatbundes“ ging auf Bernhard Dietrich zurück. Obwohl das Veto der französischen Besatzungsmacht jede weitere Propaganda für die alpine Union obsolet gemacht hatte, hing der Singener Bürgermeister zu Beginn des Jahres 1946 noch immer diesem Konzept nach. Konnte er seine Alpenlandpläne schon nicht im ganzen verwirklichen, so gab er sich überzeugt, nun im kleineren Rahmen beginnen zu müssen. „Schwaben und das Alemannische Stammesgebiet“ 115 waren in der Vorstellungswelt Dietrichs neben Österreich und „AltBayern" die Komponenten des Alpenlandes; was sprach also dagegen, zuerst die territoriale Zersplitterung Südwestdeutschlands nach der Katastrophe des Nationalsozialismus zu bereinigen und dann mit dem Bau einer alpenländischen Konföderation fortzufahren?

An General Schwartz in Freiburg formulierte Dietrich im Januar 1946 die Bitte, die Gründung des „Heimatbundes e. V.“ als „Landesverband“ des „Aktionskomitees der alpinen Union“ zu genehmigen ${ }^{116}$. „Voralpen“ sollte der neue Staat, der als Teil des Alpenlandes gedacht war, heißen und sich aus den französisch besetzten Teilen Badens, Württembergs und Bayerns zusammensetzen. Unabhängigkeit von einer preußischdeutschen „Föderation“ und Verbundenheit mit den „Nachbarländern" lauteten die Prämissen Dietrichs. Wahlrecht sollten nur Alemannen, Schwaben und Bayern besitzen,

hausen keinen Hinweis auf die Alpenlandbewegung weder nördlich noch südlich des Bodensees.

112 Offiziell sind die Quellen des Vatikanischen Geheimarchivs bis zum Tod Benedikts XV. im Jahr 1922 freigegeben. Ein neues Pontifikat würde in der Regel die Freigabe der Akten von Pius XI. bewirken. Mündliche Auskunft des Leiters des Vatikanischen Geheimarchivs, Präfekt Pater Metzler, vom 15. 9. 1993 an den Verfasser.

${ }^{113}$ Leiber im Gespräch mit Walter von Cube, zitiert nach Kock, Weg, S. 210 Anmerkung 66; zu Leiber außerdem S. 71.

114 Weder im Nachlaß des Freiburger Erzbischofs Conrad Gröber noch in der Registratur oder in anderen Unterlagen des EAF sind derartige Spuren zu finden. Für die Archivalien der Diözese Rottenburg am Neckar gilt diese Feststellung ebenfalls.

115 Bericht, 1945, S. 2.

116 Dietrich an G. M. de Bade (General Schwartz) vom 11. 1. 1946; AdO HCFA AP Dir. de l'Int. c. 228 p. 21 d. 33. Kopie in: AdO W-H 1 f. Ser. Div. c. 2528 p. 3 d. 2. 
die älter als 21 Jahre waren, die Hinzugezogenen mußten seit mindestens 1914 im Südwesten leben und obendrein den Interessen der „Voralpen“ dienen. Als Mittel der Propaganda wünschte er sich die Genehmigung von Zeitungen und „anderen Schriften, die mit den Ideen des Alpenlandes konform gingen "117. Die führenden Positionen in Staat und Gesellschaft durften nach Dietrichs Willen nur mit Einheimischen besetzt werden, insgesamt sollte der Verwaltungsapparat radikal ausgedünnt werden. Als Fernziel sah er die Schaffung einer europäischen Föderation an.

Die in acht Paragraphen die Ziele und Funktionsweise regelnden „Vorläufigen Statuten des Heimatbundes" 118 gingen mit gleicher Post dem Freiburger Oberdelegierten zu. „Der Eintritt in die Vereinigung ist den Mitgliedern eines anderen deutschen Stammes nicht verboten, sofern diese ausdrücklich die Ziele, die wir verfolgen, anerkennen“, lautet die Formulierung im zweiten Paragraph, der die Mitwirkung Leopold Paurs gewährleistete. Im pfälzischen Zweibrücken geboren, war der in Engen lebende Jurist staatsrechtlich ein Bayer, stammesmäßig aber ein Franke. Der dritte Unterzeichner der Statuten fügte sich von seiner Herkunft problemloser in den Heimatbund ein: Karl Harder ${ }^{119}$, Betriebsrat bei der Firma Maggi, war ein in Singen geborener Alemanne.

Das Projekt stieß bei den französischen Dienststellen in Konstanz, Freiburg und Baden-Baden auf wenig Gegenliebe ${ }^{120}$. General Schwartz leitete die Ausarbeitungen Dietrichs an Emile Laffon weiter. In Baden-Baden beschäftigte sich in dessen Auftrag der Directeur Général des Affaires Administratives, Maurice Sabatier, mit dem Problem. Der Vichy-belastete Sabatier nahm Anstoß an der Bezeichnung „alemannisch“ und erkannte die Gefahr, die von dem Ziel, die Alemannen in einem Staat zu vereinen, ausging. Waren in dieser Bezeichnung nicht auch die deutschsprachigen Schweizer, die Vorarlberger und vor allem die Elsässer eingeschlossen? Eine Eingrenzung auf die Alemannen Südwestdeutschlands mußte deutlich in den Statuten vermerkt werden ${ }^{121}$, nur so glaubte Sabatier eine Gefahr für das erneut französisch gewordene Elsaß abwenden zu können. Die Nähe zum Programm des Alpenlandes stand Sabatier deutlich vor Augen, wenngleich er den Heimatbund lediglich als Plagiat für das „zu ausgedehnte Programm“ des Alpenlandes ansah, „das aufgegeben werden kann“122. Von General Schwartz forderte er daher alle erreichbaren Mitteilungen an, die er umgehend erhielt. Sabatier zeigte sich zufrieden mit den Ausführungen des Oberdelegierten, der eine Eingrenzung der Aktivitäten des Heimatbundes und eine Beschränkung der Mitglieder auf Personen, die in Deutschland ihren Wohnsitz hätten, vorschlug. Damit trieb er eine Spitze gegen die Bregenzer Honoratioren, die durch diese Bestimmung ausgeschlossen waren. Beide Offiziere stimmten darin überein, daß die Bezeichnung „alemannisch“ in diesem Zusammenhang verboten

117 Ebenda.

118 „Projets de statuts du ,Heimatbund“ vom 6. 1. 1946; AdO HCFA AP Dir, de l'Int. c. 228 p. 21 d. 33 . Kopie in: AdO W-H 1 f. Ser. Div. c. 2528 p. 3 d. 2.

119 Karl Harder; 1945 Betriebsrat der Firma Maggi; 1946-56 Stadtrat von Singen/Htwl. (BCSV/ CDU); 1946 Mitgründer des „Schwäbisch-Alemannischen Heimatbundes“; später Anhänger der „Altbadener" um Leo Wohleb.

120 Bislang ging die Forschung davon aus, daß die Initiative für den Heimatbund von der französischen Besatzungsmacht ausgegangen sei; Bury, Volksentscheid, S. 10.

121 Im Satz: „Es handelt sich darum, die zum alemannischen, schwäbischen und bayrischen Stamm gehörigen Menschen zu sammeln", unterstrich Sabatier den Begriff „alemannisch“ und fügte handschriftlich hinzu: „(= residant en Allemagne $)^{\prime}$.

122 Sabatier an Schwartz vom 13. 2. 1946; AdO HCFA AP Dir. de l'Int. c. 228 p. 21 d. 33. 
werden sollte ${ }^{123}$. Die inhaltliche Nähe zur elsässischen Autonomiebewegung der Zwischenkriegszeit stach ins Auge, Sabatier bat Schwartz um mehr Informationen über die Autonomistenzeitung „Heimat" vor 1940124, die Zusammenhänge lagen auf der Hand. Überhaupt hatte die französische Besatzungsmacht mit dem Prädikat „schwäbisch-alemannisch“ ihre Probleme. Die 1924 gegründete „Vereinigung der Schwäbisch-Alemannischen Narrenzünfte", eine Dachorganisation der südwestdeutschen, organisierten Narren, erhielt erst am 24. Mai 1948 die Zulassung der Militärregierung. Die unpolitische Vereinigung wurde in ihrem Wirkungskreis zudem auf das französisch besetzte $\mathrm{Ba}$ den und auf die Bezeichnung "Vereinigung alemannischer Narrenzünfte" beschränkt. Das Adjektiv „schwäbisch“" wurde im Verbandsnamen ausdrücklich verboten ${ }^{125}$.

Der Konstanzer Bezirksdelegierte Marcel Degliame, ausgewiesener Gegner der Autonomie- und Heimatrechtstendenzen, zitierte Dietrich zu sich, weil ihm an einer strengeren Definition des Begriffes „Heimatbund“ gelegen war. Die Ziele der Vereinigung schienen Degliame höchst vage umrissen. Die hierarchischen Strukturen, die langatmigen Postwege und die Kompetenzunklarheiten innerhalb der französischen Militärregierung verhinderten augenscheinlich die zügige Bearbeitung der Angelegenheit. Erst Ende März lancierte Dietrich nach einem Gespräch mit Degliame einen erneuten Vorstoß ${ }^{126}$. Wunschgemäß präzisierte er die Ziele und den Begriff „Heimatbund“, wahrscheinlich auf Veranlassung aus Baden-Baden. Der Heimatbund wollte nun geographisch diejenigen Teile der Französischen Besatzungszone in einem unabhängigen Staat umfassen, die vormals zu Baden, Württemberg und Bayern gehört hatten. Nach Dietrichs Auffassung schloß der historische und geographische Charakter des schwäbischalemannischen Staates jede Expansionsbestrebung aus, die Ziele des Heimatbundes lägen in der Verteidigung und Propaganda der Idee der Eigenständigkeit eines autonomen, föderativ aufgebauten Staates, der jedem Einfluß Preußens entzogen sein würde.

Zwischenzeitlich hatte sich in der württembergischen Kreisstadt Rottweil am oberen Neckar eine Gruppe Männer zusammengefunden, die gleicherweise einen schwäbischalemannischen Heimatbund zu gründen beabsichtigten. Der führende Kopf, Dr. Franz Mederle, Oberstaatsanwalt und Bürgermeister in Rottweil, dachte aber nicht wie Dietrich an eine kulturell-politische Vereinigung, vielmehr suchte er bei den französischen Behörden um die Lizenzierung einer politischen Partei nach ${ }^{127}$. Es bleibt unklar, ob Dietrich und Mederle sich schon im März 1946 kannten und eventuell im Vorgehen abstimmten oder ob sie sich erst im Frühsommer 1946 kennenlernten. Jedenfalls war Mederle nach Ablehnung der Lizenz für eine "Schwäbisch-Alemannische Volkspartei“ im

\footnotetext{
${ }^{123}$ Sabatier an Schwartz vom 19. 3. 1946; AdO, ebenda.

${ }^{124}$ Ebenda. Die Heimat. Revue Régional d'Alsace et de Lorraine. Monatsschrift für christliche Kultur und Politik lautete der Titel einer zwischen 1923 und 1939 im Alsatia-Verlag erschienenen Zeitschrift. Gegründet von Dr. X. Haegy, war Die Heimat von Marcel Stürmel verantwortlich geleitet worden.

125 „70 Jahre Vereinigung Schwäbisch-Alemannischer Narrenzünfte“. Sondernummer des Südkuriers vom November 1994, hier S. VII. Ob die Streichung des Adjektivs „schwäbisch“ als Reaktion auf die Aktivitäten des "Schwäbisch-Alemannischen Heimatbundes" zurückzuführen ist, muß dahingestellt bleiben.

${ }_{126}$ Dietrich an Degliame vom 29. 3. 1946; AdO W-H 1 f. Ser. Div. c. 2528 p. 3 d. 2.

${ }^{127}$ Zur „Schwäbisch-Alemannischen Volkspartei“ vgl. Kapitel V/2.
} 
Umfeld Dietrichs anzutreffen und steuerte mit seinem Bürgermeisterkollegen auf direktem Weg auf die Gründung des „Schwäbisch-Alemannischen Heimatbundes“ zu.

Generalverwalter Laffon hatte sich derweilen in die Angelegenheit eingeschaltet; wohlinformiert durch Maurice Sabatier kam er Anfang Juli 1946 zu der Überzeugung, daß der Heimatbund mit den geänderten Statuten tragbar sei, und gab sein Einverständnis zur Gründung ${ }^{128}$. Der neue Oberdelegierte von Baden, Pierre Pène, übermittelte die Entscheidung dem Konstanzer Kreisdelegierten Hoeppfner mit Schreiben vom 17. Juli $1946^{129}$, wobei der Heimatbund theoretisch auch seine Aktivitäten auf WürttembergHohenzollern ausdehnen konnte. Am 25. Juli 1946 erhielt Bernhard Dietrich die langersehnte Genehmigung für den Heimatbund, sechs Monate nach der ersten Antragstellung ${ }^{130}$. Der Singener Bürgermeister handelte nun rasch und informierte die interessierten Kreise. Für den 17./18. August berief er die Gründungsversammlung des „Schwäbisch-Alemannischen Heimatbundes“ in die Stadt am Hohentwiel ein. In der Aula der Oberrealschule versammelten sich am 17. August über 100 Teilnehmer aus ,allen Landschaften Südbadens, Südwürttembergs und aus Lindau"131. Als Leiter der Versammlung übernahm Bernhard Dietrich die Begrüßungsansprache und erörterte die Gründe, die zur Bildung des Heimatbundes geführt hatten. Die Tagesordnung umfaßte sechs Punkte, die eine Abstimmung über das Programmatische Manifest, die Verlesung und Beschlußfassung der Satzungen, Wahlen, die Frage der Mitgliedsbeiträge, die Organisation der Landschafts- und Ortsverbände und ein Zeitschriftenprojekt ${ }^{132}$ beinhalteten.

Das bereits im voraus formulierte Programmatische Manifest wurde sogleich verlesen und einstimmig angenommen ${ }^{133}$. Als Präsident erhielt sodann Bernhard Dietrich das Vertrauen, der politisch bereits neben Theopont Diez ${ }^{134}$ als Gründungsmitglied der BCSV 135 in Singen in Erscheinung getreten war. Dem Präsidenten sollten zwei Vizeprä-

${ }^{128}$ Laffon an Schwartz vom 2. 7. 1946; AdO HCFA AP Dir. de l'Int. c. 228 p. 21 d. 33.

129 Pène an Hoeppfner vom 17. 7. 1946; AdO Bade C 2128.

130 Josef Dusel, ein Vertrauter Dietrichs aus Singen, notierte auf dem Gründungsbericht des „Aktionskomitees des Alpenländischen demokratischen Bundes“: „Gründungsurkunde des ,Heimatbundes" am 25. Juli 1946 bei Dr. Dietrich eingetroffen"; StadtA SI Depositum Dusel.

131 „Protokoll - Über die Gründungsversammlung des, Schwäbisch-Alemannischen Heimatbundes“ am 17. und 18. August 1946 zu Singen - Hohentwiel“; NL Bernhard Dietrich und AdO Bade C 2128.

132 Das geplante Zeitschriftenprojekt Oberland wurde vom Konstanzer Stadtarchivar Otto Feger betreut und vorangetrieben. Vgl. Kapitel IV/2.

133 „Programmatisches Manifest des ,Schwäbisch-Alemannischen Heimatbundes““; NL Bernhard Dietrich, AdO Bade C 2128 und StA FR C 5/1 2749.

${ }^{134}$ Diez löste Dietrich nach den Gemeinderatswahlen im September 1946 als Bürgermeister in Singen ab.

Theopont Diez (1908-1993), Sohn des MdR Carl Diez; Jurist; 1946-69 (Ober-)Bürgermeister von Singen; 1952-72 MdL Baden-Württemberg (CDU); zeitweilig als Landesbeauftragter mit der Leitung der Universität Konstanz betraut.

Die Pläne Dietrichs wurden von seinem Amtsnachfolger als utopisch eingeschätzt. Diez riet seinem Vorgänger, „er solle aus den Wolken herabsteigen und sich auf den Boden der Realität stellen“; Interview mit Theopont Diez vom 7. 5. 1993; StadtA KN Cc 775 a.

135 Die Gründung der BCSV in Singen erfolgte „im Frühjahr 1946“, Dietrich wurde von Wilhelm Grimm (Ders., Jahr, S. 37 und S. 39) als Gründungsmitglied genannt. Bei den Gemeinderatswahlen vom September 1946 erhielt Dietrich zwar das Mandat eines Gemeinderates, auf Druck der $\mathrm{DP}$ rückte die $\mathrm{BCSV}$ jedoch von Dietrich als Bürgermeister $\mathrm{ab}$, und man einigte sich auf Theopont Diez; Weinacht, Urprung, S. $91 \mathrm{f}$. 
sidenten beigegeben werden, wobei zwecks Wahrung des Parteienproporzes ein Amt von einem württembergischen Sozialdemokraten, das andere auf jeden Fall von einem Mitglied der Demokratischen Partei bekleidet werden mußte; beide Vizepräsidentenämter wurden auf der Gründungsversammlung nicht besetzt. Die „Bundesleitung“, bestehend aus dem "Gesamt-Vorstand" und dem "Direktions-Ausschuss", wurde gewählt; als Mitglieder des "Gesamt-Vorstandes“ fanden Dr. Leopold Paur (Engen), Bertold Fahrensbach (Singen), Dr. Otto Feger (Konstanz), Karl Harder (Singen), Dr. Leo Götte $^{136}$ (Todtmoos), Dr. Franz Mederle (Rottweil), Wilhelm [Willi] Ernst (Rottweil), Karl Hugger (Oberndorf/Neckar), Rudolf Schmidt (Balingen) und Conrad Huther ${ }^{137}$ (Überlingen) die Zustimmung der Anwesenden ${ }^{138}$. Der "Direktions-Ausschuss“ hingegen war der eigentliche Kopf des „Schwäbisch-Alemannischen Heimatbundes“. Zum Generalsekretär wurde Leopold Paur bestellt, als Schatzmeister fungierte Bertold Fahrensbach, für Presseangelegenheiten zeichnete Otto Feger verantwortlich. Ohne bestimmten Aufgabenbereich gehörte Franz Mederle dem „Direktions-Ausschuss“ an, ein weiterer Posten in dem Gremium wurde für eine Persönlichkeit, die aus Lindau ${ }^{139}$ stammen sollte, freigehalten.

Ohne Zwischenfälle ging die Gründungsversammlung nicht vonstatten. Ein Mitarbeiter der kommunistischen Tageszeitung Der Neue Tag mußte nach mehrfacher Aufforderung den Saal verlassen, obwohl er sich durch eine Einladung ausweisen konnte ${ }^{140}$. Aber

${ }^{136}$ Leo Götte (1895-1987), 1945-48 Bürgermeister von Todtmoos im Schwarzwald.

Der Haß auf Preußen war zentrales Motiv in der Vorstellungswelt Göttes. Auch gegenüber dem Badischen Staatspräsidenten machte er aus dieser Einstellung keinen Hehl. Vgl. Götte an Wohleb vom 7. 8. 1947; StA FR T1 NL Leo Wohleb I/1 63. Er schloß den Brief mit einer Andeutung zur Neugliederung des deutschen Südwestens: „Um aus den Nöten der Gegenwart herauszukommen, bedarf es einer konstruktiven Staatsidee, einer Neuordnung des Gesellschaftslebens auf christlicher Grundlage, wozu die Voraussetzungen für Südbaden überaus günstig sind“; ebenda.

${ }^{137}$ Conrad Huther (*1910), seit 1945 in Überlingen wohnhaft; selbständiger Kaufmann; Mitbegründer der BCSV in Überlingen.

In einem Interview mit dem Verfasser vom 23. 4. 1993 gab Huther zu Protokoll, daß er nur ein einziges Mal bei einer Versammlung des Heimatbundes zugegen gewesen sei, und zwar im Zähringer Hof in Überlingen. Dies deckt sich mit seinen bei Weinacht, Ursprung, S. 94 gemachten Angaben. Dem widerspricht die Tatsache, daß sowohl sein Name auf der Liste der in die „Bundesleitung" gewählten Männer steht, als auch weiteres Aktenmaterial seine Mitarbeit im "Schwäbisch-Alemannischen Heimatbund“ belegt (Einreichen des Fragebogens; ein Bericht des Überlinger Kreisdelegierten Lindenmann; u. ä.).

138 „Protokoll - Über die Gründungsversammlung des ,Schwäbisch-Alemannischen Heimatbundes' am 17. und 18. August 1946 zu Singen - Hohentwiel“; NL Bernhard Dietrich und AdO Bade C 2128.

139 In den folgenden Monaten knüpfte Dietrich Verbindungen zu Dr. Heinrich A. Ludwig (Facharzt für Dermatologie) in Lindau. Ludwig war Dietrichs Verbindungsmann in der Inselstadt; Interview mit Cordula Oexle vom 7. 4. 1993; StadtA KN Cc 775 a.

Über Ludwigs politische Aktivitäten gibt das Dossier „Heimat- und Königsbund/Lindau“ Auskunft; AdO W-H 1 f. Ser. Div. c. 2528 p. 3 d. 9. Dietrich besaß exzellente Kontakte zum Vorsitzenden des 1949 wiedergegründeten „Bayerischen Heimat- und Königsbundes“, dem Münchner Professor Anton Berr.

${ }^{140}$ Die nichtöffentliche Versammlung konnte nur mit einer schriftlichen Einladung betreten werden: „Heimatbund, Sitz Singen Htw., Einladung zur konstituierenden Gründungsversammlung. Sehr geehrter Herr! Sie werden hiermit eingeladen, an der konstituierenden Gründungsversammlung des ,Heimatbundes“ teilzunehmen. Die Tagung beginnt am Samstag, den 17. Au- 
Dietrich war nicht daran gelegen, Vertreter der Presse ${ }^{141}$ - der kommunistischen allzumal - bei der brisanten Gründungsversammlung zugegen zu wissen. Vielmehr wurde der Presse ein eigener Bericht übermittelt. Die Zusammenarbeit des „Direktions-Ausschusses" mit dem Präsidenten verlief von Beginn an nicht reibungslos. Schnell hatten sich erhebliche Spannungen vor allem zwischen Dietrich und Feger in heftigen Debatten entladen. Als "Hausstreit“ in der Neuen Zürcher Zeitung ${ }^{142}$ charakterisiert, spiegelten die Spannungen den Konflikt der unterschiedlichen Konzepte wider. Der katholische, ins christliche Abendland eingebettete schwäbisch-alemannische Staat siegte im Heimatbund über das zu neuem Leben zu erweckende alemannische respektive schwäbische, basisdemokratische „Herzogtum“. Der Konstanzer Stadtarchivar zog die Konsequenzen und erklärte seinen Rücktritt, er schied bereits im Dezember 1946 aus dem Heimatbund ${ }^{143}$. Auch Rudolf Schmidt, Karl Hugger und Leo Götte ${ }^{144}$ hatten bis Mai 1947 den „Direktions-Ausschuss“ verlassen. An ihre Stelle traten noch im selben Monat Josef Vogt, ein in Pfullendorf ansässiger BCSV-Abgeordnete des Badischen Landtages, und Max Demmler, Mitglied der DP und Kinobesitzer in Lörrach.

In mehreren gedruckten und ungedruckten Schriften machte Dietrich im ersten Halbjahr 1947 auf den Heimatbund und dessen Ziele aufmerksam. Im Januar 1947 verschickte er an die Badische Staatskanzlei eine umfangreiche Denkschrift über den Heimatbund ${ }^{145}$, der kurz darauf seine Broschüre Separatisten ${ }^{146}$ folgte, die im gesamten südwestdeutschen Raum in einer genehmigten Auflage von 25000 Exemplaren ${ }^{147}$ Verbreitung fand. Als politisches Endziel sah Dietrich auch nach 1948 den projektierten schwäbisch-alemannischen Staat als Teil eines "Staatenbundes mit autonomen Gliedern“" 148 an. Selbst mit Flugblättern versuchte Dietrich gezielt in Südwestdeutschland Stimmung für die Vereinigung zu machen ${ }^{149}$.

gust 1946, nachmittags $15.00 \mathrm{Uhr}$, in der Aula der Oberrealschule. Die Einladung gilt als Ausweis. Mit dem alten Heimatgruß ,Grüß Gott' Dr. Dietrich." Abgedruckt in dem Artikel „Raus aus dem preußisch-deutschen Ghetto!“, in: Der Neue Tag vom 21.8. 1946. Die Zeitung der Kommunisten hatte bereits in den Nummern acht ("Heimatstaat am Bodensee") und neun („Autonomes Alemannien“) sehr polemisch über die Vorbereitungen zur Gründungsversammlung berichtet.

${ }^{141}$ Die Badische Zeitung hatte bereits einige Tage zuvor aus ungenannten Quellen von der Gründung des Heimatbundes berichtet; „Für einen alemannischen Staat“, in: BZ vom 9. 8. 1946.

142 Die Neue Zürcher Zeitung widmete der Autonomiebewegung eine komplette Seite: „Ein autonomes Alemannien?", in: NZZ vom 9. 3. 1947. In diesem Artikel fiel zum ersten Mal der Begriff

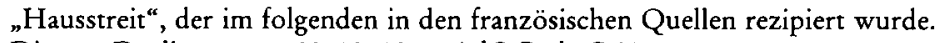

${ }_{143}$ Diez an Degliame vom 23. 12. 1946; AdO Bade C 2128.

${ }^{144}$ Götte schied im Mai 1947 aus dem Heimatbund aus; Generalsekretär Paur leitete die Meldung nach französischer Maßgabe an den Singener Bürgermeister weiter, der wiederum die Konstanzer Militärregierung informierte; Paur an Diez vom 27. 5. 1947; AdO Bade C 2128.

${ }^{145}$ Bernhard Dietrich: „Warum Heimatbund und was will er?" (masch. 13 S.) [1946/47]; StA FR C 5/1 2749.

146 Dietrich, Separatisten. Unterlagen zur Lizenzierung und der genehmigten Auflagenhöhe von 25000 Exemplaren: Licence d'Edition vom 29. 1. 1947; AdO HCFA AC RIL c. 1074/1.

147 Licence d'Edition vom 29. 1. 1947 und Zuteilung von 500 Kilogramm Papier; AdO HCFA AC c. 1124/2.

${ }_{148}$ Dietrich an Wohleb vom 19. 3. 1948; StA FR T1 NL Leo Wohleb I/1 91.

149 Teile des Inhalts eines dieser Flugblätter sind im Artikel „Autonomiebestrebungen in Schwaben" im Kurier vom 1. 4. 1947 abgedruckt. 


\section{Die Orts- und Landschaftsverbände des Heimatbundes}

In den folgenden Monaten kam es in den badischen Landkreisen Konstanz, Überlingen, Stockach, Donaueschingen, Villingen, Lörrach, Baden-Baden und Freiburg sowie im württembergischen Landkreis Rottweil zur Gründung von Orts-und Landschaftsverbänden des Heimatbundes. Jedoch erwiesen sich die Aktivitäten der Untergliederungen als zu schwach, um ein weites Vordringen der Ideen in breitere Bevölkerungsschichten zu gewährleisten. Die Resonanz politischer Fragen fand allgemein geringen Widerhall, Politik war 1945/46 nicht sehr gefragt; auch die im Entstehend befindlichen Parteien hatten mit der allgegenwärtigen Lethargie der politisch Mündigen schwer zu kämpfen ${ }^{150}$. Gleichermaßen zog der „Schwäbisch-Alemannische Heimatbund“ gegen die Politikmüdigkeit zu Felde; es sollte ihm aber nicht gelingen, eine tragfähige Basis in der Bevölkerung aufzubauen: der Heimatbund blieb eine Honoratiorenveranstaltung.

Im Landkreis Konstanz hatte der „Schwäbisch-Alemannische Heimatbund“ die meisten Ortsverbände. Generalsekretär Paur wirkte in seinem Wohnort Engen; dort hielt er in unregelmäßigen Abständen Versammlungen ab, die aber bei der hart arbeitenden ländlichen Bevölkerung auf geringen Widerhall stießen; die in den Veranstaltungen des Heimatbundes anwesenden Landwirte schliefen nach hartem Tagwerk nicht selten vor Erschöpfung ein. Ausgewiesene Anhänger scheint Paur nicht gefunden zu haben, nur unter Vorbehalt kann von einem Ortsverband Engen die Rede sein. Im September 1948 sprach Dietrich in der Hegaustadt über den Heimatbund vor zwei Dutzend Personen, die allesamt entweder Anhänger oder Mitglieder der CDU waren ${ }^{151}$. In der Hohentwielstadt selbst hatte Bernhard Dietrich einen festen Kreis von Männern um sich geschart, die am 7. Dezember 1946 den Ortsverband Singen des Heimatbundes konstituierten ${ }^{152}$. Gefestigte Strukturen und regelmäßige Zusammenkünfte sind dokumentiert. In Allensbach am Bodensee vertrat der dortige Bürgermeister Gottfried Mayer ${ }^{153}$ die Ideen Dietrichs, über seine sonstigen Bemühungen existieren keine Quellen. Im September 1948 hat Bernhard Dietrich in Allensbach nachweislich eine Versammlung des Heimatbundes abgehalten, auf der er über die Haltung des Heimatbundes zur Länderfrage referierte.

In dem erst 1936 durch Zusammenlegung der beiden östlich des Bodensees situierten Amtsbezirke Stockach und Meßkirch neugebildeten Landkreis Stockach hatte der „Schwäbisch-Alemannische Heimatbund“ mit dem Stockacher Bürgermeister Dr. Alois Deufel einen namhaften Vertreter, der sich in einem Sondierungsgespräch der Besat-

${ }^{150}$ In den Landgemeinden fanden sich für die Gemeinde- und Kreiswahlen 1946 oft keine Kandidaten für die politischen Parteien; um den Anforderungen der französischen Besatzungsmacht Genüge zu leisten, wurden kurzerhand der jeweilige Bürgermeister als Kandidat der Partei A, der Ratsschreiber als Kandidat der Partei B usw. aufgestellt. Dieses Vorgehen ist in vielen Fällen belegt. Vgl. Interview mit Josef Vogt vom 31. 8. 1993; StadtA KN Cc 775 a.

151 „Activité du ,Heimatbund“ septembre 1948“; AdO Bade C 2128. Im gesamten Landkreis Konstanz fanden im September 1948 drei Veranstaltungen des Heimatbundes, zwei der CDU und vier der SPD statt. Die DP trat nicht in Erscheinung.

${ }_{152}$ Eine gedruckte Einladung wurde verteilt; StadtA SI Depositum Dusel.

${ }^{153}$ Gottfried Mayer (1896-1989), Maurerlehre; 1915-18 Kriegsdienst; Studium der Architektur in Karlsruhe; Bauführer, dann freier Architekt in Allensbach am Bodensee; 1939-45 Hilfszöllner beim Zollgrenzschutz; 1945-48 Bürgermeister von Allensbach; ab 1948 freier Architekt und Bauführer; Wünschelrutengänger (u. a. entdeckte er die Konstanzer Thermalquelle); Stiftungsrat der katholischen Kirche in Allensbach. Nachruf: Welschinger, Mayer, S. 22. 
zungsmacht für einen Zusammenschluß des Südteils der Zone zu einem Südstaat ausgesprochen hat ${ }^{154}$; eng arbeitete er mit dem in Pfullendorf lebenden Kreiskandidaten der $\mathrm{BCSV} / \mathrm{CDU}$ und Abgeordneten des Badischen Landtages, Josef Vogt ${ }^{155}$, zusammen. Der Landtagsabgeordnete Vogt war durch die Überlinger Anhänger des Heimatbundes mit Bernhard Dietrich in Kontakt gekommen. Auf einer der zahlreichen, meist informell angekündigten Veranstaltungen, bei denen immer eine Anwesenheitsliste umlief, gewann ihn Dietrich für die Mitarbeit im „Direktions-Ausschuss“ ${ }^{156}$; die Aufnahme in das Gremium war in erster Linie eine notwendige Formalität gegenüber der französischen Besatzungsmacht. Seit Mai 1947 ging die Sûreté von der Mitarbeit Vogts im engsten Zirkel des Heimatbundes aus. Die Militärregierung vor Ort verhielt sich sehr skeptisch und überwachte die Aktivitäten der Anhänger des Heimatbundes genau ${ }^{157}$. Gerade im verzahnten Grenzgebiet zwischen Baden und Württemberg fand der Heimatbund lebhaften Zuspruch, selbst nach 140 Jahren wurden die Grenzen als künstlich empfunden. Aus dieser Mentalität resultiert auch der hohe Stimmenanteil für den Südweststaat, der in den badischen Kreisen Überlingen, Pfullendorf und Stockach entgegen dem Wahltrend im restlichen Südbaden bei der Volksabstimmung im Dezember 1951 erreicht wurde.

Die Gründungsphase der BCSV im Landkreis Überlingen vollzog sich im Spannungsfeld zwischen einer Wiederbelebung des Zentrums und dem Erstarken des „SchwäbischAlemannischen Heimatbundes"158. Das Zentrum hatte seinen Fürsprecher im schwerkriegsbeschädigten Justizinspektor August Schmid, dessen Hang zur katholischen Partei bekannt war; sein Betätigungsfeld schien günstig, hatte doch das Zentrum bei den Landtagswahlen 1929 rund 64 Prozent der Stimmen erhalten. Die Kräfte des Heimatbundes zählten - wie Schmid selbst - zu der Gründungsgruppe der BCSV: Der Überlinger Amtsrichter Dr. Walz, der in französischen Quellen noch Anfang 1948 als treibende Kraft des Heimatbundes genannt wird ${ }^{159}$, gehörte ebenso wie der Rechtsanwalt Dr. Herbert Wehrle zu den Gründern der BCSV in Überlingen. Insbesondere zu Wehrle, der in Überlingen ,im intellektuellen Milieu [...] enthusiastische“ Anhänger für den Heimatbund gefunden hatte ${ }^{160}$, verfügte Bernhard Dietrich über solide Kontakte. Der Überlinger Kreisdelegierte Lindenmann vermerkte im Februar 1947, daß die Anhängerschaft des Heimatbundes nicht zahlreich und fast ausschließlich unter den Intel-

${ }^{154}$ Französische Sondierung zum Zusammenschluß der Südzone (o. D.); AdO Bade AP Sec. Pol. c. 2801.

${ }^{155}$ Josef Vogt (1908-1996), gelernter Zeitungskaufmann; Geschäftsführer der katholischen Deutschen Bodensee-Zeitung; 1940-45 Kriegsteilnehmer; 1947-52 MdL Baden (BCSV/CDU); 195264 MdL Baden-Württemberg (CDU).

156 Dietrich ließ bei einer der Veranstaltungen Vogt wissen: „Ich brauche nicht nur Doktoren, sondern auch Herren", und drückte mit diesen Worten die Befürchtung aus, daß das starke Übergewicht der Intellektuellen im Heimatbund letztlich zum Mißerfolg führen würde; vgl. Interview mit Josef Vogt vom 31. 8. 1993; StadtA KN Cc 775 a.

157 Vogt hatte sich 1947 bei der Sûreté in Überlingen zu melden, um die Ziele des Heimatbundes darzulegen. Die französischen Offiziere machten einen sehr reservierten Eindruck, Begeisterung für den Heimatbund kam nicht auf; vgl. Interview mit Josef Vogt vom 31. 8. 1993; StadtA KN Cc 775 a.

158 Paul-Ludwig Weinacht wählte für die Darstellung der christlichen Parteigründung im Landkreis Überlingen die Überschrift: „BCSV-Gründung zwischen Zentrum und Heimatbund“, in: Ders., Ursprung, S. $93 \mathrm{f}$.

159 AdO Bade C 2128.

${ }^{160}$ Lindenmann an Pène vom 26. 2. 1947; AdO Bade C 2128. 
lektuellen zu finden sei; Wehrle hatte sich gegenüber der Militärregierung als Leiter des Überlinger Ortsverbandes des Heimatbundes zu erkennen gegeben ${ }^{161}$. Auch Conrad Huther, der im Februar 1946 in ein Reisebüro der Kreisstadt eingeheiratet hatte und gleichwohl zu den Initiatoren der BCSV zählte, ließ sich auf der Gründungsversammlung des Heimatbundes in das Führungsorgan - den „Direktions-Ausschuss“ - wählen; die ideologische Nähe des Heimatbundes und der BCSV war ihm noch nach Jahrzehnten geläufig: „Abgesehen von den gebietsmäßigen Veränderungen deckten sich die politischen Ziele des Heimatbundes mit denjenigen der BCSV. “162 Die Aktivitäten Huthers waren der Sûreté genauere Untersuchungen wert ${ }^{163}$. In Überlingen fand schließlich eine der wenigen dokumentierten Veranstaltungen des Heimatbundes statt, an der auch Huther teilnahm. Im Gasthaus Zähringer trafen sich im Spätsommer 1946 Anhänger des Heimatbundes, die aus Südbaden und Südwürttemberg angereist waren ${ }^{164}$.

Der Donaueschinger Landrat Dr. Robert Lienhart war eng mit Bernhard Dietrich befreundet und nahm bisweilen an Sitzungen des Heimatbundes teil ${ }^{165}$. In französischen Quellen wird er als Leiter des Ortsverbandes Donaueschingen des Heimatbundes genannt ${ }^{166}$. Daß sich hinter dieser Formulierung greifbare Substanz verbarg, darf als wenig wahrscheinlich gelten. Im Umfeld der Villinger Ärzteschaft konnte Dietrich mit Unterstützung seiner Pläne rechnen: Dr. Peter aus der Schwarzwaldstadt galt aus französischer Sicht als Hauptvertreter des „Schwäbisch-Alemannischen Heimatbundes“, unterstützt von dem Krankenhausarzt Dr. Sauer, dem Versicherungsagenten Weckemann und dem Gärtner Karl Beck ${ }^{167}$. Außerdem hatte Peter die beiden einflußreichen Ärzte Dr. Oscar Merroth aus Freiburg und Dr. Ott aus Löffingen für den Heimatbund gewinnen können. In Freiburg scharten sich die Anhänger eines autonomen schwäbisch-alemannischen Staates um Dr. Josef Ruby, den Gründer der „Vereinigung Abendland“. Von Aktivitäten des Ortsverbandes Freiburg unter der Leitung von Helmut Ziegler fehlen allerdings jegliche Spuren.

Die beiden Repräsentanten des "Schwäbisch-Alemannischen Heimatbundes“ in der Kurstadt Baden-Baden waren die Juristen Camill Wurz und Dr. Fröbel ${ }^{168}$. Beide hatten im April 1948 eine Denkschrift mitverfaßt und schließlich unterzeichnet, deren Ziel das Ersetzen der „Preußen“ durch Einheimische in den führenden Positionen von Rundfunk und Presse sein sollte ${ }^{169}$. Man beschwor die französische Militärregierung förmlich,

161 Ebenda.

162 Conrad Huther 1981 gegenüber Paul-Ludwig Weinacht; Ders., Ursprung, S. 94.

163 Sûreté (Kommissar Feris) an den Überlinger Kreisdelegierten Lindenmann vom 10. 9. 1946: Anforderung eines Berichts zu Conrad Huther; AdO Bade C 2128. Der angefertigte Bericht unterliegt - wie die gesamten Sûreté-Unterlagen - im Archiv der Besatzung in Colmar einer 60-jährigen Sperrfrist.

164 Zur Veranstaltung selbst vgl. Kapitel V/1.

${ }^{165}$ Lienhart nahm auch an der sogenannten "Geheimkonferenz" vom 3. 4. 1948 teil; Sûreté-Bericht über den Heimatbund vom 30. 4. 1948; AdO Bade C 2128.

166 Gliederung des Heimatbundes vom 21. 4. 1948; AdO Bade C 2128. Robert Lienhart kann „über die damals geführten Gespräche heute [1994] nichts mehr berichten“", die Pläne stießen aber auf sein "Interesse“; Lienhart an den Verfasser vom 14. 3. 1994.

${ }^{167}$ „Note concernant le Mouvement séparatiste ,HEIMATBUND“ qui signifie ,LIEN NATAL““ o. D. [1946]; AdO Bade Con. Fribourg c. 2177/2.

${ }_{168}$ Liste der Gruppierungen des Heimatbundes vom 21. 4. 1948; AdO Bade C 2128.

169 „Mémoire“ vom 25. 4. 1948, unterzeichnet von Camill Wurz, Dr. Fröbel, Professor Armbruster (vgl. Kapitel I/4) und dem Donaueschinger Landrat Dr. Robert Lienhart; AdO Bade C 2128. 
„die Leute aus Nord- und Mitteldeutschland [aus den Schaltstellen] zu verdrängen [évincer]" ${ }^{170}$, da diese vom preußischen Militarismus und Zentralismus erfüllt seien. Eine solche Geisteshaltung konterkariere die französische Politik, die doch auf die Schaffung eines föderalistischen Deutschlands gerichtet sei. Falls die französischen Stellen es wünschten, könne man sofort eine Liste mit befähigten Südwestdeutschen beibringen. Der Baden-Badener Rechtsanwalt Camill Wurz ${ }^{171}$ war 1948 bereits Mitglied der BCSV/CDU, allerdings befand er sich nicht unter den Gründungsmitgliedern in der Bäderstadt. Seine steile politische Karriere nach der Gründung des Bundeslandes BadenWürttemberg begann als Kreiskandidat von Baden-Baden. Zwischen 1956 und 1976 vertrat er nicht nur die Kurstadt im Stuttgarter Landtag, sondern er bekleidete ab 1968 für zwei Wahlperioden auch das Amt des Landtagspräsidenten.

Im äußersten Südwesten, im Dreiländereck, entfaltete der Heimatbund eine sehr erfolgreiche Propaganda. Lörrach selbst bestand konfessionell aus einem alten, markgräflich badischen und damit protestantischen Teil und aus dem 1909 eingemeindeten ehemals vorderösterreichischen katholischen Stetten. Bernhard Dietrich nahm erstmals am 26. Januar 1947 in Weil am Rhein Kontakt mit den dortigen Sympathisanten des Heimatbundes auf. Allen voran konnte er sich vor Ort auf den Kinobesitzer Max Demmler ${ }^{172}$ stützen, mit dem er sich in Anwesenheit weiterer Personen über die politischen Ziele des Heimatbundes unterhielt ${ }^{173}$. Die „Los von Preußen“-Stimmung hatte in der Lörracher Gegend eine fühlbare Verbreitung gefunden, der Nährboden für das Programm des Heimatbundes war günstig. Von dem Treffen mit Dietrich inspiriert, begann Max Demmler mit der Werbung für die Ziele des „Schwäbisch-Alemannischen Heimatbundes“. Dessen Tatkraft hatte es Dietrich zu verdanken, daß binnen weniger Monate ein Landschaftsverband „Markgräflerland“ konstituiert wurde, in dem sich laut französischer Recherchen bis Ende März 1947 etwa einhundert Personen eingeschrieben hatten $^{174}$. Auch die Schweizer Presse berichtete über die Aktivitäten des Heimatbundes in Lörrach ${ }^{175}$. Max Demmler hatte über die „Schwäbisch-Alemannische Demokratie“ Otto Fegers die Idee eines autonomen Alemanniens bereits in sich aufgesogen. Von der Schrift schaffte er eine große Zahl von Exemplaren an, vermutlich um diese für Propa-

170 Ebenda.

171 Camill Wurz (1905-1986), Studium der Rechtswissenschaften; Rundfunkratsvorsitzender des Südwestfunks; 1956-76 MdL Baden-Württemberg, Fraktionsvorsitzender der CDU; 1968-76 Landtagspräsident Baden-Württemberg. Vgl. auch Haberer, Portrait.

172 Max Demmler (1898-1986), Oberrealschule Schopfheim, 1916-18 Kriegsteilnehmer; Gewerbeschule in Basel; Banklehre bei der Süddeutschen Diskontogesellschaft in Lörrach; 1926-28 Automobilverkäufer; seit 1929 Grabsteinverkäufer; Mitglied der DDP, dann der Deutschen Staatspartei bis zur Auflösung 1933; Luftwaffeneinsatz in Frankreich; 1946 Begründer des Hebelfestes in Lörrach. Biographisches bei Vortisch, Demmler.

${ }^{173}$ Monatsbericht Januar 1947 des Lörracher Kreisdelegierten Georges vom 30. 1. 1947; AdO Bade M 1102/3.

174 Die Zahl ist vorsichtig zu bewerten, sicherlich wollte der Kreisdelegierte Georges in seinem Bericht vom März 1947 mit dieser unpräzisen Angabe ("une centaine“) auf die erstaunliche Resonanz hinweisen; AdO Bade M 1102/3. Auf eine zeitbedingt große Mitgliederzahl deutet ein gedruckter Aufnahmeantrag des Heimatbundes, der im NL Max Demmler erhalten ist. Für die Dokumente aus dem NL Demmler spricht der Verfasser dem Nachlaßverwalter, Herrn Dr. Friedrich Vortisch jun., seinen Dank aus.

175 Artikel „Alemannisch-schwäbischer Heimatbund“, in: Basler Nachrichten vom 20. 2. 1947. 
gandazwecke zu verteilen ${ }^{176}$; er selbst besaß ein in Leder gebundenes Exemplar. Sprichwörtlich manifestierte sich Demmlers Antiborussianismus in der immer wieder vorgetragenen Überzeugung, die auf den preußisch-österreichischen Krieg von 1866 anspielte: „Dr Großvattr hätts no schön gha, der hat no uff d’Preuße schieße dörfe.“177 Diese Gesinnung verband sich bei ihm mit der Überzeugung, „den Krieg gewonnen“ 178 zu haben. Derart äußerte sich Demmler oft nach 1945, und viele Lörracher, die den 8. Mai als Datum der Befreiung betrachteten, empfanden seine Einstellung als anstößig. Überhaupt wurde der Landschaftsverband „Markgräflerland“ zum breiten Sammelbecken der föderalistischen Kräfte im Dreiländereck. Über die Parteigrenzen hinweg fanden sich Politiker, die sich für den „Schwäbisch-Alemannischen Heimatbund“ einsetzten. Neben Demmler ist an erster Stelle Peter Hartmann ${ }^{179}$, der damalige Bürgermeister von Weil am Rhein, zu nennen; dessen föderalistische und frankophile Einstellung war bei der französischen Besatzungsmacht augenscheinlich bekannt. Hartmann engagierte sich beim Aufbau der Demokratischen Partei und bekleidete das Amt des stellvertretenden Vorsitzenden des Kreisvereins Lörrach ${ }^{180}$. Er fand in der unmittelbaren Nachkriegszeit über Max Demmler Zugang zum „Schwäbisch-Alemannischen Heimatbund“. Auch dem Lörracher Bürgermeister Josef Pfeffer (1879-1960), einem ehemaligen Zentrumsmitglied, lag die Zielsetzung des Heimatbundes am Herzen. Für einen Mann des alten Zentrums besaß das Bismarckreich nach den Erfahrungen des Kulturkampfes keine große Attraktion, Pfeffer spielte mit einer süddeutschen Lösung des deutschen Problems. Die SPB war ebenfalls im engeren Zirkel der Lörracher Sektion des Heimatbundes vertreten. Der Kreistagsabgeordnete Dr. Hess, wegen seiner Gegnerschaft zum Nationalsozialismus erst nach 1945 zum Schuldienst zugelassen, vertrat den föderalistischen Flügel der Sozialdemokraten und gehörte zum inneren Zirkel des Landschaftsverbandes „Markgräflerland“ des Heimatbundes.

${ }^{176}$ Im NL Max Demmler befindet sich „eine Kiste voll druckfrischer Exemplare der Fegerschen Schrift über die Schwäbisch-alemannische Demokratie"; schriftliche Auskunft von Friedrich Vortisch an den Verfasser vom 3.6. 1994. Außerdem besaß er eine ledergebundene Ausgabe der Schrift, der folgendes Einlegeblatt beigefügt war: „Lieber Leser! Dies Buch soll sein wie ein Samenkorn, das in gute Erde fällt, Wurzeln schlägt, hundertfache Frucht und unserer Sache hunderte von Freunden und Anhängern bringt. Bitte, behandle es deshalb sorgfältig und beanspruche es nicht länger als unbedingt erforderlich. Alsdann gib es zurück oder gib es weiter an Freunde und Bekannte, damit unser Heimatstaat Tatsache werde. Schwäbisch-Alemannischer Heimatbund - Landschaftsverband ,Markgräflerland". " Kopie im Besitz des Verfassers; Schreiben Vortischs an den Verfasser vom 22. 9. 1994.

177 „Mein] Großvater hat es noch gut gehabt, der durfte noch auf die Preußen schießen. “ Demmler spielte damit auf den preußisch-österreichischen Krieg von 1866 an, in dem badische Truppen zusammen mit württembergischen und bayerischen Einheiten gegen die preußischen Verbände gekämpft hatten. Für das Zitat vgl. das Schreiben Vortischs an den Verfasser vom 3.6. 1994.

178 Friedrich Vortisch sen. an Hans Vortisch vom 25. 4. 1946; PA Friedrich Vortisch.

${ }^{179}$ Peter Hartmann (1904-1967), Lehre bei der IG Farben; 1923 Wechsel zu Degussa nach Rheinfelden; 1926-38 Tätigkeit im Laboratorium einer Textilfirma in Weil am Rhein; seit 1929 Mitglied der DDP; 1939-44 Kriegsdienst; seit April 1945 Bürgermeisterstellverteter; 1946-57 Bürgermeister von Weil am Rhein; 1959-67 Gemeinderat daselbst. Vgl.: Weiler Zeitung vom 20. 10. 1954 und 20.10. 1964; Badische Zeitung vom 19. 10. 1964.

${ }^{180}$ Die Leitung des Kreisvereins Lörrach der DP hatte Rechtsanwalt Friedrich Vortisch sen. inne, dessen Sohn Friedrich Vortisch jun. Max Demmler noch zu Lebzeiten zu seinem zukünftigen Nachlaßverwalter bestimmt hat. 
Der einzige funktionsfähige Ortsverband des „Schwäbisch-Alemannischen Heimatbundes " in Südwürttemberg bestand in Rottweil. Der dortige Bürgermeister und Oberstaatsanwalt Franz Mederle hatte sich im Frühjahr 1946 vergebens bei der französischen Besatzungsmacht um die Lizenzierung einer „Schwäbisch-Alemannischen Volkspartei“ bemüht ${ }^{181}$. In die Planungen war auch der spätere Staatspräsident von WürttembergHohenzollern und Rottweiler Rechtsanwalt Lorenz Bock eingeweiht. Oberstaatsanwalt Mederle schloß sich nach dem Mißerfolg den Bestrebungen des Bodenseeraumes an und wirkte bei der Gründungsversammlung des „Schwäbisch-Alemannischen Heimatbundes“ mit. Sein Vertrauter und ständiger Ansprech- und Diskussionspartner war der Rottweiler Installateurmeister Willi Ernst. Beide zusammen führten in zahllosen Unterredungen weitere Rottweiler Bürger an den Heimatbund heran, die Schwäbisch-Alemannische Demokratie von Otto Feger galt ihnen als Bibel. Öffentliche Veranstaltungen können quellenmäßig nicht nachgewiesen werden, doch hat die stammesföderalistische Idee über Rottweil hinaus im intellektuellen und großbürgerlichen Milieu Württermberg-Hohenzollerns Zustimmung gefunden.

Die Sympathisanten des Heimatbundes waren nämlich im gesamten französisch besetzten Teil Württembergs vorhanden. Der oberschwäbische Adel bildete nur eine Gruppe, die mit dem „Schwäbisch-Alemannischen Heimatbund“ in Berührung gekommen war ${ }^{182}$. Doch Dietrichs Ressentiments gegenüber dem Adel verboten jede wirklich handfeste Zusammenarbeit. Die „Dekadenz“ des Adels wirkte auf den Singener Bürgermeister abstoßend, und gerade die auf Dynastien begründeten Länder Baden, Württemberg, Hohenzollern und Bayern standen seinem Föderalismuskonzept diametral entgegen. „Der Adel verdient unsere Unterstützung nicht“, resümierte Dietrich in späteren Jahren und fuhr fort: „er lebt in der Welt von vorgestern“ ${ }^{183}$. Indessen fühlten sich auch andere Bevölkerungsgruppen im mehrheitlich katholischen Oberschwaben durch den Heimatbund angesprochen. Der Tübinger Kreisdelegierte Courtois wußte im Juni 1946 an seinen Vorgesetzten Widmer zu berichten, daß in der Universitätsstadt eine „separatistische schwäbische politische Partei“, deren Ziel „die Schaffung einer schwäbischen Republik unter französischem ,Protektorat “" sei, sich konstituiere ${ }^{184}$. Einer Heimatpartei gab Courtois große Chancen für einen durchschlagenden Erfolg bei der Bevölkerung. In den französischen Quellen finden sich allerdings keine Lizenzierungsgesuche, so daß sowohl Hintermänner als auch Programm nicht erhellt werden konnten. Das Material dürfte sich aller Wahrscheinlichkeit nach in privaten Nachlässen befinden. Das de-factoVersammlungs- und Organisationsverbot Widmers verhinderte des weiteren die Gründung von Ortsverbänden des „Schwäbisch-Alemannischen Heimatbundes“ in Württemberg-Hohenzollern. Der Textilfabrikant Heinzelmann aus Reutlingen stimmte mit

${ }^{181}$ Zur „Schwäbisch-Alemannischen Volkspartei“ vgl. Kapitel V/2.

$182 \mathrm{Zu}$ den Familien Waldburg-Zeil und Waldburg-Wolfegg vgl. Kapitel II/2.

${ }_{183}$ Dietrich an Berr vom 4. 9. 1950; IfZ NL Fischbacher ED 719/168. Seine Verachtung drückte Dietrich in dem Brief auch mit den Diminutiven „Fürstchen und Prinzchen“ aus. Einzig eine Familie schien Dietrich nolens volens mangels Alternativen in seine Überlegungen einbezogen zu haben: „Ich kann mir nur einen Habsburger vorstellen, der dazu [zur Führung einer Konföderation] berufen sein könnte, wenn es ein Fürst sein soll“; Dietrich an Berr vom 3.12. 1950; IfZ NL Fischbacher; ebenda.

${ }^{184}$ Cercle de Tübingen: Rapport mensuel Juin 1946; AdO W-H p)Tübingen c. 2967 p. 4 d. 29/I. 
den Zielen des Heimatbundes überein und war bereit, mitzuarbeiten ${ }^{185}$. Das gleiche galt für den Trossinger Akkordeonfabrikanten Hohner, der sich mit dem Rottweiler Bürgermeister mehrmals im Frühjahr 1946 über die politische Neugliederung auf stammesföderalistischer Grundlage unterhalten hatte. Obwohl Kommunist, war der Tailfinger Bürgermeister Reinhold Gonser wegen seiner frankophilen Überzeugung ebenfalls zur Zusammenarbeit mit dem Heimatbund bereit. Anfang April 1947 erreichte Dietrich zudem ein Schreiben zweier Jugendgruppen des Kreises Tuttlingen, nämlich der „Katholischen Schwabenjugend“ und dem „Bund junger Schwaben“, die ihm die Zusammenarbeit anboten ${ }^{186}$. Ihre Triebfeder war die befürchtete „Verpreußung“ der Jugendarbeit in Württemberg-Hohenzollern, die sie auch in einem offenen Brief an das Staatssekretariat in Tübingen zum Ausdruck brachten ${ }^{187}$. Motiviert war der Vorstoß durch den Willen zur Umsetzung größerer Autonomie für den Südwesten Deutschlands.

Aber auch weitergehende Neugliederungsvorstellungen wurden in WürttembergHohenzollern diskutiert; paradigmatisch seien hier die Ausarbeitungen von Franz Musenbock aus Biberach kurz umrissen: Auf der Grundlage von fünf deutschen Bundesstaaten propagierte er im September 1948 für den Süden einen föderalistischen Zusammenschluß von „Südbaden, Südwürttemberg, Bayrisch-Schwaben und Südbayern“ ${ }^{188}$. Die Selbstverwaltung der genannten vier Länder innerhalb eines „süddeutschen Bundesstaates" stand im Vordergrund seiner Denkschrift, als Motivation diente Musenbock eine aus geschichtsrevisionistischer Position gezimmerte „Vergewaltigungstheorie“. Erwähnenswert für das propagierte zukünftige staatliche Gesicht des Südwestens ist die gewichtige Bedeutung der die nördlichen und südlichen Landesteile trennenden Donau: „Hier südlich liegt das älteste Kulturland diesseits der Alpen [...]. Das gemeinsame Kennzeichen der Volksstämme südlich der Donau [...] ist ihre gemeinsame römischchristliche Religion. "189 Die Abendlandvorstellung als verbindender Faktor für die Pläne Musenbocks und Dietrichs liegt auf der Hand, auch die Erinnerung an die vorderösterreichische Herrschaft im Südwesten spielte für den Biberacher eine nicht unbedeutende Rolle.

\section{Die Furcht der Militärregierung vor den elsässischen Autonomisten}

Schon die Alpenlandbewegung hatte hinsichtlich des Elsasses tiefes Mißtrauen im Apparat des französischen Außenministeriums geweckt. Das Konzept einer alpinen Union, so mutmaßte im Oktober 1945 der französische Konsul in Basel gegenüber dem französischen Botschafter in Bern, Henri Hoppenot, könnte „die Idee wiedererstehen lassen,

${ }^{185}$ Cercle de Rottweil: Rapport mensuel du mois de mars 1946; AdO W-H l)Rottweil c. 2256 p. 3.

186 Der Brief wird zitiert in einem Bericht der Sûreté über die Aktivitäten des Heimatbundes im ersten Trimester 1947 vom 24. 4. 1947; AdO Bade C 2128.

${ }^{187}$ Der offene Brief ist abgedruckt im Artikel: „Die ,preußische Invasion““, in: Der Tagesspiegel vom 18. 4. 1947. Darin heißt es unter anderem: „Von allen Verwaltungsstellen, vom Staatssekretariat angefangen bis zu den Landrats- und Bürgermeisterämtern, schallt uns der aus der Militärzeit so wohlvertraute preußische Kommißton entgegen. Preußengeist weht in Schulen und Krankenhäusern und pfeift, wie könnte es anders sein, durch die Wachen und Büros der Polizei. [...] Gerade im Hinblick auf die Flüchtlinge wäre eine Entpreußung der südwürttembergischen Verwaltung und des öffentlichen Lebens überhaupt unbedingt notwendig."

${ }_{188}$ Musenbock an Wohleb vom 19. 9. 1948; StA FR C 5/1 3469.

189 Ebenda. 
nach der das Elsaß gleichfalls Teil dieser süddeutschen Konföderation sein müßte "190. Ein knappes Jahr später trat auf allen Ebenen der französischen Besatzungsmacht eine vorherrschend skeptische Haltung in bezug auf die Ziele des „Schwäbisch-Alemannischen Heimatbundes“ zutage, auch eine Drahtzieherschaft der elsässischen Autonomisten schien nicht ausgeschlossen; der Lörracher Kreisdelegierte Georges brachte die verbreitete Einschätzung im März 1947 auf den Punkt: „Es ist eindeutig, daß diese schwäbisch-alemannische Bewegung mit Interesse [...] von den als, Autonomisten' bezeichneten Milieus [im Elsaß] verfolgt wird. Diese Bewegung verdient also eine ganz besondere Aufmerksamkeit, und es ist nötig, insbesondere die autonomistisch-separatistischen Drahtzieher im Elsaß zu überwachen." ${ }^{\text {"191 }}$

Die Erfahrungen mit dem Autonomismus im Elsaß datierten auf die Jahre nach dem Ersten Weltkrieg zurück. Die politischen Zugeständnisse, die Elsaß-Lothringen nach 1871 dem Deutschen Reich hatte abtrotzen können, wurden nach 1918 von Frankreich unter den Tisch gekehrt. Fortan mußte französisch gesprochen werden, ein laizistischer Wind wehte durch das ganze Land. Die Tätigkeit der berüchtigten commissions de triage, die Sequestrierung und Liquidation deutscher Vermögenswerte und die Klassifizierung der Bevölkerung nach „nationalen Gütekategorien“ lösten seit 1918 ein ständig wachsendes Unbehagen in Elsaß-Lothringen aus. Frankreich hatte mit dieser Vorgehensweise rasch den politischen Vorschuß verspielt, den es 1918 ohne Zweifel besessen hatte ${ }^{192}$.

Mit der Einsetzung des neuen französischen Ministerpräsidenten und Führers der Radikalsozialisten, Edouard Herriot, betrat im Mai 1924 ein entschiedener Verfechter einer prononciert laizistischen Kulturpolitik das Feld; die Trennung von Staat und Kirche bezeichnete er als sein Hauptanliegen. Die daraufhin angekündigten Regierungsmaßnahmen lösten in Elsaß-Lothringen einen Sturm der Entrüstung aus, schlagartig wurde der Bevölkerung klar, wie schlecht es um die Vertretung ihrer Interessen in Paris bestellt war. Allenthalben regte sich nun der Protest. Regierungsfeindliche Versammlungen und Demonstrationen waren an der Tagesordnung, und eine Kulturkampfstimmung erfaßte das Land. Gegen die geplante Einführung der Simultanschule kamen rasch 600000 Unterschriften zusammen, von den Kanzeln der Kirchen wetterte der katholische Klerus gegen die gottlose Regierung. Von einer Änderung des Kirchen- und Schulstatuts mußte Herriot wegen des massiven Widerstands Abstand nehmen. Der Konflikt hatte der Bevölkerung vor Augen geführt, daß nur ein geschlossenes und konzertiertes Handeln in Paris Eindruck machte.

Am 9. Mai 1925 erschien die erste Ausgabe des publizistischen Organs einer sich formierenden Heimatrechtsbewegung, die den bezeichnenden Untertitel Unabhängige Wochenschrift zur Verteidigung der Elsaß-Lothringischen Heimat- und Volksrechte tragende Zeitschrift Die Zukunft. In der ersten Nummer wurden die Kernprobleme der späteren Jahre angeschnitten: Kirchenstatut, Schul- und Sprachenfrage und einheimischer Einfluß auf Wirtschaft und Verwaltung. Die Zukunft hatte einen Stein ins Rollen

\footnotetext{
190 Konsul in Basel an Hoppenot vom 11. 10. 1945; AdO CCFA Con. Pol. 197-III-0.

191 Rapport mensuel de Lörrach (März 1947); AdO Bade M 1102/3.

${ }_{192}$ Zur politischen Situation im Elsaß-Lothringen der zwanziger Jahre vgl.: Kettenacker, Volkstumspolitik, S. 13-57. Die nachfolgenden Ausführungen stützen sich, soweit nicht anders vermerkt, weitgehend auf die Arbeit von Kettenacker.
} 
gebracht, der immer schneller an Geschwindigkeit gewann. Die elsässischen Parteien mußten auf die Autonomieforderungen eingehen, wollten sie nicht Gefahr laufen, ihre Wähler zu verlieren. Die Kommunisten schwenkten als erste auf die neue Linie ein. In ihrem Manifest forderten sie am 25. September 1925 die vollständige staatliche Selbständigkeit Elsaß-Lothringens. Die elsässische Volkspartei zog im November 1925 nach und „nahm durch einstimmigen Delegiertenbeschluß die Forderung nach ,Verwaltungsautonomie " in ihr Programm auf "193. Die Heimatrechtsbewegung war mittlerweile derart angeschwollen, daß die bestehenden politischen Parteien sie nicht mehr vollständig kanalisieren konnten. Daher planten führende Persönlichkeiten, ein überparteiliches, politisches Gebilde zu schaffen. Die Quintessenz der Überlegungen war die Gründung des „Elsässisch-Lothringischen Heimatbundes“ am Pfingstmontag 1926. Ein Manifest wurde verabschiedet, das die „vollständige Autonomie im Rahmen Frankreichs“ forderte $^{194}$. Man verstand sich nicht als eine neue Partei, sondern als eine überparteiliche Organisation, welche die bestehenden Parteien zum Handeln zwingen wollte. „Es lebe ein selbstbewußtes, starkes und freies Elsaß-Lothringen“ lautete der programmatische Schlußsatz des Manifests.

Frankreich konnte in dieser Organisation nicht länger eine Angelegenheit der Politik sehen, vielmehr schien die Sicherheit des Staates selbst gefährdet. Die volonté générale, der französische Einheitsstaat schlechthin, stand zur Disposition. Paris reagierte folglich sofort mit Sanktionen gegenüber den Personengruppen, die sich in einem Abhängigkeitsverhältnis zum Staat befanden: die Entlassung oder Amtsenthebung von Lehrern, Notaren, Bürgermeistern und Eisenbahnbeamten stand auf der Tagesordnung. Eine tendenziöse Pressekampagne, die von der Regierung gesteuert wurde, folgte den Maßnahmen auf dem Fuß. Es kam unter den Augen der Polizei zu tätlichen Angriffen französischer Nationalisten auf führende Vertreter des Heimatbundes. Die eingeschüchterte Bevölkerung sah, wie die Organisation des Heimatbundes durch solche Vorgehensweise weitgehend lahmgelegt wurde. Die Parteien nutzten die unklare Situation und stellten ihre Mitglieder vor die Entscheidung zwischen Parteimitgliedschaft und Heimatbund. Der „Elsässisch-Lothringische Heimatbund“ war damit vor die Alternative der Einstellung der Aktivitäten oder der Etablierung als politische Partei gestellt.

Ein kleiner Teil der Heimatbundanhänger wählte den Weg der Parteigründung. Am 29. September 1927 wurde daher die Autonomistische Landespartei ins Leben gerufen. Das Programm der Partei, die sich bald Unabhängige Landespartei nannte und von unrealistischen, deutsch-völkischen Vorstellungen geprägt war, gebärdete sich noch weit radikaler als der „Elsässisch-Lothringische Heimatbund“. Unter den gegebenen Vorzeichen fuhr die Pariser Regierung deshalb mit ihrer Politik fort, den Autonomismus auf das schärfste zu bekämpfen. Die Zukunft und zwei weitere heimatrechtliche Zeitschriften wurden verboten, Hausdurchsuchungen fanden bei den führenden Aktivisten statt. Am Neujahrstag 1928 nahm die Polizei eine größere Zahl Heimatrechtler unter dem Vorwurf, an einem Komplott gegen die Staatssicherheit beteiligt zu sein, fest. Bei den Kammerwahlen vom April 1928 wurden die eingekerkerten und des Hochverrats be-

${ }^{193}$ Ebenda, S. 16.

${ }^{194}$ Das Manifest des „Elsässisch-Lothringischen Heimatbundes“ ist vollständig abgedruckt bei Rothenberger, Autonomiebewegung, S. 253-256; hier S. 253. 
schuldigten Autonomisten Dr. Eugen Ricklin ${ }^{195}$ und Joseph Rossé ${ }^{196}$ aus dem Gefängnis heraus gewählt. Die französische Kammer erkannte beiden jedoch die Mandate ab; kurzerhand ersetzten die Autonomisten sie durch jüngere Gesinnungsgenossen. Der Colmarer „Komplott-Prozeß“197, der am 1. Mai 1928 begonnen hatte, ließ die Wogen nicht nur im Elsaß hochschlagen. Der „Sundgaulöwe“ Eugen Ricklin wurde neben anderen des Hochverrats angeklagt und schließlich verurteilt. Der Prozeß wurde aber zu einem Debakel für die französische Justiz, Ministerpräsident Poincaré sah sich im Februar 1929 zur Begnadigung der Verurteilten gezwungen. Von der dominierenden, katholisch ausgerichteten Elsässischen Volkspartei (Union Populaire Républicaine) ${ }^{198}$ spaltete sich 1928 der nationalfranzösische Flügel ab und nannte sich fortan Action Populaire Nationale d'Alsace (APNA); es gelang ihm aber nicht, die Massen der Wähler ins eigene Lager zu ziehen. Die Elsässische Volkspartei, vertreten durch Ricklin und Haegy, die beide schon im elsässischen Zentrum gewirkt hatten, sowie deren Nachfolger Rossé, Keppi und Stürmel, blieb die bestimmende Kraft des politischen Katholizismus im Elsaß.

Aus eigener Erfahrung kannte Bernhard Dietrich die Verhältnisse im Elsaß. Ebenso wie sein Freund Julius Wachter verfügte er seit spätestens Ende der zwanziger Jahre über gediegene Kontakte nach Mülhausen. Sein Vertrauter war Dr. Paul Specklin, bei dem der Singener Arzt 1933 nach seiner Flucht aus Deutschland für einige Monate unterkommen konnte. Dietrich schilderte Specklin nach 1945 gegenüber Offizieren der Besatzungsmacht als Vertreter der Action Française, einer nationalen Sammelbewegung. In Mülhausen stand Dietrich auch mit dem Chefredakteur des 1928 ins Leben gerufenen Elsässer Boten $^{199}$, Dr. Haenggy, in Verbindung. Der Elsässer Bote war das publizistische Organ der nationalen APNA. Es steht außer Zweifel, daß Dietrich um die Pläne der Autonomisten wußte, das Manifest des „Elsässisch-Lothringischen Heimatbundes“ dürfte ihm gleichwohl bekannt gewesen sein. Es ist nicht von der Hand zu weisen, daß die Idee, nach 1945 einen „Schwäbisch-Alemannischen Heimatbund“ zu gründen, ihre Wurzeln im Elsaß hat.

Über direkte Kontakte Dietrichs zu den Autonomisten ist hingegen nichts bekannt ${ }^{200}$; Dietrich hätte zum damaligen Zeitpunkt die Forderungen nach Autonomie für ElsaßLothringen wohl auch nicht unterstützt, für ihn war die Integrität des französischen Staates schon im Hinblick auf die damaligen Verhältnisse in Deutschland unantastbar. Sein Wille, in der Umbruchzeit der Jahre 1933/34 französischer Staatsbürger zu werden, mag dies verdeutlichen. Außerdem sah Dietrich die Rechte eines autonomen Elsaß-Lo-

195 Biographische Angaben, aus der Sicht eines Freundes geschrieben, sind zu finden bei: Stürmel, Ricklin.

${ }^{196}$ Joseph Rossé wurde unmittelbar nach Kriegsende wegen Kollaboration erschossen. Trotz Druckverbots konnten die katholischen Schriftsteller Reinhold Schneider (vgl. Kapitel II/1) und Theodor Haecker bei Rossé im Alsatia-Verlag in Colmar publizieren; vgl. Hell, relations, S. 131.

${ }^{197}$ Zum Verlauf des Prozesses aus der Sicht der Autonomisten: Stürmel, Lebensbild, S. $22 \mathrm{ff}$.

198 Ausführlich hierzu: Maugé, Particularisme, S. 65-69.

${ }^{199}$ Zur Motivation der katholischen Kirche vgl. Kettenacker, Volkstumspolitik, S. 287 Anmerkung 43 .

200 Die wenigen biographischen Zeugnisse Dietrichs waren für die französische Besatzungsmacht bestimmt. Daß Dietrich darin seine Verbindungen zu nationalen Kreisen im Elsaß herausstrich, ist nicht verwunderlich. Kontakte zu den Autonomisten hätten seine Pläne in den Augen der Besatzungsmacht a priori diskreditiert. 
thringen in einem diktatorischen Deutschland weit mehr gefährdet, als dies im republikanischen Frankreich der Fall sein konnte.

Nach dem deutschen Einmarsch in Frankreich solidarisierten sich viele Autonomisten mit der nationalsozialistischen Politik. Andere, wie etwa Marcel Stürmel, schlossen sich wiederum aktiv der deutschen Widerstandsbewegung an ${ }^{201}$. Das Jahr 1945 ließ ein Wiederaufflammen des Autonomismus im Elsaß nicht mehr zu. Führende Autonomisten wurden verhaftet, verurteilt und manche auch hingerichtet. Vor diesem Hintergrund ist die französische Besatzungspolitik in Südwestdeutschland zu sehen. Konnte die französische Besatzungsmacht in Deutschland den Gedanken des Stammesföderalismus unterstützen und sich zu eigen machen, wenn gleichzeitig im Elsaß jede Form des Autonomismus hart unterdrückt wurde? Bestand nicht die Gefahr, daß die Idee eines schwäbisch-alemannischen Staates in den Kreisen der Autonomisten begeistert aufgenommen würde? Die ambivalente Haltung vieler - auch konservativ gesonnener - Offiziere lag in diesen Überlegungen begründet.

\section{Die Singener Föderalistenkongresse}

Vom 8. bis 10. Oktober 1947 tagte in Singen ein „Kongress der autonomen Föderalisten ". Von Bernhard Dietrich einberufen, fand sich eine illustre Schar deutscher Föderalisten und Heimatrechtler in der Twielstadt ein. Der „Schwäbisch-Alemannische Heimatbund" stellte neben dem Präsidenten drei weitere Teilnehmer, nämlich den Generalsekretär Leopold Paur, Franz Mederle und den Leiter des Ortsverbandes Freiburg, Helmut Ziegler. Ferner waren aus der Pfalz die "Separatisten“ der Union des Amis de la France unter Vorsitz von Karl Steiner anwesend, der von Heinrich Steiner und Adolf Bley begleitet wurde ${ }^{202}$. Auch der Leiter des „Komitees für ein Eigenstaatliches Rheinland", Peter J. Nauheimer, hatte die Reise von Worms Richtung Schweizer Grenze angetreten. Von der Rheinisch-Republikanischen Volkspartei wurden Peter Dannhäuser und Dr. Hermann Klein auf den Kongress entsandt. Die Deutsche Partei war durch Eberhard Jagemann vertreten. Georg von Eisenhard, Friedrich Brahm und Anton Putz kamen aus München als Delegierte der Bayernpartei in den Hegau. Auch der prominente Fürsprecher eines vereinten Schwabens ließ sich diese Plattform nicht entgehen: Otto Färber ${ }^{203}$, der Chefredakteur der Stuttgarter Nachrichten, beehrte Dietrich mit seinem Besuch.

Diskussionspunkte der Veranstaltung waren zum ersten die Einrichtung einer „Permanenten Konferenz" in Singen und zum zweiten die Verabschiedung des sogenannten „Singener Manifests der Autonomen Föderalisten“. Unter Vorsitz von Bernhard Dietrich legten die Vertreter der einzelnen Organisationen die jeweiligen Programme vor und stellten sie zur Diskussion. Es wurden fünf Entscheidungen getroffen:

1. Eine „Permanente Konferenz“, die schnell zusammentreten könnte, sollte in Singen eingerichtet werden.

2. Die Anschrift der „Permanenten Konferenz“ sollte die Adresse Dietrichs sein.

201 Ein autobiographisches, durch intensives Quellenstudium angereichertes Zeugnis: Stürmel, Elsaß, S. 59-128.

${ }^{202} \mathrm{Zu}$ den "Separatisten“ in der Pfalz vgl.: Wünschel, Separatismus und Ders., Neoseparatismus.

${ }^{203} \mathrm{Zu}$ Otto Färber vgl. Kapitel II/1. 
3. Von Singen aus sollten alle Schriftstücke an die Mitglieder der „Permanenten Konferenz" verteilt werden.

4. Eine Pressenotiz ${ }^{204}$ sollte nach Genehmigung durch die Militärregierung an die Teilnehmer zwecks Weiterleitung an die Presse ausgehändigt werden.

5. Die Teilnehmer verpflichteten sich, gegenseitig Nachrichten und Informationen auszutauschen.

Über die getroffenen Entscheidungen zeigte sich Dietrich befriedigt; die Frage stellte sich jedoch für ihn, inwieweit die hier begonnene Zusammenarbeit weiter Früchte tragen würde. Das Manifest umriß die altbekannten Ziele der „autonomen“ Föderalisten: Ablehnung des deutschen Nationalstaates Bismarckscher Prägung, Neugliederung Deutschlands unter stammesföderalistischen Gesichtspunkten bei gleichzeitiger Einbindung der Stammesstaaten in eine europäische Konföderation, Übernahme der Kriegslasten aus dem Erbe des „Dritten Reiches“, Pflege der abendländischen Kultur, Schaffung einer europäischen Konföderation und Herstellung des sozialen Friedens im Innern der autonomen deutschen Staaten. Doch kein Wort fiel über die Strategie zur Umsetzung der Ziele mittels praktischer Politik. Die französische Besatzungsmacht verfolgte gespannt die Konferenz. Alle maßgeblichen Dienststellen von Freiburg über Baden-Baden bis zur französischen Kontrollratsgruppe in Berlin ${ }^{205}$ erhielten umgehend eine Übersetzung der Beschlüsse.

Mit wesentlich geringerem Erfolg berief Dietrich Anfang März 1948 den zweiten Föderalistenkongreß nach Singen ein. Die Resonanz, die seine Einladung fand, enttäuschte ihn tief. Von neun eingeladenen, aus anderen Regionen stammenden Föderalisten erschienen nur zwei am 10. März in der Stadt am Hohentwiel, und damit schmolz der Teilnehmerkreis auf insgesamt vier Personen zusammen. Anwesend waren der Präsident und der Generalsekretär des "Schwäbisch-Alemannischen Heimatbundes" sowie Dr. Erich Opitz aus Köln als Vertreter der Rheinischen Union und ein ungeladener Repräsentant der Deutschen Partei206, Grappentin, aus Hannover. In letzter Minute hatte Klein aus Rolandswerth im Rheinland abgesagt ${ }^{207}$. Das Ziel der Konferenz sah Dietrich einerseits in der Ausarbeitung eines Planes zur kantonalen Gliederung Deutschlands

${ }^{204}$ Die Pressenotiz wurde in der Münchener Zeitung Echo der Woche am 22.11.1947 mit folgendem Wortlaut veröffentlicht: „Vom 8.-10. Oktober trafen sich in Singen/Hohentwiel Delegierte der autonomen föderalistischen Bestrebungen aus den drei Westzonen. Es war das erste Mal, daß deutsche Föderalisten, die gleichzeitig entschiedene Verfechter der Autonomie ihrer Heimatländer sind, zusammenkamen. Schon am ersten Tage der Besprechungen wurde eine auffallende Gleichheit der Auffassungen festgestellt. Die autonomen Föderalisten lehnen die Rückkehr in einen nationaldeutschen Staatsverband einhellig ab. Sie werden nach Erreichung der Eigenstaatlichkeit ein föderales Verhältnis zu einander schaffen, das in seiner Auswirkung bereits eine europäische Konföderation darstellt. Es kommt daher für sie eine deutsche Bundesregierung nicht in Frage. Sie sprengen mit Vorbedacht nationaldeutschen Rahmen, um auf europäischen Boden vorzustoßen."

${ }^{205}$ Schreiben der Direction de l'Intérieur et des Cultes an die GFCC (Seydoux) vom 29. 10. 1947. Dem Schreiben liegen Übersetzungen der auf der Konferenz verfaßten Papiere bei; AdO Berlin GMFB c. 168 d. H2a.

206 Ursprünglicher Name: Niedersächsische Landespartei.

${ }^{207}$ Die Teilnehmerliste und eine Zusammenfassung der Konferenzergebnisse sind dokumentiert in einem Brief des Kommissars der Sûreté, Feris, an dessen vorgesetzte Dienststelle (Contrôleur de la Sûreté pour le Pays de Bade) in Freiburg vom 13. 3. 1948; AdO Bade C 2128. 
nach Schweizer Vorbild und andererseits in der Vorbereitung eines großen Föderalistenkongresses in naher Zukunft. Doch mangels Masse gelang den vier Herren nur die Erarbeitung eines Kommentars zum „Singener Manifest der Autonomen Föderalisten“, der sich auf die erneute Ausführung der Forderungen nach einer staatenbundlichen Lösung, nach einer stammesmäßigen Gliederung Deutschlands und gleichzeitiger Schaffung einer europäischen Konföderation sowie einem Aufruf zur Ächtung kriegerischer Gewalt beschränkte ${ }^{208}$.

Keineswegs konnte Bernhard Dietrich mit dem Verlauf der Konferenz zufrieden sein, die mangelnde Resonanz bei den führenden Föderalisten ließ auf noch weniger Anteilnahme in der Bevölkerung schließen. Auch der „Schwäbisch-Alemannische Heimatbund" hatte bis dato nicht den Funken gezündet, der zur Durchsetzung der politischen Ziele notwendig gewesen wäre. Unermüdlich hatte Dietrich zwar Versammlungen abgehalten, die Schaffung einer weitgreifenden Organisation mit tragfähiger Basis war jedoch fehlgeschlagen. Hat nicht gerade die fehlende Unterstützung der Besatzungsmacht dies mitverschuldet? Tatsächlich wurde der Heimatbund zu keinem Zeitpunkt durch französische Dienststellen gefördert. Die Lage der Vereinigung erwies sich 1948 als sehr prekär. Noch einmal - dies als letzte Gelegenheit verstanden - sollten alle Kräfte gebündelt und der Besatzungsmacht gewisse Zugeständnisse abgerungen werden. Ein letztes Mal mobilisierte Dietrich daher die Vertreter des Heimatbundes, indem er nach Singen zu einer „Geheimkonferenz“ einlud. Am 3. April 1948 fand mit Zustimmung der Sûreté das Treffen statt, die Gründe der Stagnation und ein letztes Konzept zur Rettung des Heimatbundes sollten erarbeitet werden. Sechzehn Teilnehmer aus dem südbadischen und südwürttembergischen Raum hatten sich versammelt ${ }^{209}$.

Generalsekretär Paur führte die Gründe der Schwäche des Heimatbundes auf die verweigerte Unterstützung seitens der Militärregierung und die Pressekampagne gegen den Föderalismus im allgemeinen sowie gegen den Heimatbund im besonderen zurück. Die Anwesenden waren sich einig, daß die Struktur des Heimatbundes geändert werden müsse. Ein „Direktorium“, dem neben Dietrich auch Feger angehören sollte, würde die Lasten der Arbeit gleichmäßiger verteilen. Das „Direktorium“, ein Vierergremium, sollte die Arbeit des Generalsekretariats des Heimatbundes koordinieren. Verlegt von Engen nach Konstanz, erhoffte man sich vom Generalsekretariat am Sitz der Bezirksmilitärregierung eine höhere Effektivität. In allen größeren Städten sollten sodann Sekretariate eingerichtet werden, an denen die Komitees des Heimatbundes hingen. Der Start weiterer Aktivitäten wurde zum einen von der Lizenz für eine Tages- oder zumindest

208 "Aufruf“" (masch. 1 S.) März 1948; StA FR T1 NL Leo Wohleb I/1 91.

209 Aus Singen selbst waren anwesend: der Geschäftsführer Karl Harder, der Wirtschaftsprüfer Bertold Fahrensbach, der Steuerberater Stefan Schmid und der Journalist Walter Ferber. Dem Präsidenten Dietrich stand Generalsekretär Paur zur Seite, das Markgräflerland war durch den Weiler Bürgermeister Peter Hartmann, den Lörracher Kaufmann Max Demmler und den Referenten im Landwirtschaftsamt Laufenburg, Ludwig Spross, vertreten. Helmut Ziegler vom Ortsverband Freiburg des Heimatbundes, der Landrat von Donaueschingen, Robert Lienhart, und der Bürgermeister von Allensbach, Gottfried Mayer, rundeten das Aufgebot der südbadischen Vertreter ab. Aus dem württembergischen Rottweil nahm der rastlos agierende Franz Mederle teil. Als Gäste wohnten der „Geheimkonferenz" die beiden oberschwäbischen Grafen Heinrich und Johannes von Waldburg-Wolfegg sowie der im Streit geschiedene Otto Feger bei. Die Teilnehmerliste entstammt einem umfassenden Bericht über den Heimatbund: ${ }_{n}$ Rapport $\mathrm{N}^{\circ}$ 93/INT/S du 24 Avril 1948 sur le ,Heimatbund“" (masch. 18 S.); AdO Bade C 2128. 
Wochenzeitung und zum anderen von „gewissen Garantien“ französischerseits bezüglich der Autonomie des Südteils der FBZ abhängig gemacht. Drei Monate Zeit setzten die Anwesenden dafür an, ansonsten beschloß man die Auflösung des Heimatbundes.

Der in Singen stationierte Repräsentant der Sûreté, Kommissar Feris, unterstützte die Forderungen des Heimatbundes. An den Konstanzer Delegierten Noël gab er die Empfehlung weiter, auf jeden Fall schnellstmöglich eine Lizenz für eine Wochenzeitung zu erwirken. Durch Papier, Büroartikel, Reifen und Benzin müsse die Arbeit des Heimatbundes erleichtert werden, außerdem sei eine „diskrete Hilfe“ bei der Einrichtung der Sekretariate in den größeren Städten nötig210. Bezüglich der Garantien für einen autonomen, zukünftigen südwestdeutschen Staat, der aus dem Südteil der FBZ hervorgehen sollte, hatte Feris gegenüber den Vertretern des Heimatbundes deutlich gemacht, daß eine derartige Entscheidung nicht binnen kurzer Frist zu erwarten sei. Freilich blieb die für den Heimatbund existentielle Entscheidung aus. Überhaupt unternahm die französische Besatzungsmacht auch in den folgenden Monaten nichts, was auch nur auf eine minimale Unterstützung des Heimatbundes schließen ließe. Statt dessen kamen die Widersprüche, Unzulänglichkeiten und internen Unstimmigkeiten immer deutlicher zum Vorschein. Wenige Tage nach der „Geheimkonferenz" informierte Franz Mederle von Rottweil aus den Konstanzer Bezirksdelegierten über die konzeptionellen Mängel des Heimatbundes und die Inaktivität des Generalsekretärs ${ }^{211}$. Scharf kritisierte er die Haltung Paurs, erst dann mit Großversammlungen an die Öffentlichkeit treten zu wollen, wenn die Unterstützung durch die Militärregierung zweifelsfrei gegeben sei. Nur eine Persönlichkeit konnte den Heimatbund in den Augen Mederles mit neuem Leben erfüllen: „Herr Feger wäre nach meiner Überzeugung seiner ganzen Persönlichkeit nach auch imstande [...], dieses Programm zu verwirklichen, da er sich in einem noch relativ günstigen Lebensalter befindet, eine erhebliche Erfahrung besitzt und nüchtern denkt, ohne dabei die Fähigkeit einzubüssen, gegebenenfalls auch als Diskussionsredner eine beachtliche Leistung zu bieten."212 In erster Linie sah Mederle die Grundvoraussetzung für eine erfolgreiche Politik nicht gegeben: Der Heimatbund habe es versäumt, offensiv an die Öffentlichkeit zu treten und eine latent vorhandene positive Stimmung in der Bevölkerung zu nutzen. Auch in Lörrach glaubte Max Demmler nur ein Strohfeuer entzündet zu haben, denn der Heimatbund ließ im Dreiländereck keine weiteren Aktionen folgen.

Aus der verfahrenen Situation gab es keine Rettung. Otto Feger drückte unmißverständlich seinen Willen aus, im Heimatbund keine führende Rolle mehr zu übernehmen. Mitte 1947 legte er schriftlich seine Haltung in dem unveröffentlichten Artikel „Schwäbischer Pangermanismus" 213 nieder. Er wehrte sich vehement gegen die Behauptung, seine Schwäbisch-Alemannische Demokratie weise rassistische oder annexionistische Tendenzen auf. In diesem Zusammenhang legte Feger Wert auf die Feststellung, daß er „mit dem Kreis in Singen nichts zu tun“214 habe. Die Alpenlandpläne Dietrichs beurteilte der Konstanzer Archivar als „eine Chimäre, ein Phantasiebild, ohne Berücksichti-

\footnotetext{
${ }^{210}$ Feris an Noël vom 30. 4. 1948; AdO Bade C 2128.

211 Mederle an Noël vom 12. 4. 1948; AdO Bade C 2128.

212 Ebenda.

213 „Schwäbischer Pangermanismus“ (masch. 4 S.) unveröffentlicht [1947]; NL Otto Feger.

${ }^{214}$ Ebenda.
} 
gung der tatsächlichen Verhältnisse entstanden, nur von wenigen ernst genommen, sehr rasch zu den Akten gelegt “215. An eine Wiederbelebung des Heimatbundes durch das Engagement Otto Fegers war also nicht zu denken. Die Aktivitäten des „SchwäbischAlemannischen Heimatbundes“ wurden daher bis Ende 1948 eingestellt, und mit dem Austritt Paurs im März 1949 erlosch die Vereinigung, die sich überlebt hatte, gänzlich.

\section{Die Verbindungen zur Bayernpartei}

Nicht nur im Südwesten, sondern ebenso in Bayern haben sich unmittelbar nach dem Zusammenbruch des "Dritten Reiches“ in Reaktion auf den Zentralismus und dessen mutmaßliche preußischen Wurzel antizentralistische und antipreußische Tendenzen gezeigt. Nach der Ablösung von Fritz Schäffer als erstem bayerischen Ministerpräsidenten und der Abberufung Pattons als Militärgouverneur in Bayern im September 1945 sahen monarchistische Kreise ihre Stunde gekommen. Am 14. Oktober 1945 legten sie der Militärregierung das Programm einer „Bayerischen Heimat- und Königspartei“ (BHKP) zwecks Zulassung vor. Der engere Kreis der Gründungsmitglieder bestand aus bürgerlichen Honoratioren, meist Freiberuflern, und Adeligen ${ }^{216}$. Die Leitung lag in den Händen von Professor Max Lebsche, einem katholischen Mediziner, dessen monarchistische Einstellung bekannt war. Die Zulassung für den Stadtkreis München erhielt die BHKP am 23. Januar 1946. Die BHKP trat in den folgenden Monaten nur einmal an die Öffentlichkeit. Am 28. April 1946 trug Max Lebsche die „Grundsätze und Ziele“ der Partei auf einer großen Kundgebung vor ${ }^{217}$ : Durchsetzung der christlichen Weltanschauung, ständische Gliederung und Ablehnung der Volkssouveränität waren dabei die markantesten Punkte. Seine Geschichtsauffassung war apologetischer Natur, Lebsche meinte eine gerade Linie von 1866 bis 1945 erkennen zu können: „Kann auch nur der geringste Zweifel darüber bestehen, daß der deutsche Zentralismus in jeder Form sowohl dem ganzen deutschen Volk wie auch seinen Stämmen nichts als Unglück, Schaden und Schande gebracht hat?" 218 Die BHKP trat deshalb für eine staatenbündische Lösung der deutschen Frage ein; Bayern selbst müsse seine „Staatspersönlichkeit“ wiederfinden. Das State Department in Washington hegte an der demokratischen Gesinnung der BHKP arge Zweifel, man erachtete die Partei als reaktionär und bewertete sie als eine Gefahr für den Aufbau eines föderativen Deutschlands. Druck aus Washington veranlaßte General Clay am 10. Mai 1946, die BHKP zu untersagen. Deren Anhänger schlossen sich nach dem Verbot mehrheitlich der im Entstehen begriffenen Bayernpartei an.

In Unterfranken wurde am 19. Dezember 1945 eine weitere Vorläuferorganisation der Bayernpartei von der Militärregierung zugelassen; die „Bayerische Bauernpartei“ konnte wenig später auch in München eine Ortsgruppe ins Leben rufen. Bedeutung hat die Partei allerdings nur in Lohr am Main, dem Gründungsort, erlangt. Ihr Spiritus rector, Dr. Alfred Klein ${ }^{219}$, überführte die Bauernpartei in die Bayernpartei und übernahm gleichzeitig die Organisation in Unterfranken. Seine Überzeugung von der Notwendig-

\footnotetext{
215 Ebenda.

216 Unger, Bayernpartei, S. 18.

217 Ebenda, S. 19.

218 Programm der BHKP; IfZ NL Baumgartner; zitiert nach Unger, Bayernpartei, S. 19.

${ }^{219}$ Alfred Klein; promovierter Volkswirt und Landwirt in Partenstein im Spessart.
} 
keit einer stammesföderalistischen Gliederung Deutschlands brachte Klein durch Teilnahme auf dem Singener Föderalistenkongress im Oktober 1947 zum Ausdruck.

Eine weitere Wurzel der Bayernpartei entwickelte sich im Chiemgau und in Rosenheim. In bäuerlichem Umfeld arbeitete Dr. Jakob Fischbacher ${ }^{220}$ den Plan aus, eine „Bayerische Freiheitspartei“ zu gründen. Er war ein Verfechter des Zusammenschlusses von Bayern und Österreich, seine tiefverankerte Abneigung gegen alles Norddeutsche und Preußische bildete hierfür das Fundament ${ }^{221}$. Doch Ludwig Max Lallinger ${ }^{222}$ kam Fischbacher durch die Gründung der Bayempartei zuvor. In der Demokratischen Union, deren Landesvorstand Lallinger im Juli 1946 zum Vorsitzenden gewählt hatte und deren Lizenzierung die Amerikaner verweigerten, lag der Keim der späteren Bayernpartei. Der offizielle, wenngleich die Anfangsquerelen überdeckende Gründungsakt im Straubinger Hof in München datiert auf den 28. Oktober 1946. Unmittelbar nach der Gründung schlossen sich einige Mitglieder der verbotenen BHKP der Bayernpartei an, zum größten Teil junge Akademiker und Angehörige des Mittelstandes. Die Führungsmannschaft um Lallinger wurde damit um entschiedene Verfechter einer vollständigen Neugliederung Mitteleuropas erweitert, deren Vorstellungen auf die Schaffung eines Ständestaates, die Einführung des Zweikammersystems und die Ernennung eines Staatspräsidenten abzielten. Der Zusammenschluß Bayerns mit Österreich zu einem Donaubund oder dessen Erweiterung mit der Schweiz zu einer Alpenföderation waren fester Bestandteil ihrer politischen Ziele ${ }^{223}$.

Innerhalb der Bayernpartei hatte sich insbesondere Anton Putz ${ }^{224}$ Gedanken über die staatliche Neuordnung in Deutschland gemacht; Putz ging sogar einen Schritt weiter und legte seine Pläne im Oktober 1946 auch in Baden-Baden vor ${ }^{225}$. Durch das Verbot der BHKP glaubte er, nicht mehr auf die Unterstützung durch die amerikanische Militärregierung hoffen zu können. Putz trat offen für eine vollkommene Atomisierung Deutschlands ein, selbst ein lockerer deutscher Staatenbund kam für ihn nicht in Frage. Preußenhaß und Heimatliebe verbanden sich auch bei ihm zu einem Konglomerat politischer Vorstellungen, die im Zusammenschluß der süddeutschen, katholischen Länder

220 Jakob Fischbacher (1886-1972), Bauernsohn aus Toetzham/Kreis Wasserburg; humanistisches Gymnasium in Wasserburg und Freising; 1906-1913 Studium der Rechts- und Staatswissenschaften, Geschichte und Philosophie in Erlangen und München; Promotion; Tätigkeit beim Christlichen Bauernverein; 1914-17 Kriegsteilnahme; 1921-34 Direktor des Christlichen Bauernvereins Oberbayern; seit 1934 für eine schweizerische Versicherung tätig; 1945-47 Kreisdirektor des Bayerischen Bauernverbands, Bezirk Oberbayern; 1948-61 Kreisvorsitzender der Bayernpartei, Bezirk Oberbayern; 1950-62 MdL; 1952-53 Landesvorsitzender der Bayernpartei; 1950-53 Zweiter Vizepräsident des Bayerischen Landtags; 1957-60 Fraktionsvorsitzender.

${ }^{221}$ Unger, Bayernpartei, S. 26.

222 Ludwig Max Lallinger (1908-?), 1926 im Dienst der bayerischen Landespolizei; Besuch von Polizeischulen; Studium an der Verwaltungsakademie; 1938 verbeamtet; 1945 Dienst bei der politischen Abteilung der Kriminalpolizei München; seit Herbst 1945 Leibwächter von Ministerpräsident Wilhelm Hoegner; Begründer der Bayernpartei.

${ }^{223}$ Unger, Bayernpartei, S. 29.

224 Anton Putz; bis 1933 Mitglied der SPD; Verfolgung durch die Nationalsozialisten; nach 1945 Mitglied der Bayernpartei; 1947 Parteisekretär des Kreisverbandes München Stadt und Land; Vorsitzender des Presseausschusses der BP; P. rechnete sich selbst zum linken Flügel der BP; 1948 Teilnehmer der Tagung der „Autonomen Föderalisten“ in Singen.

${ }^{225}$ Anton Putz: „Richtlinien einer Bayerisch-Französischen Zusammenarbeit zur Sicherung von Freiheit und Frieden" (masch.) vom 9. 10. 1946; AdO HCFA Cab. Civil POL-II-B p. 27. 
fußten. Für Bayern, Baden und Württemberg empfahl er deshalb die vollkommene Autonomie und die radikale Loslösung von Deutschland. Die drei süddeutschen Staaten sollten eine Union, eine Art Donaukonföderation, bilden, um gemeinsame Interessen zu regeln. Zollunion und wirtschaftliche Ankoppelung an Frankreich hätten die ökonomischen Grundlagen der Union zu sichern. Aber die französischen Stellen gingen auf die Vorschläge von Putz mit keiner Silbe ein, das Schreiben aus München landete unkommentiert in der Ablage. Den Zentralismus sah Putz in den folgenden Monaten sich allerorten Platz bahnen ${ }^{26}$, weshalb er sich der Bewegung der „Autonomen Föderalisten“ unter Leitung von Bernhard Dietrich anschloß. Auf dem ersten Singener Föderalistenkongreß im Oktober 1947 waren bereits mehrere Teilnehmer der Bayernpartei unter seiner Führung zugegen. Über die Hintergründe der frühen Kontakte Dietrichs nach München geben die vorhandenen Quellen allerdings keine Auskunft. Präzise aber läßt sich die Kontaktaufnahme zu den prominenten Mitgliedern der Bayernpartei Jakob Fischbacher und Professor Anton Berr ${ }^{227}$ quellenmäßig rekonstruieren ${ }^{228}$. Beide Politiker gehörten innerhalb der Bayernpartei einer Randgruppe an. Der Schriftwechsel Dietrichs mit Fischbacher bezeugt in der Frage der Alpenlandpläne keine Übereinstimmung. Berr, Gründer des in der Presse kritisch beobachteten „Außenpolitischen Arbeitskreises der $\mathrm{BP}^{\prime 229}$, neigte hingegen zu einer alpenländischen Lösung, weshalb sich die Parteiführung von ihm distanzierte; sein Programmm stand zu sehr im Geruch des „Separatismus". Als Sprecher des "Außenpolitischen Arbeitskreises" hatte sich Berr wiederholt für ein auf das altbayrische Gebiet geschrumpftes Bayern ausgesprochen, das sich einem Donaustaat $^{230}$ anschließen sollte ${ }^{231}$. Die fränkischen Gebiete Bayerns mußten nach seinen Vorstellungen - weil „protestantisch und preußisch“ - abgetrennt werden ${ }^{232}$.

Konsequenterweise suchte sich Berr im Mai 1948 einen Verbündeten, der sich bereits durch schriftliche Äußerungen für einen Alpenstaat eingesetzt hatte: Bernhard Dietrich. Getrieben von dem Hintergedanken, eine Zusammenarbeit zwischen BP und Heimatbund zu begründen, wandte er sich an den Präsidenten des „Schwäbisch-Alemannischen Heimatbundes" 233 und knüpfte damit einen ersten Kontakt. Ein reger Briefwechsel kam dadurch in Fluß, der erst im Laufe des Jahres 1952 sein Ende fand und der deutlich belegt, daß Dietrich trotz des Mißerfolges an seinen Alpenlandplänen festgehalten hat. Im ersten Antwortbrief machte er dem Münchener Professor seinen Standpunkt deutlich: „Die alpenländischen und voralpenländischen Gebiete gehören ihrer Natur nach zusammen, sie allein sind zu einem Bund vereinigt imstande, den Deutschlandwahn zu erledigen. Wenn der voralpenländische Bund der deutschen Altstämme der Bayern, der

226 Anton Putz: Der Weg zur Macht (masch. 3 S.) vom 30. 8. 1947; AdO ebenda.

227 Anton Berr (1900-?), Professor an der Landwirtschaftlichen Hochschule Weihenstephan; 1947 Mitglied der Bayernpartei; Sprecher des „Außenpolitischen Arbeitskreises der BP“; 1949 Gründer eines neuen „Bayerischen Heimat- und Königsbundes“.

${ }_{228}$ Der Schriftwechsel zwischen Dietrich und Fischbacher bzw. Dietrich und Berr ist im NL Fischbacher erhalten. Vgl. IfZ NL Fischbacher ED 719/148 und 168. Zur politischen Lage in Bayern: Kock, Weg, S. 102-169.

${ }^{229}$ Vgl. etwa Der Spiegel vom 12.6. 1948.

230 Synonym können auch die Begriffe „Donau-Alpenstaat", „Alpenland“ oder „Union alpine“ eingesetzt werden.

231 Kock, Weg, S. 147 Anmerkung 231.

232 Färber, Bayern, S. 177.

233 Berr an Dietrich vom 1. 5. 1948; IfZ NL Fischbacher ED 719/168. 
Schwaben und der Alemannen nicht kommt, der seine normale Erweiterung durch die Österreicher mit der Zeit erfahren müßte, sind unsere Anstrengungen nutzlos. “234 Auf Dauer gesehen müsse auch die Schweiz, so fuhr Dietrich fort, „das größte Interesse" an einem solchen Bund haben. Mit diesen Neugliederungsplänen rannte er bei Berr, der eine vollkommene Übereinstimmung mit Dietrich konstatierte, offene Türen ein. Auch Berr vertrat den Standpunkt, „daß man nach dem stämmischen Prinzip vorgehen, $d . h$. einen - wirklichen - foederalen Bund innerhalb des Gebietes, das heute Bayern, Württemberg, Baden und Österreich umfaßt, von unten nach oben zu einem, Alpen-Donaubund" aufbauen müßte"235.

\section{Die Pläne für eine föderalistische Zeitung}

Die ersten Versuche, die Lizenz für eine konsequent föderalistische Zeitschrift zu erhalten, datieren auf den Sommer 1946 zurück. Auf der Gründungsversammlung des „Schwäbisch-Alemannischen Heimatbundes“ hatte Otto Feger bereits angekündigt, eine Zeitschrift mit dem Titel Oberland ${ }^{236}$ in Zusammenarbeit mit dem Konstanzer Verleger Curt Weller herausgeben zu wollen. Dazu war der Chefredakteur der Zeitschrift Das Neue Abendland, Walter Ferber, eigens aus der Amerikanischen Besatzungszone übergesiedelt, nachdem er in Augsburg mit dem Verleger Johann Wilhelm Naumann gebrochen hatte; von Dietrich war er mit dem Versprechen in die französische Zone gelockt worden, eine föderalistische Zeitschrift redigieren zu können. Doch 1946 ließ sich ein solches Projekt wegen der restriktiven Papierzuteilung und der undurchsichtigen französischen Politik nicht durchführen. Nach dem Bruch mit Feger hoffte Dietrich erneut, eine föderalistische Zeitung auf die Beine stellen zu können. Walter Ferber hatte mittlerweile bei der Schwarzwälder Post eine Anstellung gefunden, wäre aber jederzeit bereit gewesen, als Chefredakteur eine Zeitung zu leiten. Auch die Namenswahl gestaltete sich problemlos: Der Freie Süden ${ }^{237}$ war Titel und Programm in einem. Tatsächlich hatte Franz Mederle aus diesem Grund im Frühjahr 1947 mit der Balinger Druckerei Daniel telephonisch Kontakt aufgenommen. Die Druckerei wäre in der Lage gewesen, stündlich 10000 Exemplare einer vierseitigen Tageszeitung zu drucken - damit war sie die leistungsfähigste im Kreis Balingen. Der Besitzer, Hermann Daniel, der in den Jahren des Nationalsozialismus die Zeitung Der Wille gedruckt hatte, erhielt daher am 7. Juni 1947 von Franz Mederle Besuch. Der Rottweiler Rechtsanwalt verdeutlichte Daniel, daß der Heimatbund eine Auflage von 50000 Exemplaren einer vorerst wöchentlich erscheinenden Zeitung anvisiere, um rasch bei gleich hoher Auflage die Zeitung Der Freie Süden zweimal pro Woche herauszubringen ${ }^{238}$. Noch in derselben Woche reiste Bernhard Dietrich nach Baden-Baden, um das Zeitungsprojekt erneut den zuständigen Dienststel-

\footnotetext{
234 Dietrich an Berr vom 13. 5. 1948; IfZ NL Fischbacher ED 719/168.

235 Berr an Dietrich vom 26. 5. 1948; IfZ NL Fischbacher ED 719/168.

${ }^{236}$ Zum Oberland-Projekt vgl. Kapitel IV/2.

237 Von dieser Zeitung muß auch eine Probenummer erschienen sein, da Dietrich um die Lizenz nachgesucht hat. Im AdO in Colmar konnte der Verfasser kein Material zu der Zeitung ausfindig machen.

238 „Parution prochaine d'un journal fédéraliste“; Sûreté de Balingen vom 9.6. 1947; AdO HCFA AP c. 3302 p. 87 d. 87.
} 
len zu unterbreiten. Ohne definitiv abgelehnt zu werden, verschwand der Projektantrag in den Baden-Badener Schubladen ${ }^{239}$.

Ende Oktober 1948 schien sich Dietrich noch ein letztes Mal die Chance für eine föderalistische Zeitung zu eröffnen. Der Münchener Professor und Gründer des „Außenpolitischen Arbeitskreises“ der Bayernpartei, Anton Berr, hatte bei der amerikanischen Militärregierung zwecks Lizenzierung der Zeitschrift Der Bayer nachgesucht, wurde aber im ungewissen gelassen. Mit Hilfe der französischen Besatzungsmacht hoffte er sodann, sein Projekt doch noch in die Tat umsetzen zu können. Im bayerischen Teil der FBZ, mutmaßte Berr in einem Brief an Dietrich, müsse es doch möglich sein, die Lizenz für eine dem Föderalismus dedizierte Tageszeitung zu erhalten, die für den gesamten süddeutschen Raum konzipiert wäre ${ }^{240}$. Auch einen geänderten Titel hatte er in Anlehnung an die gemeinsamen politischen Vorstellungen bereit: Alpen-Donau-Bote. Freilich kam der Plan nicht über ein anfängliches und rudimentäres Projektstadium hinaus.

\section{Französische Presse kontra Heimatbund}

Im Januar 1946 hatte Bernhard Dietrich die Gründung eines „Heimatbundes e. V.“ bei der Militärregierung beantragt, wobei er den Heimatbund als „Landesverband“ des im Oktober 1945 in Bregenz gegründeten „Aktionskomitee des Alpenländisch demokratischen Bundes" verstanden wissen wollte ${ }^{241}$. Erst nach Abwandlung der Statuten erhielt der „Schwäbisch-Alemannische Heimatbund“ nach Monaten die Zulassung durch Baden-Baden. Eine stringente Politik hat die Militärregierung dabei nicht verfolgt, Emile Laffon gab nolens volens seine Zustimmung, General Schwartz in Freiburg zeigte verhaltene Sympathie, General Widmer in Tübingen erwies sich als erklärter Gegner des Heimatbundes.

Guillaume Widmer sah im Heimatbund einen Anachronismus, der jeder Realität beraubt sei. Der Tübinger Oberdelegierte erwies sich daher auch als das Haupthindernis bei der organisatorischen Ausweitung des „Schwäbisch-Alemannischen Heimatbundes" in Württemberg-Hohenzollern. Und Widmer betrieb ein doppeltes Spiel. Gegenüber seinem Freiburger Kollegen Schwartz und dem gemeinsamen Vorgesetzten Laffon gab Widmer vor, sich auf der Linie der Genehmigung des Heimatbundes zu bewegen ${ }^{242}$. Hatte der Tübinger Oberdelegierte im Juli 1946 nur zähneknirschend der Gründung des Heimatbundes zugestimmt, behinderte er in den folgenden Monaten mit allen Mitteln eine Ausdehnung im südwürttembergisch-hohenzollerischen Raum. Von Emile Laffon um eine Stellungnahme zu seinem Verhalten gebeten, stellte sich Widmer auf den Stand-

${ }^{239}$ In einem Zeitungsartikel äußerte Willy Häusler die Vermutung, daß es in Baden-Baden heftige Widerstände gegen das Projekt Der Freie Süden gäbe, womit er wohl den wunden Punkt traf; Willy Häußler: „Schwäbischer ,Föderalismus““, in: Neue Zeitung vom 12. 2. 1948.

${ }^{240}$ Berr an Dietrich vom 22. 10. 1948; IfZ NL Fischbacher ED 719/168.

241 "Nous vous prions de nous permettre de fonder suivant les projets de statuts conjoints le ,Heimatbund e. V. comme une groupe du pays du comité de l'Action de l'Union Alpine. [...] Constitution du territoire d'occupation français de Bade, de Württemberg et de Bavarie [sic!] à un état nouveau ,Voralpen'."; Dietrich an die Oberdelegation in Freiburg vom 11. 1. 1946; AdO HCFA Dir. de l'Int. c. 228 p. 21 d. 33.

242 "J'émets un avis tout à fait favorable à ce que le ,Heimatbund" exerce son activité en zone française du Wurtemberg“; Widmer an Laffon vom 20.6. 1946; AdO W-H 1 f. Ser. Div. c. 2528 p. 3 d. 2. 
punkt, den Heimatbund in Württemberg-Hohenzollern niemals offiziell zugelassen zu haben $^{243}$. Für Widmer waren die Autonomievorstellungen „Hirngespinste und allgemeine Gehirnerweichung "244.

Die unterschiedliche Einschätzung und die zuweilen offene Ablehnung, die dem „Schwäbisch-Alemannischen Heimatbund“ von Teilen der Besatzungsmacht vor Ort entgegenschlug, erhöhte keineswegs dessen Akzeptanz in maßgeblichen Baden-Badener Kreisen. Die zur Jahreswende 1946/47 einsetzenden Berichte französischer Zeitungen zu den Vorgängen in der Zone brachten das Faß an den Rand des Überlaufens. Am 20. August 1946, wenige Tage nach Gründung des „Schwäbisch-Alemannischen Heimatbundes", hatte bereits der Figaro eine polemische Attacke geführt, Le Monde hieb am 4. Januar 1947 in dieselbe Wunde. Auch der Avant-Garde vom 8. Januar 1947 kritisierte die Militärregierung und brandmarkte den Heimatbund als rassistisch-faschistische Organisation. Der Artikel in Le Monde erregte im gesamten französischen Verwaltungsapparat großes Aufsehen und führte zu hektischen Nachforschungen.

In Le Monde hatte der Journaliste Rodolphe-E. Singer mit spitzer Feder den Heimatbund angegriffen und ihn des Rassismus bezichtigt ${ }^{245}$. Weitere Analogien mit dem Nationalsozialismus seien sein „Imperialismus“, da auch Teile von Bayern und Vorarlberg in dem geplanten schwäbisch-alemannischen Staat ihren Platz finden sollten, des weiteren betrachtete Singer den Rückzug in die Stammeskategorie „Schwabe“ als neue Herrenrassentheorie. Eine ausgewogene Berichterstattung lag nicht vor, vielmehr wollte der Journalist den Eindruck vermitteln, daß zum einen die Fundamente dieser Idee auf dem Nationalsozialismus basierten und zum anderen ehemalige Nationalsozialisten für diese Ideologie am empfänglichsten seien. Bei genauerer Betrachtung der Zusammenhänge waren für den informierten Zeitgenossen beide Vorwürfe leicht zu entkräften.

Die Zeitungsartikel verfehlten jedoch ihre Wirkung in der französischen Öffentlichkeit nicht; die angegriffene Militärregierung sah sich umgehend zum Handeln gezwungen. Der Anlaß war Generalverwalter Laffon willkommen, da die föderalistischen Vorstellungen Frankreichs zu keinem Zeitpunkt eine Auflösung der historisch gewachsenen Länder zuließen, ein Ziel, das der wenig geliebte Heimatbund verfolgte. Generalverwalter Laffon glaubte, dem Heimatbund die Genehmigung entziehen zu müssen, allerdings nicht, ohne zuvor die Meinung der für Baden und Württemberg zuständigen Oberdelegationen gehört zu haben ${ }^{246}$. Der Freiburger Oberdelegierte Pène, der im Sommer 1946 General Schwartz abgelöst hatte, teilte nicht den reservierten Standpunkt seines Baden-

${ }^{243}$ In einem nie abgeschickten Antwortschreiben an Laffon wählte Widmer folgende Formulierung: „je n'ai jamais autorisé le ,Heimatbund“ à exercer une activité quelconque en zone française du Wurtemberg “, die er im wesentlich gekürzten tatsächlichen Schreiben in ${ }_{\text {je }}$ n'ai jamais cru devoir autoriser le Heimatbund" abmilderte; Widmer an Laffon vom 20. 2. 1947; AdO WH 1 f. Ser. Div. c. 2528 p. 3 d. 2.

244 "billevisées et paralysie générale“ notierte Widmer handschriftlich an den Rand der Feger und Dietrich betreffenden Seite eines Berichtes des Straßburger Centre d'Etudes Germaniques; Hauptmann Rieffel: "Le problème du Fédéralisme“ (masch. 29 S.) [Anfang 1948]; AdO WH $1 \mathrm{f}$. Ser. Div. c. 2519 p. 6.

${ }^{245}$ Rodolphe-E. Singer: „Une organisation raciste en zone française: l',Union souabo-alémanique “", in: Le Monde vom 4.1.1947.

246 „La question se pose donc de savoir s'il n’y aurait pas lieu de retirer l'autorisation donné au Heimatbund. Pour ma part, je serais assez disposé à envisager cette mesure"; Laffon an Widmer und Pène vom 5. 2. 1947; AdO Bade C 2128 und AdO W-H 1 f. Ser. Div. c. 2528 p. 3 d. 2. 
Badener Vorgesetzten. Selbständig hatte er den Konstanzer Bezirksdelegierten Degliame schon im Januar 1947 angewiesen, eine ausführliche Untersuchung über die Hintergründe der Zeitungsartikel, die er für tendenziös erachtete, einzuleiten ${ }^{247}$. Mit den notwendigen Recherchen betraute jener den Konstanzer Informationsoffizier Georges Ferber, der über die Tageszeitung Le Monde Kontakt zu dem in Zürich lebenden Journalisten Singer aufnahm ${ }^{248}$. Eine Rezitation des Artikels von Singer hatte bereits stattgefunden, Zeitungen in ganz Frankreich und gerade auch im Elsaß berichteten über den „Schwäbisch-Alemannischen Heimatbund“. Singer gab vor, den in Form des Heimatbundes aufkeimenden Nationalismus in Deutschland an der Wurzel ausrotten zu wollen, eine Aussage, die nicht befriedigen konnte. Über die französische Botschaft in Bern brachte Ferber in Erfahrung, daß die Reputation des Journalisten zu denken gab. Damit war für den Konstanzer Informationsoffizier der Fall Singer abgeschlossen.

Eindringlich hatte Georges Ferber bereits vor den Gefahren der Alpenlandbewegung gewarnt, im Heimatbund sah er eine direkte Nachfolgeorganisation. Deshalb konnte er nicht umhin, Freiburg den Entzug der Genehmigung für den Heimatbund zu empfehlen ${ }^{249}$. Doch der Oberdelegierte Pène vertrat eine abweichende Haltung. Er lehnte gegenüber Laffon ein Verbot des Heimatbundes ab, in seinen Augen hätte das als Bestätigung der Angriffe der französischen Presse gewirkt. Pierre Pène war von den französischen Föderalismusvorstellungen erfüllt, die im Südwesten auf eine Reorganisation und Stärkung der Länder hinausliefen; mit den Zielen des Heimatbundes konnte er sich nicht anfreunden, nichtsdestotrotz verteidigte er - wenngleich zaghaft - aus Autoritäts- und Prestigegründen dessen Existenz. Über die Einschätzung der Angelegenheit durch den Tübinger Oberdelegierten Widmer herrschte in Baden-Baden Klarheit. Der Generalverwalter stellte sich jedoch auf den Standpunkt Pènes: Nach Abflauen der Pressekampagne hielt er ein Verbot des Heimatbundes für schädlich, nur zu gut wußte er um die Attraktion alles Untersagten. Die Zeit sollte Laffon recht geben. Der „Schwäbisch-Alemannische Heimatbund" verschwand auch ohne restriktive Maßnahmen von der politischen Bühne.

\footnotetext{
${ }^{247}$ Pène an Degliame vom 16. 1. 1947; AdO Bade C 2128.

${ }^{248}$ Ferber an Singer vom 12. 2. 1947; Singer an Ferber vom 19. 2. 1947; AdO Bade C 2128. Der Brief Ferbers erreichte Singer in Zürich über den Umweg der Redaktion in Paris in nur einer Woche. Dies läßt den Schluß zu, daß die Postwege die langen Bearbeitungszeiten vieler Anträge innerhalb der Militärregierung nicht zwingend rechtfertigten.

${ }^{249}$ Ferber an Pène vom 1. 3. 1947; ebenda.
} 